\title{
Modular Growth NTR Space Transportation System for Future NASA Human Lunar, NEA and Mars Exploration Missions
}

\author{
Stanley K. Borowski ${ }^{1}$, David R. McCurdy ${ }^{2}$ and Thomas W. Packard ${ }^{2}$ \\ NASA Glenn Research Center, Cleveland, $\mathrm{OH}, 44135$
}

\begin{abstract}
The nuclear thermal rocket (NTR) is a proven, high thrust propulsion technology that has twice the specific impulse $\left(I_{s p} \sim 900\right.$ s) of today's best chemical rockets. During the Rover and NERVA (Nuclear Engine for Rocket Vehicle Applications) programs, twenty rocket reactors were designed, built and ground tested. These tests demonstrated: (1) a wide range of thrust; (2) high temperature carbide-based nuclear fuel; (3) sustained engine operation; (4) accumulated lifetime; and (5) restart capability - everything required for affordable human missions beyond LEO. In NASA's recent Mars Design Reference Architecture (DRA) 5.0 study, the NTR was selected as the preferred propulsion option because of its proven technology, higher performance, lower IMLEO, versatile vehicle design, and growth potential. Furthermore, the NTR requires no large technology scale-ups since the smallest engine tested during the Rover program - the $25 \mathrm{klb}_{\mathrm{f}}$ "Pewee" engine is sufficient for human Mars missions when used in a clustered engine configuration. The "Copernicus" crewed Mars transfer vehicle developed for DRA 5.0 was an expendable design sized for fastconjunction, long surface stay Mars missions. It therefore has significant propellant capacity allowing a reusable "1-year" round trip human mission to a large, high energy near Earth asteroid (NEA) like Apophis in 2028. Using a "split mission" approach, Copernicus and its two key elements - a common propulsion stage and integrated "saddle truss" and $\mathrm{LH}_{2}$ drop tank assembly - configured as an Earth Return Vehicle / propellant tanker, can also support a short round trip ( 18 month) / short orbital stay (60 days) Mars reconnaissance mission in the early 2030's before a landing is attempted. The same short stay orbital mission can be performed with an "all-up" vehicle by adding an "in-line" $\mathrm{LH}_{2}$ tank to Copernicus to supply the extra propellant needed for this higher energy, opposition-class mission. To transition to a reusable Mars architecture, Copernicus' saddle truss / drop tank assembly is replaced by an in-line tank and "star truss" assembly with paired modular drop tanks to further increase the vehicle's propellant capacity. Shorter "1-way" transit time fast-conjunction Mars missions are another possibility using this vehicle configuration but, as with reusability, increased launch mass is required. "Scaled down" versions of Copernicus (sized to a SLS lift capability of $\sim 70 \mathrm{t}-100 \mathrm{t}$ ) can be developed initially allowing reusable lunar cargo delivery and crewed landing missions, easy NEA missions (e.g., 2000 SG344 also in 2028) or an expendable mission to Apophis. Mission scenario descriptions, key vehicle features and operational characteristics are provided along with a brief discussion of NASA's current activities and its "pre-decisional" plans for future NTR development.
\end{abstract}

$\begin{array}{ll}\text { Nomenclature } \\ \text { SLS / HLV } & =\text { Space Launch System / Heavy Lift Vehicle } \\ I M L E O & =\text { Initial Mass in Low Earth Orbit } \\ K & =\text { temperature (degrees Kelvin) } \\ k l b_{f} & =\text { thrust (1000's of pounds force) } \\ L E O & =\text { Low Earth Orbit (= 407 km circular) } \\ L O X / L H_{2} & =\text { Liquid Oxygen / Liquid Hydrogen propellant } \\ t & =\text { metric ton }(1 \mathrm{t}=1000 \mathrm{~kg}) \\ \Delta V & =\text { velocity change increment }(\mathrm{km} / \mathrm{s})\end{array}$

${ }^{1}$ DSS Branch Chief \& Lead Engineer, NTP Systems, 21000 Brookpark Road, MS: 86-4, AIAA Associate Fellow.

${ }^{2}$ Vantage Partners, LLC at Glenn Research Center, 3000 Aerospace Parkway, Brook Park, OH 44142 


\section{Introduction and Background}

$\mathrm{T}$ he use of common or "modular" elements in NTR Mars transfer vehicle (MTV) designs is not a new idea. Initial vehicle concept designs [1,2,3] developed for human Mars missions in the early 1960's started off with stages "customized" for a particular mission maneuver. Engine restart capability was not considered and engine burn times were limited to $\sim 30$ minutes. For short round trip/short stay time "opposition-class" missions, three expendable tandem stages, each with a $100-150 \mathrm{klb}_{\mathrm{f}}$-class NERVA-derived engine, were used for the trans-Mars injection (TMI) maneuver and were then jettisoned. Separate expendable stages with lower thrust engines were used for the Mars orbit capture ( $75 \mathrm{klb}_{\mathrm{f}}$ for MOC) and trans-Earth injection $\left(\sim 50 \mathrm{klb}_{\mathrm{f}}\right.$ for TEI) maneuvers as well, with crew recovery utilizing direct ballistic capsule re-entry at the end of the mission.

Customized stages were later replaced by common stages [3] and then by a common propulsion module [4] with supplemental "in-line" and expendable $\mathrm{LH}_{2}$ propellant "drop tanks" (Fig. 1) once engine burn times exceeding one hour, and multiple engine restarts were successfully demonstrated by the NERVA program's NRX-A6 and NRX-XE engine tests in 1967 and 1969 [5]. A single $100 \mathrm{klb}_{\mathrm{f}}$-class NERVA engine was typically used with this MTV option.

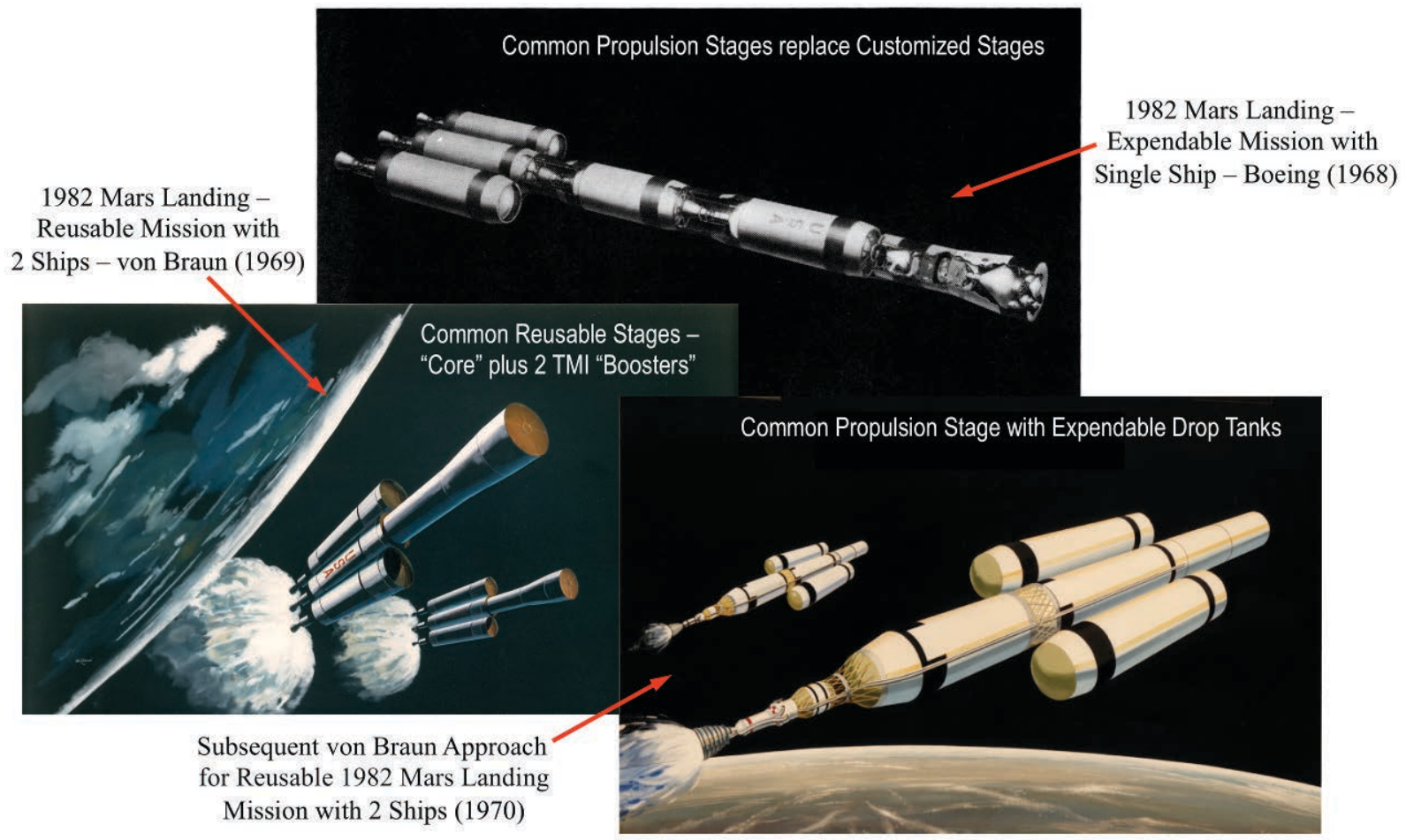

Figure 1. Early NTR Mars Vehicle Design Transition from Expendable Stages to Expendable Drop Tanks

Less than a month after the successful landing of Apollo 11 on the Moon, Wernher von Braun, then director of NASA's Marshall Space Flight Center, outlined a plan for a human Mars landing in 1982 to the Senate Committee on Aeronautics and Space Science [6]. It involved two ships each using $100 \mathrm{klb}_{\mathrm{f}}$-class NERVA engines and carrying 6 crewmembers. The initial ship design featured three common NTR propulsion modules - a central "core" module plus two reusable, tandem "booster" stages providing TMI assist. This design was later replaced by a single core propulsion module option with in-line and expendable drop tanks that supplied the additional $\mathrm{LH}_{2}$ propellant required for the mission (Fig. 1). In NASA's proposed "post-Apollo" Integrated Space Program Plan (1970 - 1990), von Braun envisioned a reusable NTR propulsion stage that would function as a "workhorse" space asset delivering cargo and crew to the Moon initially for lunar base construction, and then for sending human missions to Mars [7,8].

Despite the technological triumph of Apollo, the public's interest in the program waned and Apollo flights 18, 19 and 20 were cancelled, along with NASA's plans for a post-Apollo program that envisioned the construction of a lunar base and a human mission to Mars in the early 1980's. After the final Apollo 17 mission to Taurus-Littrow in December 1972 and cancellation of the Rover/NERVA programs in January 1973, short of flight demonstration, interest in human Moon/Mars missions and NTP development remained relatively dormant for more than a decade. 
On July 20, 1989, the $20^{\text {th }}$ anniversary of Apollo 11, President Bush proposed a Space Exploration Initiative (SEI) for the United States, which called for a return to the Moon "to stay", followed by a journey to Mars [9]. From 1989 - 1993, NASA conducted and funded both in-house and industry studies $[10,11,12]$ that outlined a campaign of human exploration that included the establishment of a transportation node in LEO, a permanent base on the Moon, then human missions to Mars. During SEI, NASA's Glenn Research Center (GRC), then known as the Lewis Research Center, quantified the benefits of NTP for both lunar and Mars missions. With its high thrust and specific impulse capability, NTP enabled a reusable lunar transfer vehicle (LTV) that could return itself and a single stage $\mathrm{LOX} / \mathrm{LH}_{2}$ lunar excursion vehicle (LEV) to LEO for refueling, refurbishment and reuse [13]. By adding modular propellant tanks to the LTV's "core" propulsion stage [14], a reusable MTV was developed for the reference mission - a 434 day round trip / 30 day stay "opposition-class" mission to Mars in 2016. Both the reusable NTP LTV and MTV designs used a single $75 \mathrm{klb}_{\mathrm{f}}$ NERVA-derived NTR engine with "composite fuel" (shown in Fig. 2).

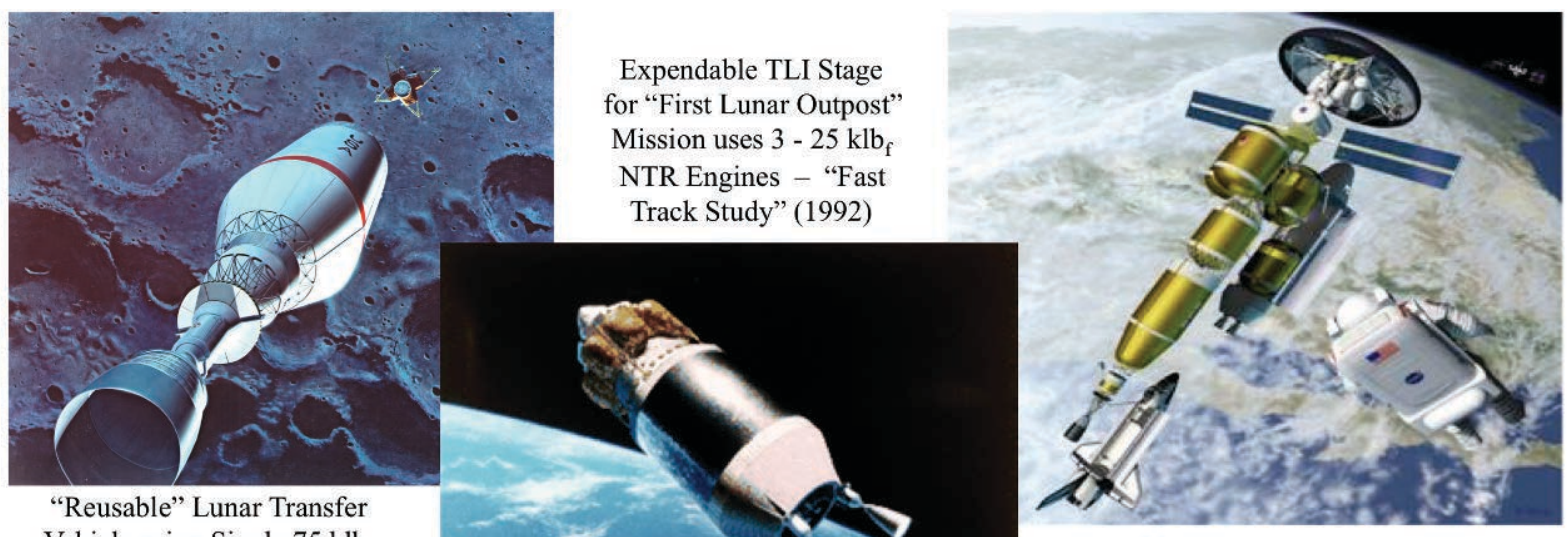

Vehicle using Single $75 \mathrm{klb}_{\mathrm{f}}$ NTR Engine - SEI (1990 - 91)

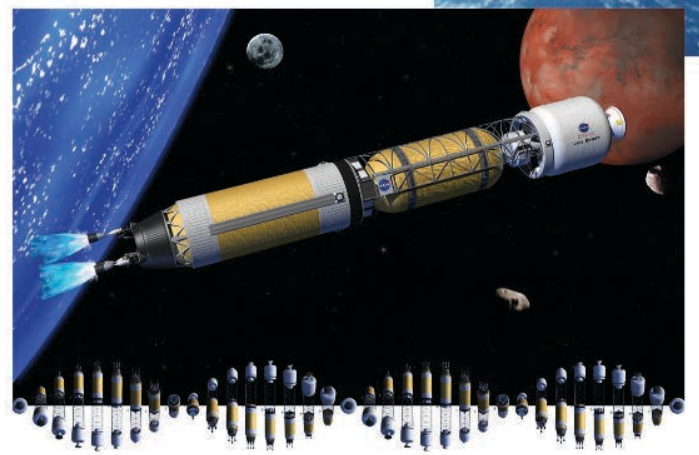

"Artificial Gravity" Crewed MTV uses 3 - $15 \mathrm{klb}_{\mathrm{f}} / 25 \mathrm{~kW}_{\mathrm{e}}$ "Bimodal NTR Engines - Mars DRM 4.0 (1999)
Reusable "Modular" Crewed MTV uses Single $75 \mathrm{klb}_{\mathrm{f}}$ NTR Engine - SEI (1990 - 91)

Figure 2. GRC's Lunar and Mars Transfer Vehicle Designs Have Transitioned Away From
Large Single to Small Clustered Engines, Some Capable of Generating Electrical Power

In NASA's First Lunar Outpost (FLO) study [15], an expendable NTP trans-lunar injection (TLI) stage powered by three $25 \mathrm{klb}_{\mathrm{f}}$ "Pewee-class" engines [5] was analyzed for sending a large $(\sim 96 \mathrm{t})$ integrated lander and ascent stage to the Moon. The FLO study marked the first use of smaller clustered NTR engines to help improve packaging and overall mission reliability. In 1999, GRC introduced the "Bimodal" NTR (BNTR) and "Artificial Gravity" (AG) crewed MTV design (Fig. 2) in NASA's Design Reference Mission (DRM) 4.0 study [16,17]. The AG MTV's "core" propulsion stage featured three $15 \mathrm{klb}_{\mathrm{f}} \mathrm{BNTR}$ engines that produced up to $50 \mathrm{~kW}_{\mathrm{e}}$ of electrical power needed to run the crewed MTV's subsystems during the mission. Vehicle rotation out to Mars and back produced a centrifugal force and AG environment to help maintain crew health and fitness. Ten years later, in NASA's recent Mars Design Reference Architecture (DRA) 5.0 study [18,19], non-bimodal NTR engines and a zero-gravity $\left(0-\mathrm{g}_{\mathrm{E}}\right)$ crewed MTV design were again selected to provide an "apples-to-apples" comparison with chemical propulsion. A sampling of lunar and Mars transfer vehicle concepts developed by GRC over the last 2 decades is shown in Fig. 2. 
NASA's recent Mars DRA 5.0 study [18] examined both short and long surface stay landing missions. The "fast conjunction" long surface stay option was selected for the design reference because it provided adequate time at Mars ( $\sim 540$ days) for the crew to explore the planet's rich geological diversity while also reducing the crew "1-way" transit times to and from Mars to $\sim 6$ months, or $\sim 1$ year in deep space. Long surface stay missions also have lower energy requirements than the short round trip time, short surface stay "opposition-class" missions, and therefore require less propellant and less mass delivered to LEO.

The NTR was the propulsion system of choice in DRA 5.0 because of its high thrust (10's of $\mathrm{klb}_{\mathrm{f}}$ ) and high specific impulse ( $\mathrm{I}_{\mathrm{sp}} \sim 900-950 \mathrm{~s}$ ), its increased tolerance to payload mass growth and architecture changes, and its lower IMLEO which is important for reducing the HLV launch count, overall mission cost and risk. With a $100 \%$ higher $I_{\text {sp }}$ than today's best chemical rockets, the use of NTP reduced the required launch mass by over $400 t-$ the equivalent mass of the International Space Station (ISS). More importantly, the NTR is a proven technology and the only advanced propulsion option to be successfully ground tested at the performance levels required for a human mission to Mars. No large technology or performance scale-ups are needed as with other propulsion options. In fact, the smallest and highest performing engine tested during the Rover / NERVA programs [5] - the $25 \mathrm{klb}_{\mathrm{f}}$ "Pewee" engine is sufficient for a human mission to Mars when used in a clustered engine arrangement.

DRA 5.0 featured a "split mission" approach using separate cargo and crewed Mars transfer vehicles. Both vehicle types utilized a common "core" propulsion stage each with three $25 \mathrm{klb}_{\mathrm{f}}$ "composite fuel" Pewee-class engines. Two cargo vehicles were used to pre-deploy surface and orbital assets to Mars ahead of the crew who arrived during the next mission opportunity ( 26 months later). The crewed MTV called "Copernicus" $[19,20]$ is a $0-\mathrm{g}_{\mathrm{E}}$ vehicle design consisting of three basic components: (1) the NTR propulsion stage; (2) the crewed payload element; and (3) an integrated "saddle truss" and $\mathrm{LH}_{2}$ propellant drop tank assembly that connects the two elements.

Although Copernicus was operated in an "expendable mission mode" to reduce IMLEO as mandated in DRA 5.0, substituting an "in-line" $\mathrm{LH}_{2}$ tank and "star truss" assembly with modular drop tanks for the saddle truss / drop tank assembly, can provide the additional propellant needed to operate Copernicus in a "reuse mode" assuming of course that LEO infrastructure (e.g., a transportation node / propellant depot with refueling capability) is in place to support reusability. Although designed as an expendable spacecraft, Copernicus was sized to allow it to perform all of the fast-conjunction missions over the 15 -year synodic cycle. It therefore has significant propellant capacity that can be utilized for a variety of other mission applications currently under study by NASA and the international space exploration community. Smaller, "scaled-down" versions of the Copernicus spacecraft can also be configured as reusable lunar cargo transports as envisioned by von Braun, or as a reusable crewed Asteroid Survey Vehicle (ASV) like the "Search Lite" concept illustrated in Fig. 3.

The Global Exploration Roadmap (GER), developed by the International Space Exploration Coordination Group (ISECG), reflects the initial efforts of NASA and 13 other space agencies to define feasible and sustainable pathways for future human space exploration that includes the Moon, near-Earth asteroids, and eventually Mars, the long-term goal of the GER. The initial GER [21], released in September 2011, identified two possible pathways for future human missions after ISS utilization. These pathways have been designated the "Moon Next" and "Asteroid Next" scenarios. Both approaches utilize a stepwise development and demonstration of capabilities that are required for the eventual human exploration of Mars.

The "Moon Next" pathway has a strong appeal to many countries that would like to see humans again walk on its surface and to whom the Apollo program has become a distant memory. Located just 3 days from Earth, the Moon is an entire world awaiting exploration, future settlement and potential commercialization. It is also an ideal location to test and demonstrate key technologies and systems (e.g., surface habitation, long-range pressurized rovers, surface power and resource extraction systems) that will allow people to explore, work, and live self-sufficiently on another planetary surface. Crewed NEA missions would follow that demonstrate the additional in-space capabilities needed to reach Mars (e.g., advanced propulsion). Efficient propulsion and an affordable in-space transportation system with reuse capability will also be required if initial lunar outposts are to evolve into eventual settlements capable of supporting commercial activities.

The "Asteroid Next" pathway has as its focus the development and demonstration of key in-space exploration technologies and capabilities (e.g., reliable life support systems, long duration habitation and cryogenic fluids management, and advanced propulsion) necessary for traveling through and living in deep space. In addition to the scientific knowledge gained by an "up close and personal" examination of these primordial objects, NEA missions can also provide a proving ground for validating the spacecraft systems that will be needed for sending astronauts to Mars. In the GER, the ISECG shows the first crewed mission to a NEA beginning in 2028. Deep space asteroid missions as precursors to a human Mars mission is also consistent with the current United States' National Space Policy [22] that states NASA shall: By 2025, begin crewed missions beyond the Moon, including sending humans to an asteroid. By the mid-2030s, send humans to orbit Mars and return them safely to Earth. 
AIAA-2012-5144

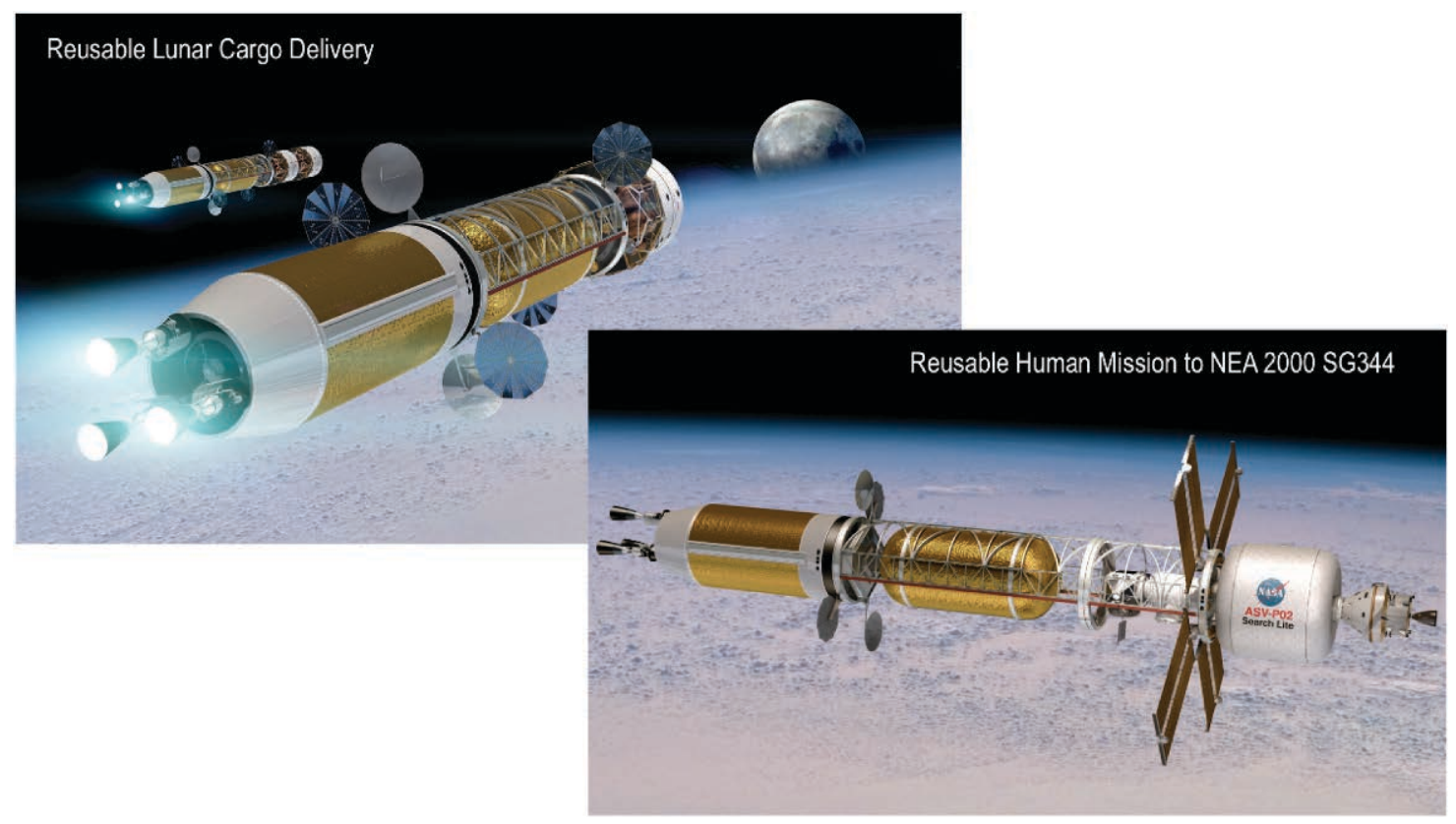

Figure 3. Reusable Lunar and NEA NTR Missions Possible using $70 \mathrm{t}$ - 100 t-class SLS

Over the last several years, NASA's Human Architecture Team has pursued a strategy, referred to as a Capability Driven Framework (CDF), which assumes the utilization of evolving capabilities to pursue more demanding missions. With CDF, nearer-term technologies (chemical and solar electric propulsion) would be developed and demonstrated on less demanding missions (e.g., Earth-Moon L1, L2, Sun-Earth L2) first, before developing the real technologies and systems needed for more challenging lunar landing, NEA and Mars missions. Such an approach could be short-sighted and jeopardize NASA's ability to orbit Mars by 2035 by diverting resources away from proven technologies like NTP towards less capable systems that are large and operationally complex to use. Furthermore, a short round trip / short orbital stay mission to Mars is best performed in the 2033-2035 timeframe when the mission $\Delta \mathrm{V}$ budgets are near their minimum values over the 15 -year synodic cycle. After that, the $\Delta \mathrm{V}$ budgets for successive short round trip missions increase significantly with the next minimum occurring in 2045 .

This paper presents analysis that can support either the "Asteroid Next" or "Moon Next" pathways. It utilizes a "Technology Driven Framework" focused on developing and demonstrating the technologies and systems found in Copernicus' two key elements, its propulsion stage and integrated saddle truss/drop tank assembly, then validating them on NEA and lunar missions in the late 2020's/early 2030's in preparation for an orbital Mars mission in 2033. By focusing the resources of NASA and other space agencies on developing several key technologies and systems (the NTR, reverse turbo-Brayton refrigeration for zero-boiloff $\mathrm{LH}_{2}$ storage, and large composite structures) and exploiting the technology synergies that exist between Copernicus, the HLV (e.g., large aluminum / lithium (A1/Li) $\mathrm{LH}_{2}$ tanks) and existing flight-tested chemical rocket hardware (e.g., $\mathrm{LH}_{2}$ turbopumps, regenerative- and radiationcooled nozzles and skirt extensions), substantial savings in development time and cost are expected.

This paper examines alternative mission possibilities using the Copernicus MTV design and outlines a growth path using "modular" components that can increase its capability for more demanding missions. This same "modular growth" strategy can be applied to "scaled down" vehicle components configured for launch on the $70 \mathrm{t}-100 \mathrm{t}$ SLS. The paper covers the following topic areas. First, the operational principles and performance characteristics of the baseline $25 \mathrm{klb}_{\mathrm{f}}$ NTR engine used in this analysis are presented along with a summary of the Rover/NERVA programs' technical accomplishments. Mission and transportation system ground rules and assumptions used in the analysis are then presented along with a brief overview of the "7-Launch" Mars Mission Strategy for DRA 5.0 and a description of the Copernicus MTV design. Additional mission options for Copernicus along with increased capability made possible by using the modular growth strategy are discussed next. The paper's focus then turns to scaled down versions of Copernicus sized for reusable and expendable NEA missions, as well as, reusable cargo and crewed lunar missions and includes mission scenario descriptions, key vehicle features and operational characteristics. The paper ends with a brief discussion of NASA's current activities and future plans for developing NTP followed by a summary of our findings and some concluding remarks. 


\section{NTR System Description and Performance Characteristics}

The NTR uses a compact fission reactor core containing 93\% "enriched" Uranium (U)-235 fuel to generate 100's of megawatts of thermal power $\left(\mathrm{MW}_{\mathrm{t}}\right)$ required to heat the $\mathrm{LH}_{2}$ propellant to high exhaust temperatures for rocket thrust. In an "expander cycle" Rover/NERVA-type engine (Fig. 4), high pressure $\mathrm{LH}_{2}$ flowing from twin turbopump assemblies (TPAs) cool the engine's nozzle, pressure vessel, neutron reflector, and control drums, and in the process picks up heat to drive the turbines. The turbine exhaust is then routed through the core support structure, internal radiation shield, and coolant channels in the reactor core's fuel elements where it absorbs energy produced from the fission of U-235 atoms, is superheated to high exhaust temperatures $\left(T_{\text {ex }} \sim 2550-3000 \mathrm{~K}\right.$ depending on fuel type and uranium loading), then expanded out a high area ratio nozzle $(\varepsilon \sim 300: 1-500: 1)$ for thrust generation.

Controlling the NTR during its various operational phases (startup, full thrust and shutdown) is accomplished by matching the TPA-supplied $\mathrm{LH}_{2}$ flow to the reactor power level. Multiple control drums, located in the reflector region surrounding the reactor core, regulate the neutron population and reactor power level over the NTR's operational lifetime. The internal neutron and gamma radiation shield, located within the engine's pressure vessel, contains its own interior coolant channels. It is placed between the reactor core and key engine components to prevent excessive radiation heating and material damage.

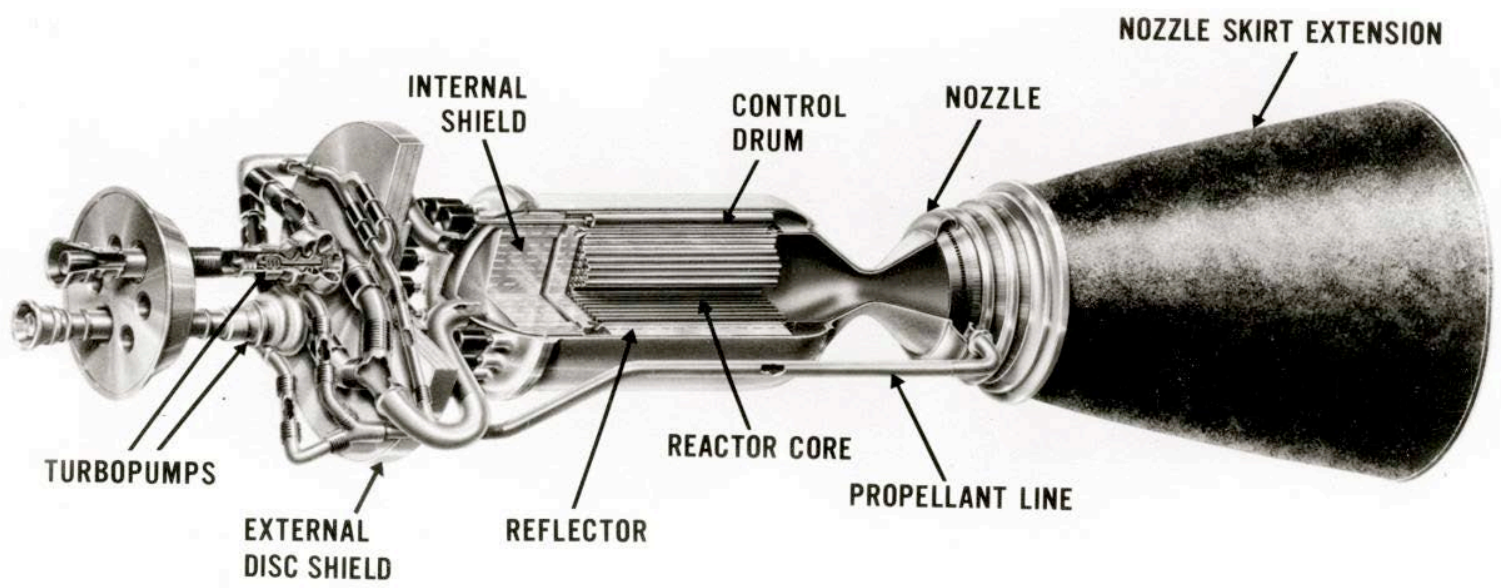

Figure 4. Schematic of "Expander Cycle" NTR Engine with Dual $\mathrm{LH}_{2}$ Turbopumps

A Rover / NERVA-derived engine uses a "graphite matrix" material fuel element (FE) containing the U-235 fuel in the form of either coated particles of uranium carbide $\left(\mathrm{UC}_{2}\right)$ or as a dispersion of uranium and zirconium carbide ( $\mathrm{UC}-\mathrm{ZrC}$ ) within the matrix material, referred to as "composite" fuel (shown in Fig. 5). The basic FE [5] has a hexagonal cross section ( $\sim 0.75$ " across the flats), is 52" long and produces $\sim 1 \mathrm{MW}_{\mathrm{t}}$. Each FE has 19 axial coolant channels, which along with the element's exterior surfaces, are coated with $\mathrm{ZrC}$ using chemical vapor deposition (CVD) to reduce hydrogen erosion of the graphite. This basic shape was introduced in the KIWI-B4E and became the standard used in the $75 \mathrm{klb}_{\mathrm{f}}$ Phoebus-1B, $250 \mathrm{klb}_{\mathrm{f}}$ Phoebus-2A, $25 \mathrm{klb}_{\mathrm{f}}$ Pewee and the $55 \mathrm{klb}_{\mathrm{f}}$ NERVA NRX series of engines. These elements were bundled around and supported by cooled coaxial core support tie tubes. Six elements per tie tube were used in the higher power Phoebus and NRX reactor series. In the smaller Pewee engine, the ratio was reduced to three elements per tie tube. To provide sufficient neutron moderation and criticality in the smaller Pewee core, sleeves of zirconium hydride moderator material were added to the core support tie tubes (shown in Fig. 5).

The Rover program's $25 \mathrm{klb}_{\mathrm{f}}$ Pewee engine [5] was designed and built to evaluate higher temperature, longer life fuel elements with improved coatings, and in the process Pewee set several performance records. The Pewee full power test consisted of two 20-minute-long burns at the design power level of $\sim 503 \mathrm{MW}_{\mathrm{t}}$ and an average fuel element exit gas temperature of $\sim 2550 \mathrm{~K}$, the highest achieved in the Rover/NERVA nuclear rocket programs. The peak fuel temperature also reached a record level of $\sim 2750 \mathrm{~K}$. Other performance records included average and peak power densities in the reactor core of $\sim 2340 \mathrm{MW}_{\mathrm{t}} / \mathrm{m}^{3}$ and $\sim 5200 \mathrm{MW}_{\mathrm{t}} / \mathrm{m}^{3}$, respectively. A new CVD coating of $\mathrm{ZrC}$ was also introduced and used in Pewee that showed performance superior to the niobium carbide $(\mathrm{NbC})$ coating used in previous reactor tests. 
AIAA-2012-5144

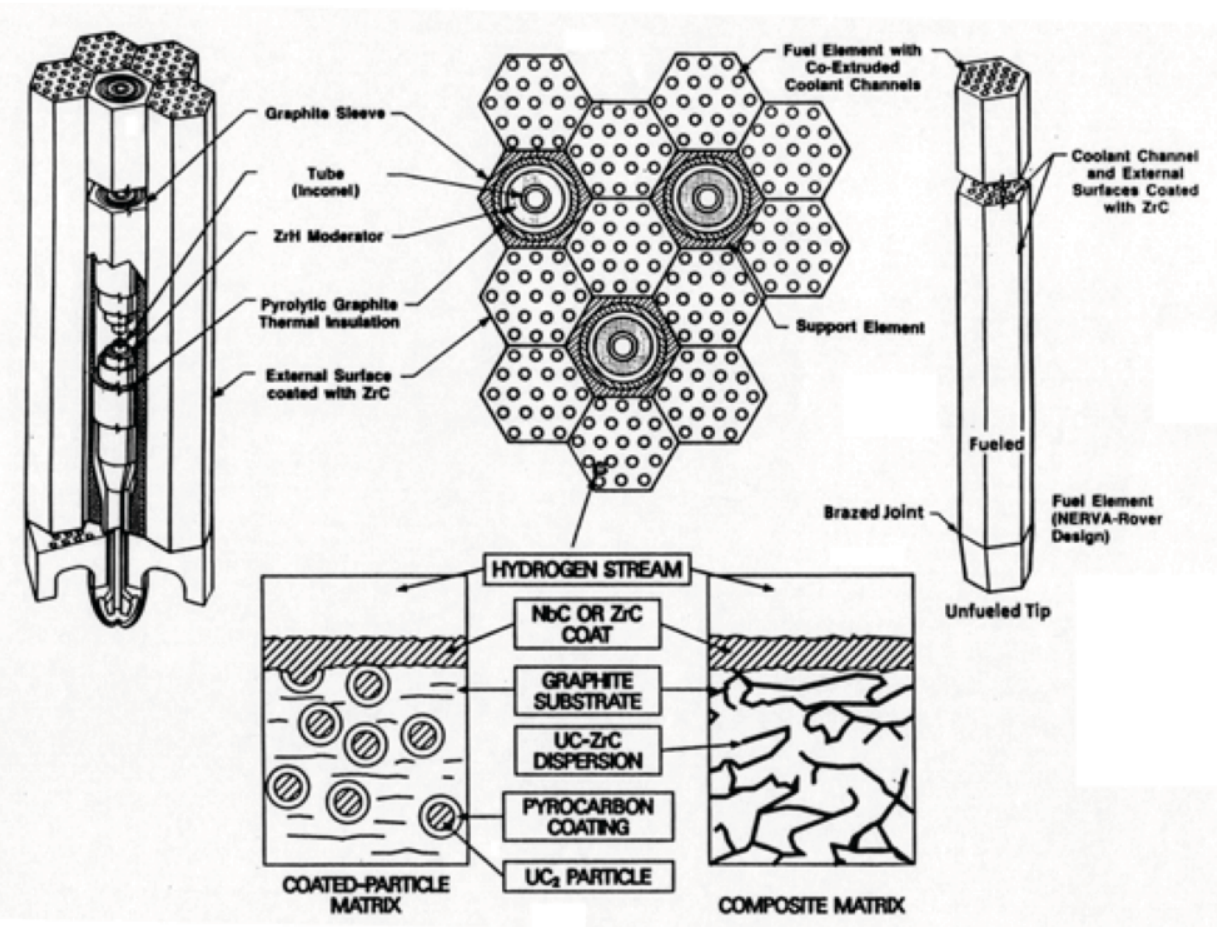

Figure 5. Coated Particle and Composite Rover / NERVA Fuel Element and Tie Tube Arrangement

In follow on tests in the "Nuclear Furnace" fuel element test reactor [5], higher temperature composite fuel elements with $\mathrm{ZrC}$ coating were evaluated. They withstood peak power densities of $\sim 4500-5000 \mathrm{MW} / \mathrm{m}^{3}$ and also demonstrated better corrosion resistance than the standard coated particle graphite matrix fuel element used in the previous Rover/NERVA reactor tests. Composite fuel's improved corrosion resistance is attributed to its higher coefficient of thermal expansion (CTE) that more closely matches that of the protective $\mathrm{ZrC}$ coating, thereby helping to reduce coating cracking. Electrical-heated composite fuel elements were also tested by Westinghouse in hot hydrogen at $2700 \mathrm{~K}$ for $\sim 600$ minutes - equivalent to ten 1-hour cycles. At the end of Rover / NERVA, composite fuel performance projections [23] were estimated at $~ 2-6$ hours at full power for hydrogen exhaust temperatures of $\sim 2500-2800 \mathrm{~K}$ and fuel loadings in the range of $\sim 0.60$ to $0.45 \mathrm{grams} / \mathrm{cm}^{3}$. In addition to these carbide-based fuels, a ceramic-metallic or "cermet" fuel consisting of uranium dioxide $\left(\mathrm{UO}_{2}\right)$ in a tungsten $(\mathrm{W})$ metal matrix was developed in the GE-710 and ANL nuclear rocket programs [24,25] as a backup to the Rover/NERVA fuel. While no integrated reactor/engine tests were conducted, a large number of fuel specimens were produced and exposed to non-nuclear hot $\mathrm{H}_{2}$ and irradiation testing with promising results. Both fuel options are under development today.

The NTR engine baselined in DRA 5.0 and in this analysis is a $25 \mathrm{klb}_{\mathrm{f}}$ "Pewee-class" expander cycle engine with the following performance parameters: $\mathrm{T}_{\mathrm{ex}} \sim 2790 \mathrm{~K}$, chamber pressure $\sim 1000 \mathrm{psia}, \varepsilon \sim 300: 1$, and $\mathrm{I}_{\mathrm{sp}} \sim 906 \mathrm{~s}$. The $\mathrm{LH}_{2}$ flow rate is $\sim 12.5 \mathrm{~kg} / \mathrm{s}$ and the engine thrust-to-weight ratio is $\sim 3.50$. The overall engine length is $\sim 7.01 \mathrm{~m}$, which includes an $\sim 2.16 \mathrm{~m}$ long, retractable radiation-cooled nozzle skirt extension. The corresponding nozzle exit diameter is $\sim 1.87 \mathrm{~m}$. Recent Monte Carlo N-Particle (MCNP) transport modeling of the engine's reactor core [26], indicates that an $\mathrm{I}_{\mathrm{sp}}$ range of $\sim 894 \mathrm{~s}$ to $940 \mathrm{~s}$ is achievable by increasing the FE length from $0.89 \mathrm{~m}$ to $1.32 \mathrm{~m}$ and lowering the U-235 fuel loading in the core from $\sim 0.45$ to $0.25 \mathrm{grams} / \mathrm{cm}^{3}$ which allows the peak fuel temperature to increase while still staying safely below the melt temperature.

Lastly, the state-of-the-art for NTP can be summarized as follows: It is a proven technology! A high technology readiness level (TRL 5-6) was demonstrated during the Rover / NERVA programs (1955-1972) [5]. Twenty rocket reactors were designed, built and ground tested in integrated reactor / engine tests that demonstrated: (1) a wide range of thrust levels $\left(\sim 25,50,75\right.$ and $\left.250 \mathrm{klb}_{\mathrm{f}}\right)$; (2) high temperature carbide-based nuclear fuels that provided hydrogen exhaust temperatures up to $2550 \mathrm{~K}$ (achieved in the Pewee engine); (3) sustained engine operation (over 62 minutes for a single burn on the NRX-A6); as well as; (4) accumulated lifetime; and (5) restart capability (>2 hours during 28 startup and shutdown cycles on the NRX-XE experimental engine) - all the requirements needed for future human NEA and Mars exploration missions. 


\section{Mission and Transportation System Ground Rules and Assumptions}

Specific mission and NTR transportation system ground rules and assumptions used in this paper are summarized in Tables 1 and 2, respectively. Table 1 provides information about the mission destinations, operational scenarios, and the assumed parking orbits at Earth, the Moon and Mars. Specific mission dates, trajectory details and $\Delta \mathrm{V}$ budgets are provided within the appropriate sections of the paper. In addition to the large $\Delta \mathrm{V}$ requirements for the primary propulsion maneuvers, like Earth orbit capture (EOC), smaller $\Delta \mathrm{V}$ maneuvers are needed for rendezvous and docking (R\&D) of vehicle components during the LEO assembly phase, for spacecraft attitude control during in-space transit, and for "split mission" Mars orbital operations involving R\&D of the pre-deployed Earth Return Vehicle (ERV) with the "spent" crewed MTV for payload element transfer discussed in Section V.

Cargo delivery and crewed lunar landing missions are also considered in this paper. On lunar cargo flights, single or multiple habitat landers are delivered to LLO by a reusable NTR transport in a manner reminiscent of von Braun's reusable lunar NTR shuttle [7]. A single stage LOX/LH $\mathrm{LLV}_{2}$ and Orion MPCV are transported to LLO on the crewed landing missions. The LLV is a "heritage" design [12] analyzed in considerable detail during SEI. It carried a crew of 4 plus $5 \mathrm{t}$ of surface payload stored in two "swing-down" containers mounted on each side of the crew cab. The LLV mass breakdown with propellant loadings for a range of landed payload is shown in Table 1.

\section{Table 1. Mission and Payload Ground Rules and Assumptions}

\begin{tabular}{|c|c|}
\hline $\begin{array}{l}\text { Mission Destinations / Profiles: } \\
\text { - Moon - Cargo delivery and crewed lunar landing } \\
\text { missions (starting in late } 2020 \text { timeframe) } \\
\text { - } 2000 \text { SG344 in } 2028 \text { (Small / Low Energy NEA) } \\
\text { - "Apophis" in } 2028 \text { (Large / High Energy NEA) } \\
\text { - Mars orbital mission in } 2033 \text { (Round trip time: } \\
\text { - } 545 \text { days with } 60 \text { days in Mars orbit) } \\
\text { - Mars landing mission after 2033 (Round trip time: } \\
\text { - } 900 \text { days with } 540 \text { days at Mars) }\end{array}$ & $\begin{array}{l}\text { - Lunar Missions: "All-Up" mission profile assumed for crewed } \\
\text { mission; 14 day stay time extendable with pre-deployed Habitat } \\
\text { landers; "Reusable" scenario returns MPCV and LLV to } 24 \text {-hr EEO } \\
\text { - NEA Missions: "All-Up" mission profile is the baseline; no asset } \\
\text { pre-deployment; 1-year mission duration; "Reusable" scenario } \\
\text { returns all payload elements (including the MMSEV) to an EEO } \\
\text { - Mars Orbital Mission: "All-Up" mission profile; } \sim 18 \text { months mission } \\
\text { duration; "Split mission" option pre-deploys ERV ahead of crew } \\
\text { - Mars Landing Mission: Assumes DRA 5.0 mission profile } \\
\text { - Orion capsule for crew recovery at Earth at mission end }\end{array}$ \\
\hline $\begin{array}{l}\text { Missions depart from low Earth orbit (LEO) and return } \\
\text { to either a 6-hr or 24-hr elliptical Earth orbit (EEO) } \\
\text { for reusable mission scenarios; capture and depart } \\
\text { from either low lunar orbit (LLO) or a 24-hr elliptical } \\
\text { Mars orbit (EMO) }\end{array}$ & $\begin{array}{l}\text { - LEO: } 407 \mathrm{~km} \text { circular } \\
\text { - 6-hr EEO: } 500 \mathrm{~km} \times 20,238 \mathrm{~km} \\
\text {-24-hr EEO: } 500 \mathrm{~km} \times 71,136 \mathrm{~km} \\
\text { - LLO: } 300 \mathrm{~km} \text { circular } \\
\text {-24-hr EMO: } 250 \mathrm{~km} \times 33,793 \mathrm{~km}\end{array}$ \\
\hline Lunar, NEA and Mars Mission $\Delta \mathrm{V}$ Budgets: & - Mission dates, trip times $\& \Delta \mathrm{V}$ budget details provided in the paper \\
\hline $\begin{array}{l}\text { Additional } \Delta V \text { Requirements: Advanced Material } \\
\text { Bipropellant Rocket (AMBR) RCS thrusters used } \\
\text { to perform non-primary propulsion maneuvers }\end{array}$ & $\begin{array}{l}\text { - LEO R\&D between orbital elements: } \sim 15-100 \mathrm{~m} / \mathrm{s} \\
\text { - Coast attitude control and mid - course correction: } \\
\sim 15 \mathrm{~m} / \mathrm{s} \text { and } \sim 50 \mathrm{~m} / \mathrm{s} \text {, respectively } \\
\text { - Mars orbit maintenance plus R\&D: } \sim 100 \mathrm{~m} / \mathrm{s}\end{array}$ \\
\hline $\begin{array}{l}\text { Lunar Cargo / Crewed Payload Masses: Reusable NTR } \\
\text { cargo transports deliver Habitat landers to LLO; on } \\
\text { crewed lunar landing missions, reusable NTR transport } \\
\text { delivers Orion / MPCV and single stage LOX LH } \text { LH }_{2} \\
\text { Lunar Landing Vehicle (LLV) to LLO; LLV carries } 4 \\
\text { crew and up to } 5 \text { t of payload to lunar surface; lunar } \\
\text { missions return to a 24-hr EEO; crewed missions } \\
\text { return the LLV, Orion MPCV and lunar samples }\end{array}$ & $\begin{array}{l}\text { - Habitat lander: } \\
\text { - LLV crew cab: } \\
\text { - Crew (4) \& EVA suits: } \\
\text { - LLV descent /ascent stage: } \\
\text { - LLV propellant load: } \\
\text { - LLV surface payload: } \\
\text { - Orion / MPCV: } \\
\text { - Returned Samples: }\end{array}$ \\
\hline $\begin{array}{l}\text { Mars / NEA Crewed Payload Masses: Varies with crew } \\
\text { size \& mission duration; consumables based on a crew } \\
\text { consumption rate of } \sim 2.45 \mathrm{~kg} / \text { person/day; payload also } \\
\text { includes a short saddle truss (SST), a transfer tunnel } \\
\text { with second docking module (TDM) an an exterior } \\
\text { consumables container; for NEA missions, the exterior } \\
\text { container is replaced with a MMSEV for "close up" } \\
\text { inspection and sample gathering }\end{array}$ & $\begin{array}{lc}\text { - Transit Habitat: } & 22.7 \mathrm{t}-27.5 \mathrm{t} \text { (minus consumables) } \\
\text { - SST/TDM/Container: } & 2.89 \mathrm{t}-5.08 \mathrm{t} / 1.76 \mathrm{t} / 23 \% \text { of stored food } \\
\text { - Crew (4-6): } & 0.4 \mathrm{t}-0.6 \mathrm{t} \\
\text { - Total Consumables: } & 3.58 \mathrm{t}-5.37 \mathrm{t}(4-6 \text { crew for 1-yr); } \\
& \text { extra consumables stored in exterior container } \\
\text { - MMSEV: } & 6.7 \mathrm{t} \\
\text { - Orion / MPCV: } & 10.0 \mathrm{t}-13.5 \mathrm{t} \\
\text { - Returned Samples: } & 0.1 \mathrm{t} \text { (NEA); } 0.25 \mathrm{t}-0.5 \mathrm{t} \text { (Mars) }\end{array}$ \\
\hline
\end{tabular}


For crewed NEA and Mars missions, the mass of some key payload elements, like the transit habitat, varies with crew size, mission destination and duration. With increasing crew size and mission duration, extra life support, food and accommodations are needed. For missions exceeding $\sim 1$ year in duration, like Mars, additional food supplies are carried in a consumables container attached to the primary TransHab module via a transfer tunnel. The container, along with unneeded mass, can then be jettisoned prior to the TEI maneuver to reduce propellant consumption. Both the container and transfer tunnel are enclosed within a short saddle truss that connects the transit habitat to the rest of the spacecraft. The short saddle truss has the same diameter as the long saddle truss that is sized by the diameter of the transfer vehicle's $\mathrm{LH}_{2}$ drop tank. The mass of both truss segments therefore increases with tank diameter.

Fixed mass payload elements include the Orion Multi-Purpose Crew Vehicle (MPCV) and an auxiliary multimission space excursion vehicle (MMSEV) carried on NEA missions. The MMSEV provides a small livable volume for a crew of two for up to two weeks [27] and is attached to the TransHab module via the same transfer tunnel (shown in Fig. 6). The MMSEV provides $\sim 200-300 \mathrm{~m} / \mathrm{s}$ of translational $\Delta \mathrm{V}$, suitports for quick EVA capability, and remote manipulation capability for sample collection. For lunar and NEA missions analyzed here, it is assumed that the crew collects and returns $\sim 100 \mathrm{~kg}$ of samples. For Mars DRA 5.0, 250 kg - 500 kg of samples are returned.

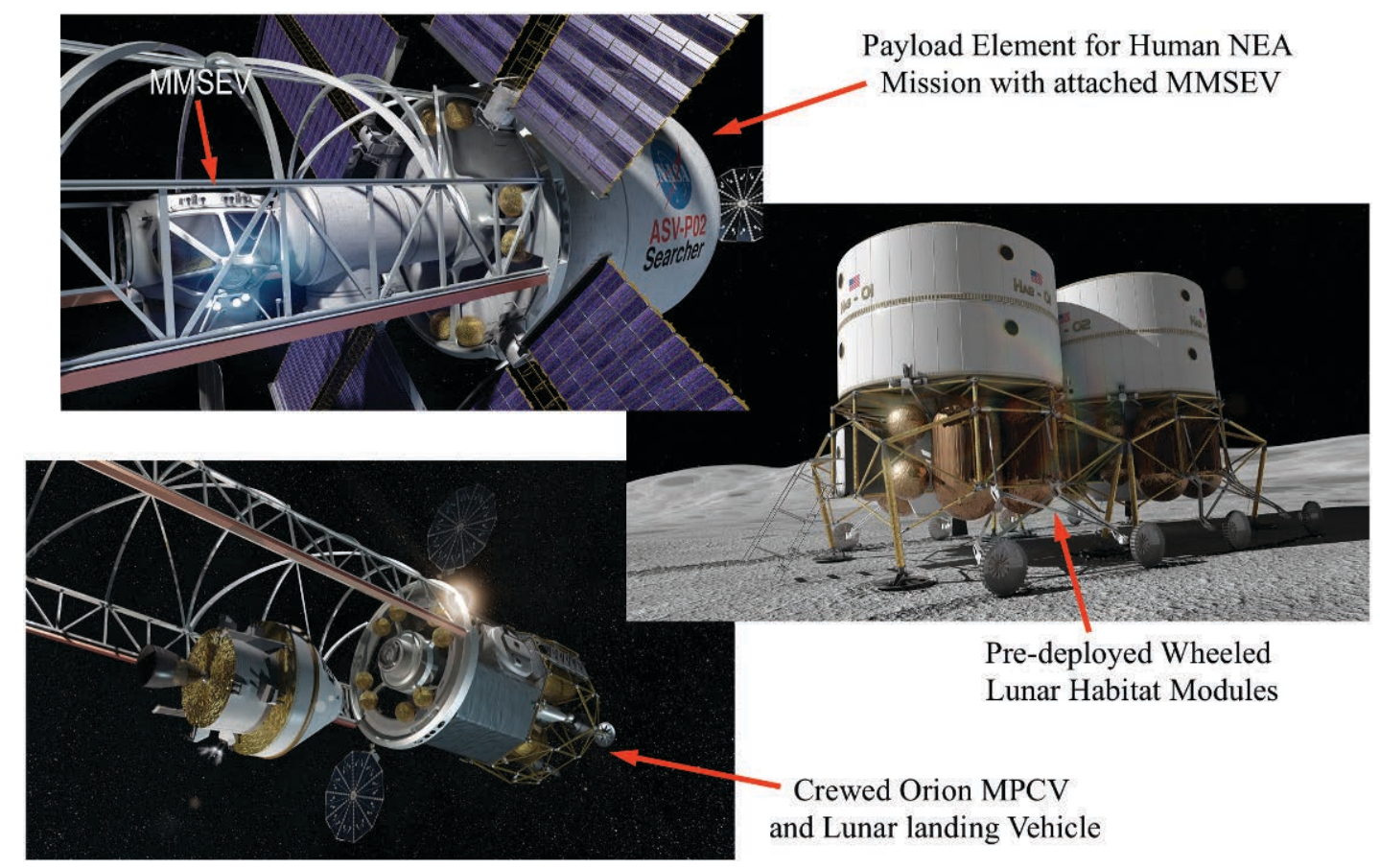

Figure 6. Payload Elements Delivered by NTP NEA and Lunar Transfer Vehicles

Table 2 lists the key transportation system ground rules and assumptions. The NTR engine and fuel type, operating characteristics, and thrust levels examined are summarized first. A three-engine cluster of $25 \mathrm{klb}_{\mathrm{f}}$ "Peweeclass" engines is baselined although lower thrust $15 \mathrm{klb}_{\mathrm{f}}$ engines (length $\sim 5.3 \mathrm{~m}$, engine thrust-to-weight ratio 3.1 ) are also considered in the paper. All engines use composite fuel with a U-235 fuel loading of $0.25 \mathrm{~g} / \mathrm{cm}^{3}$. With a hydrogen exhaust temperature $\left(\mathrm{T}_{\mathrm{ex}}\right)$ of $\sim 2790 \mathrm{~K}$, and a nozzle area expansion ratio of $\sim 300: 1$, the $\mathrm{I}_{\mathrm{sp}}$ is $\sim 906 \mathrm{~s}$ with higher $\mathrm{I}_{\mathrm{sp}}$ values achievable by increasing the fuel operating temperature. The total mission $\mathrm{LH}_{2}$ propellant loading consists of the usable propellant plus performance reserve, post-burn engine cooldown, and tank-trapped residuals. For the smaller auxiliary maneuvers, a storable bipropellant RCS system is used. All transfer vehicle configurations utilize a "split RCS" with 16 of 32 AMBR thrusters and approximately half of the bipropellant mass located on the rear propulsion stage and the forward most saddle truss adaptor ring just behind the mission-specific payload.

The $\mathrm{LH}_{2}$ propellant carried by the various vehicles is stored in the same "state-of-the-art" $\mathrm{Al} / \mathrm{Li} \mathrm{LH}_{2}$ propellant tank being developed for the SLS / HLV that will support future human exploration missions. For this analysis, tank sizing assumes a $30 \mathrm{psi}$ ullage pressure, $5 \mathrm{~g}_{\mathrm{E}}$ axial / $2.5 \mathrm{~g}_{\mathrm{E}}$ lateral launch loads, and a safety factor of 1.5 . A $3 \%$ ullage factor is also assumed. All tanks use a combination foam / multilayer insulation (MLI) system for passive thermal protection. A zero boil-off (ZBO) "reverse turbo-Brayton" cryocooler system is used on the NTR propulsion 


\section{Mars DRA 5.0: "7-Launch" NTR Mission Overview}

The 7-Launch NTR Mars mission strategy [19] for a human landing mission is illustrated in Fig. 7 and is centered around the long surface stay, split cargo / piloted mission approach. Two cargo flights pre-deploy a cargo lander to the surface and a habitat lander into Mars orbit where it remains until the arrival of the crew on the next mission opportunity ( 26 months later). The cargo flights utilize "1-way" minimum energy, long transit time trajectories. Four HLV flights carried out over 90 days ( $\sim 30$ days between launches), deliver the required components for the two cargo vehicles. The first two launches deliver the NTR propulsion stages each with three $25 \mathrm{klb}_{\mathrm{f}}$ NTR engines. The next two launches deliver the cargo and habitat lander payload elements which are enclosed within a large triconic-shaped aeroshell that functions as a payload shroud during launch, then as an aerobrake and thermal protection system during Mars aerocapture (AC) and subsequent entry, descent and landing (EDL) on Mars. Vehicle assembly involves Earth orbit rendezvous and docking $(\mathrm{R} \& \mathrm{D})$ between the propulsion stages and payload elements with the NTR stages functioning as the active element in the R\&D maneuver.

Once the operational functions of the orbiting habitat and surface cargo landers are verified, and the Mars Ascent Vehicle (MAV) is supplied with ISRU-produced ascent propellant, the crewed MTV is readied and departs on the next mission opportunity. As mentioned previously, the Copernicus MTV is a $0-\mathrm{g}_{\mathrm{E}}$ vehicle design that utilizes a fast conjunction trajectory with $\sim 6$ month "1-way" transit times to and from Mars. Like the cargo MTV, it is an "in-line" configuration that uses Earth orbit R\&D to simplify vehicle assembly. It uses the same "common" NTR propulsion stage but includes additional external radiation shielding on each engine for crew protection during engine operation. Three HLV launches over 60 days are used to deliver the vehicle's key components which include: (1) the NTR propulsion stage; (2) integrated "saddle truss" and $\mathrm{LH}_{2}$ drop tank assembly; and (3) supporting crewed payload. The crewed payload component includes the TransHab module with its six crew, a long-lived MPCV for vehicle-to-vehicle transfer and "end of mission" Earth entry, a secondary T-shaped docking module (DM), contingency consumables container and connecting structure. Four $12.5 \mathrm{~kW}_{\mathrm{e}} / 125 \mathrm{~m}^{2}$ rectangular PVAs provide $\sim 50 \mathrm{~kW}_{\mathrm{e}}$ of electrical power at Mars for crew life-support $\left(\sim 30 \mathrm{~kW}_{\mathrm{e}}\right)$, a ZBO Brayton cryocooler system $\left(\sim 10 \mathrm{~kW}_{\mathrm{e}}\right)$, and high data- rate communications $\left(\sim 10 \mathrm{~kW}_{\mathrm{e}}\right)$ with Earth. When assembly is completed, the Mars crew is delivered

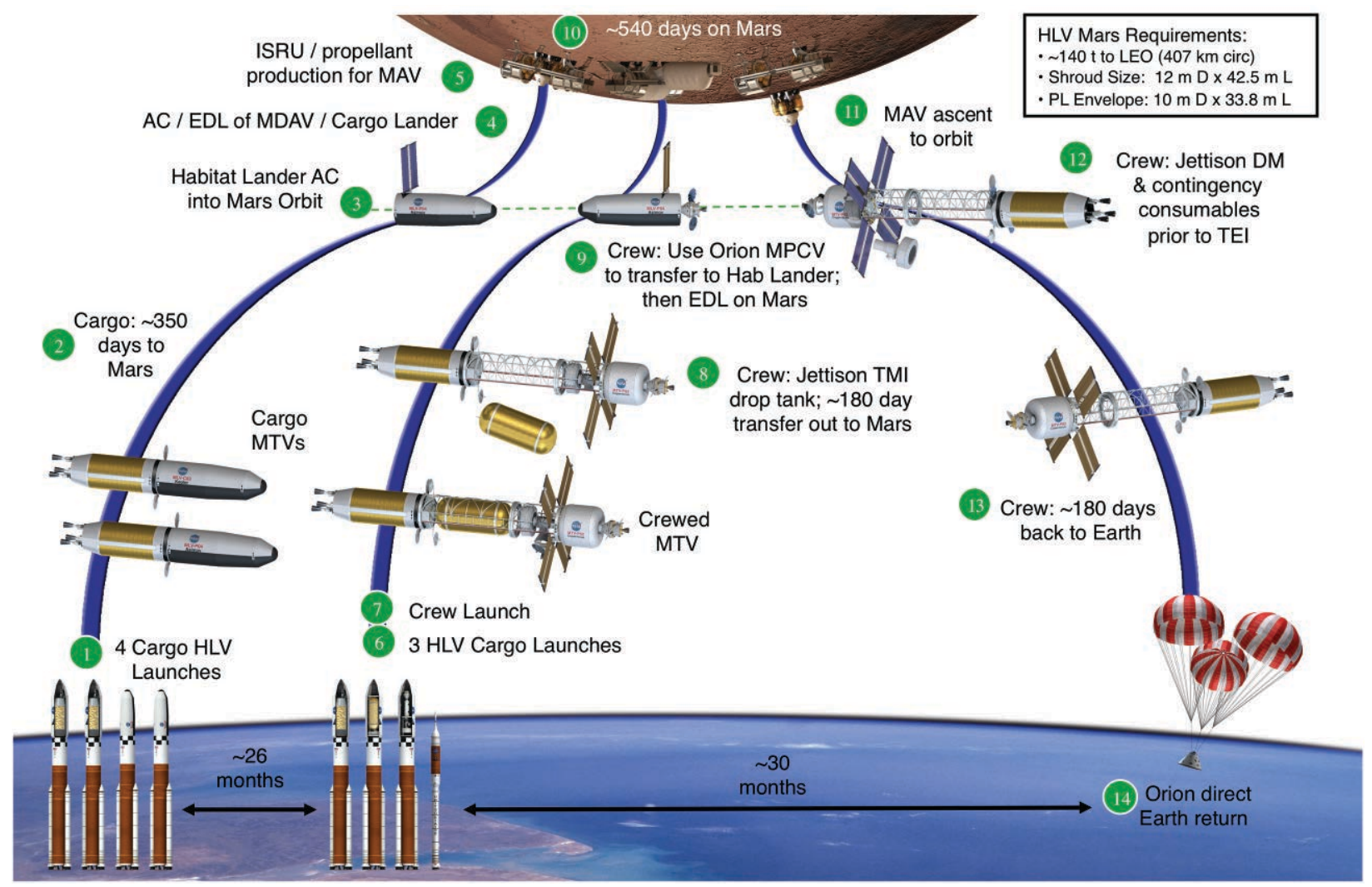

Figure 7. DRA 5.0 Long-Stay Mars Mission Overview: "7-Launch" NTR Strategy 
to Copernicus and docks on its underside using the secondary DM that connects the TransHab crew module and contingency consumables container (shown in Figs. 8 and 9).

Following the TMI maneuver, the drained $\mathrm{LH}_{2}$ drop tank, attached to the saddle truss, is jettisoned and the crewed MTV coasts to Mars under 0 - $\mathrm{g}_{\mathrm{E}}$ conditions with its four PVAs tracking the Sun. Attitude control and midcourse correction maneuvers are provided by Copernicus' split RCS that uses $200 \mathrm{lb}_{\mathrm{f}}$ storable bipropellant AMBR (Advanced Material Bipropellant Rocket) thrusters located on the rear NTR propulsion module and the short saddle truss forward adaptor ring just behind the TransHab module. After the MOC burn, Copernicus rendezvouses with the orbiting Hab lander using engine cooldown thrust and the vehicle's RCS. The crew then transfers over to the lander using the MPCV. After crew transfer, the MPCV returns and docks to the TransHab autonomously. The crew then initiates EDL near the cargo lander and begins the surface exploration phase of the mission. After $\sim 533$ days on the surface, the crew lifts off using the MAV and returns to Copernicus using its secondary DM (shown in Fig. 8). Following the transfer of the crew and samples, the MAV is jettisoned. The crew then begins a weeklong checkout and verification of all MTV systems, jettisons the DM and contingency consumables and performs the TEI burn to begin the journey back to Earth. After an $\sim 6$ month trip time, the crew enters the MPCV, separates from the MTV and subsequently re-enters the atmosphere while Copernicus flies by Earth at a "sufficiently high altitude" and is disposed of into heliocentric space. Although Copernicus was operated in an "expendable mission mode" in DRA 5.0 to reduce total IMLEO, it can readily be modified for operation in a "reusable mode" by providing the vehicle with additional propellant capacity as discussed in the next section.

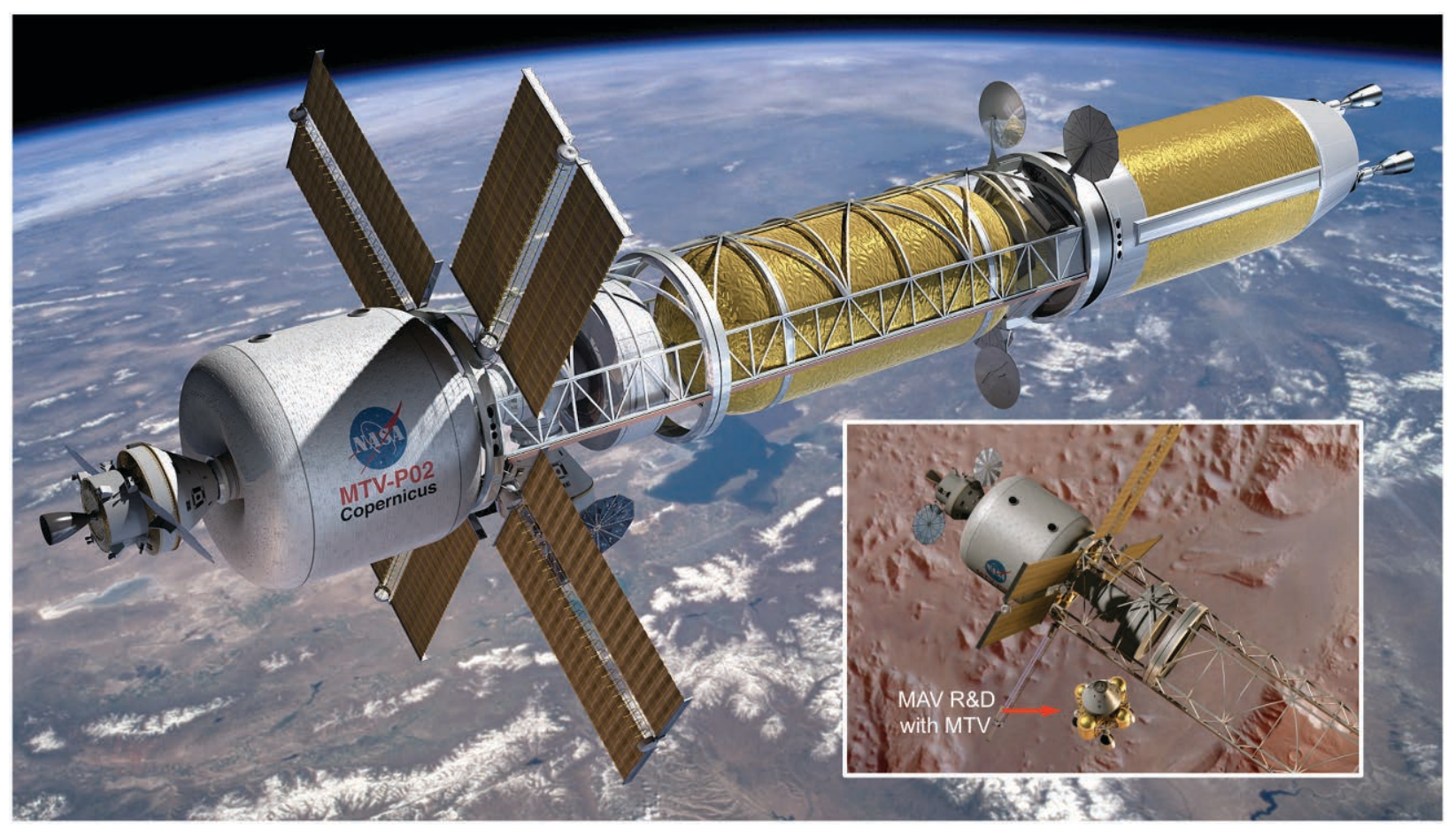

Figure 8. Copernicus' Secondary DM Provides Access to the MPCV and MAV during the Mission

The "Copernicus" crewed MTV has an overall length of $\sim 93.7 \mathrm{~m}$ (Fig. 9) and an IMLEO of $\sim 336.5 \mathrm{t}$ consisting of: (1) the NTP stage or NTPS ( 138.1 t); (2) the saddle truss and $\mathrm{LH}_{2}$ drop tank (133.4 t); and (3) the crew payload section ( $\sim 65 \mathrm{t}$ ). The NTPS uses a three-engine cluster of $25 \mathrm{klb}_{\mathrm{f}}$ NTR engines and also carries additional external radiation shield mass ( $\sim 7.3 \mathrm{t}$ ) for crew protection. The NTPS uses an $\mathrm{Al} / \mathrm{Li} \mathrm{LH}_{2}$ tank size which has a diameter (D) and length (L) of $10 \mathrm{~m} \mathrm{D} \times 19.7 \mathrm{~m} \mathrm{~L}$. The tank's $\mathrm{LH}_{2}$ propellant capacity is $\sim 87.2 \mathrm{t}$. The NTPS also carries avionics, RCS, auxiliary battery and PVA power, docking and Brayton-cycle ZBO refrigeration systems located in the forward cylindrical adaptor section. To remove $\sim 78$ watts of heat penetrating the 60 layer MLI system in LEO (where the highest tank heat flux occurs), the reverse turbo-Brayton cryocooler system needs $\sim 8.9 \mathrm{~kW}_{\mathrm{e}}$ for its operation $\left(\sim 114 \mathrm{~W}_{\mathrm{e}}\right.$ for each $\mathrm{W}_{\mathrm{t}}$ removed). Twin circular PVAs on the NTPS provide the electrical power for the ZBO system in LEO until the four primary PVAs on the crewed PL section are deployed prior to TMI. 
Copernicus' second major component is its saddle truss and $\mathrm{LH}_{2}$ drop tank assembly. The saddle truss is a rigid, spine-like composite structure that wraps around the upper half of the $\mathrm{LH}_{2}$ drop tank and connects the NTR stage to the forward payload section. It is $\sim 27.7 \mathrm{~m}$ long and has a mass of $\sim 9 \mathrm{t}$. The saddle truss is open underneath allowing the drained $\mathrm{LH}_{2}$ drop tank to be jettisoned after the TMI burn is completed. The $\sim 22.7 \mathrm{~m}$ long $\mathrm{LH}_{2}$ drop tank has a mass of $\sim 22 \mathrm{t}$ and carries $\sim 102.4 \mathrm{t}$ of propellant.

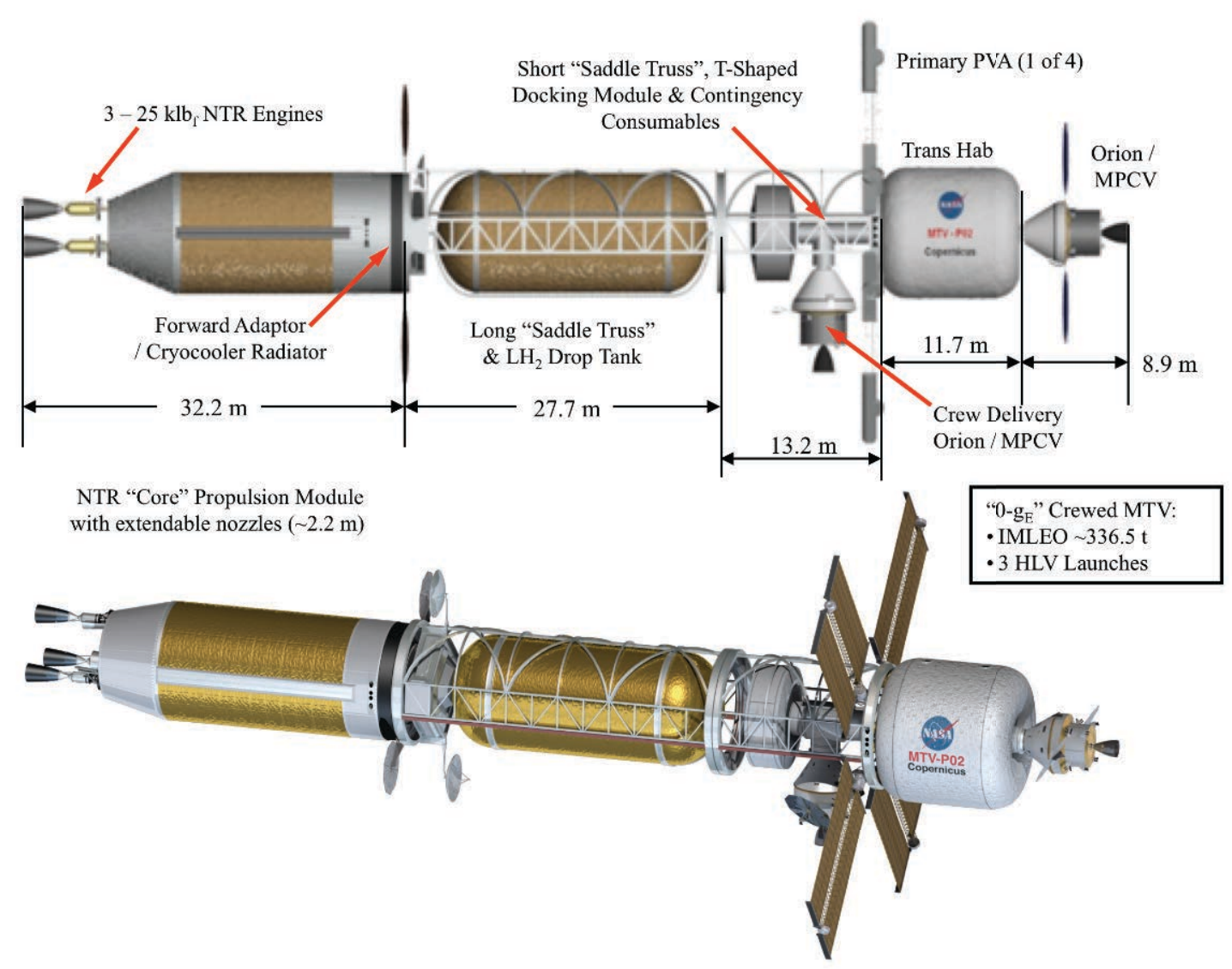

Figure 9. Key Features and Component Lengths of the Copernicus NTR Mars Transfer Vehicle

Copernicus' third and final component is its payload section. In DRA 5.0 it was designed for launch as a single integrated unit and thus determines the overall shroud size. The integrated payload element is $\sim 33.8 \mathrm{~m}$ long and includes the short saddle truss, "T-shaped" docking module (DM) and transfer tunnel, consumables container, TransHab and Orion MPCV. The DM provides "secondary access" to Copernicus for the crew delivery MPCV and the MAV (see Figs. 8 and 9). Following the crew's return from Mars and MAV separation, the DM and attached consumables container are both jettisoned to reduce vehicle mass prior to TEI (see Fig. 7).

The total crewed payload mass at TMI is $\sim 65 \mathrm{t}$ distributed as follows: (1) short saddle truss ( $\sim 5.1 \mathrm{t})$; (2) DM and transfer tunnel $(\sim 1.8 \mathrm{t})$; (3) contingency consumables and jettisonable container $(\sim 9.7 \mathrm{t})$; (4) TransHab with its primary PVAs ( 27.5 t); (5) transit consumables ( $\sim 5.3 \mathrm{t})$; (6) crew ( 0.6 t); (7) MPCV ( 10 t); and (8) forward RCS and propellant $(\sim 5 \mathrm{t})$. The crewed MTV's total RCS propellant loading is $\sim 9.1 \mathrm{t}$ with the "post-TMI" RCS propellant load split between the NTPS $(\sim 5.1 \mathrm{t})$ and the short saddle truss forward cylindrical adaptor ring $(\sim 4 \mathrm{t})$.

Lastly, for DRA 5.0, the performance requirements on operating time and restart for Copernicus' $3-25 \mathrm{klb}_{\mathrm{f}}$ NTR engines are quite reasonable. For the round trip mission, there are 4 primary burns ( 3 restarts) that use $\sim 178.4 \mathrm{t}$ of $\mathrm{LH}_{2}$ propellant. With $75 \mathrm{klb}_{\mathrm{f}}$ of total thrust and a $\mathrm{I}_{\mathrm{sp}}$ of $\sim 906 \mathrm{~s}$, the total engine burn time for the mission is $\sim 79.2$ minutes ( $\sim 55$ minutes for the "2-perigee burn" TMI maneuver, $\sim 14.5$ minutes for MOC, and $\sim 9.7$ minutes for TEI), well under the $\sim 2$ hour accumulated engine burn time and 27 restarts demonstrated by the NERVA eXperimental Engine [5] - the NRX-XE in 1969. 


\section{Modular "Growth" Options and Alternate Mission Applications for Copernicus}

In DRA 5.0, the Copernicus MTV was sized to allow it to perform all of the fast conjunction missions over the 15 -year synodic cycle $(\sim 2030-2045$ timeframe) with transit times to and from Mars ranging from $\sim 150-210$ days. The baseline mission trajectory, trip times and $\Delta \mathrm{V}$ budget details for the DRA 5.0 "7-Launch" NTR strategy included the following: Earth departure $\mathrm{C}_{3} \sim 18.40 \mathrm{~km}^{2} / \mathrm{s}^{2}, \Delta \mathrm{V}_{\mathrm{TMI}} \sim 3.992 \mathrm{~km} / \mathrm{s}$, outbound transit time $\sim 180$ days, arrival $\mathrm{V}_{\text {inf }} \sim 4.176 \mathrm{~km} / \mathrm{s}$, and $\Delta \mathrm{V}_{\text {MOC }} \sim 1.771 \mathrm{~km} / \mathrm{s}$, stay time at Mars $\sim 540$ days, Mars departure $\mathrm{C}_{3} \sim 14.80 \mathrm{~km}^{2} / \mathrm{s}^{2}$, $\Delta \mathrm{V}_{\text {TEI }} \sim 1.562 \mathrm{~km} / \mathrm{s}$, inbound transit time $\sim 180$ days, and total mission duration $\sim 900$ days. For 180 -day transit missions returning to a $24-\mathrm{hr}$ EEO, the capture $\Delta \mathrm{V}_{\mathrm{EOC}}$ is $\sim 1.855 \mathrm{~km} / \mathrm{s}$. (Gravity loss is also added to the ideal $\Delta \mathrm{V}$ values shown). As mentioned previously, the "3-element" Copernicus spacecraft (Fig. 10 - Configuration 1) has significant propellant capacity that can be exploited for a variety of other mission applications. These include human missions to large, high energy NEAs, as well as, reusable lunar cargo delivery and crewed lunar landing missions. Mission details and vehicle characteristics for these applications are provided in later sections of this paper.

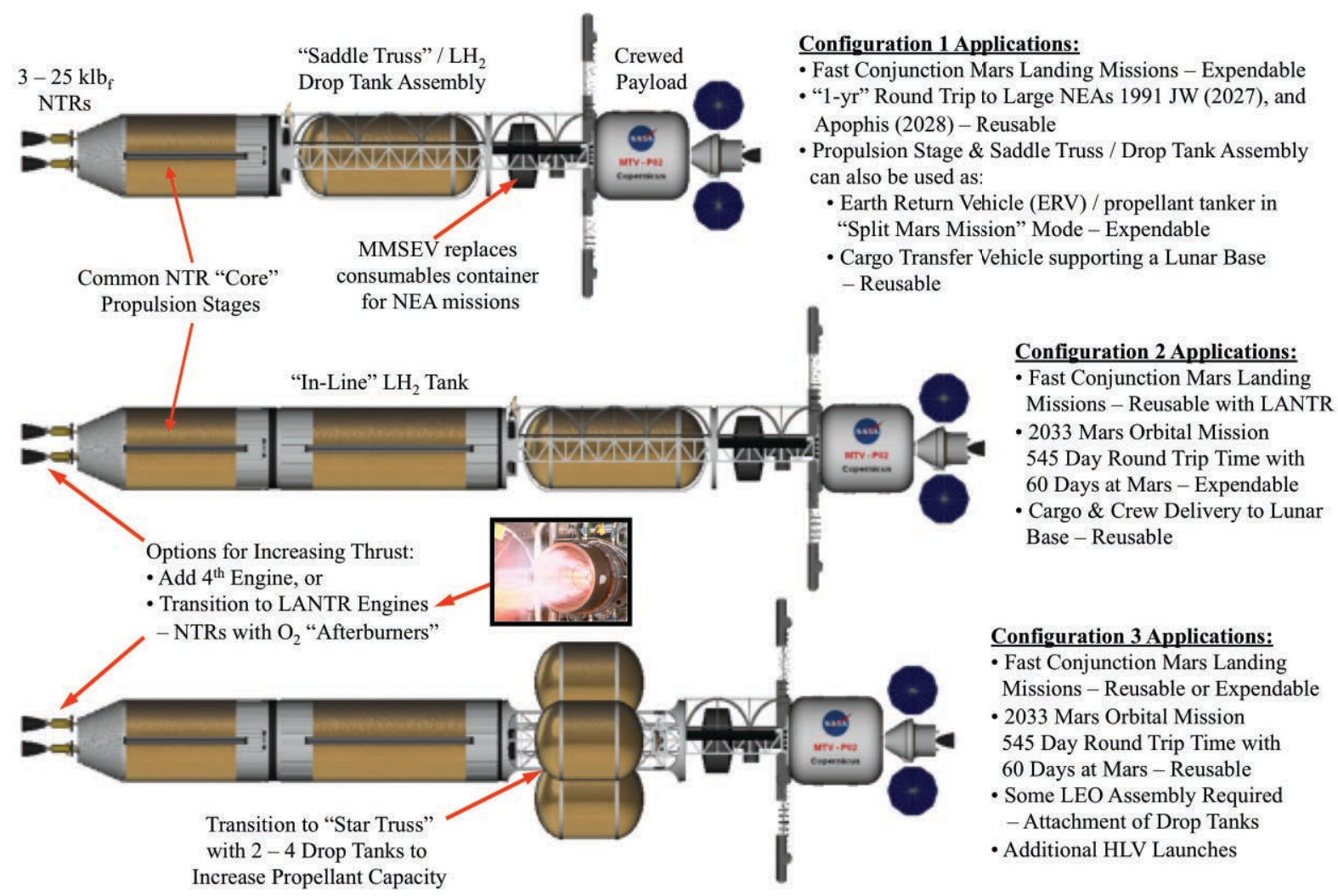

Figure 10. Growth Paths and Alternative Missions for Copernicus Spacecraft using Modular Components

Currently, the United States' National Space Policy states that NASA shall: By the mid-2030s, send humans to orbit Mars and return them safely to Earth. Short round trip / short orbital stay "opposition" missions to Mars have higher energy requirements than those in DRA 5.0 and are best performed in the $2033-2035$ timeframe when the mission $\Delta \mathrm{V}$ budgets are near their minimum values over the 15 -year synodic cycle. After that the $\Delta \mathrm{V}$ budgets for successive short round trip missions increase significantly necessitating larger quantities of propellant and extra spacecraft mass being launched in order to perform the mission. Using the Copernicus spacecraft and its two key components - the NTPS and integrated saddle truss / drop tank assembly - configured as an Earth Return Vehicle (ERV) / propellant tanker, a "split cargo / crewed mission" approach can be utilized for an initial Mars orbital survey mission before a human landing mission is attempted. The split mission option can also eliminate the additional time and cost to develop the extra vehicle components needed for an "all up" mission. Use of a predeployed ERV is not a new idea. In NASA's DRM 1.0 study in 1993 [14], the ERV was one of the key transportation system elements used in the mission architecture. 


\section{Short Round Trip / Short Orbital Stay Expendable "Split Mars Mission” Option:}

Using the Copernicus spacecraft, outfitted as a Mars Survey Vehicle (MSV), plus an ERV / propellant tanker, a 545-day round trip / 60-day stay crewed mission to Mars is possible in 2033 using the split mission approach outlined in Fig. 11. The ERV is pre-deployed to Mars orbit in advance of the crew. It departs from LEO in December 2030 (departure $\mathrm{C}_{3} \sim 10.794 \mathrm{~km}^{2} / \mathrm{s}^{2}, \Delta \mathrm{V}_{\mathrm{TMI}} \sim 3.662 \mathrm{~km} / \mathrm{s}$ ), on a 283-day "minimum-energy" trajectory out to Mars. The ERV then arrives at Mars (arrival $V_{\text {inf }} \sim 3.480 \mathrm{~km} / \mathrm{s}$ ) and propulsively captures into a "24-hour" elliptical parking orbit $\left(\sim 250 \mathrm{~km} \times 33,793 \mathrm{~km}, \Delta \mathrm{V}_{\mathrm{MOC}} \sim 1.34 \mathrm{~km} / \mathrm{s}\right)$ in October 2031 where it remains until the crewed MSV, called "Searcher", arrives on the next opportunity $\sim 2$ years later.

Searcher departs LEO with its 6 crew in May 2033 (departure $\mathrm{C}_{3} \sim 14.62 \mathrm{~km}^{2} / \mathrm{s}^{2}, \Delta \mathrm{V}_{\mathrm{TMI}} \sim 3.83 \mathrm{~km} / \mathrm{s}$ ). It uses a high energy, opposition trajectory out to Mars arriving $\sim 159$ days later (arrival $\mathrm{V}_{\text {inf }} \sim 3.79 \mathrm{~km} / \mathrm{s}$ ), then propulsively captures $\left(\Delta \mathrm{V}_{\mathrm{MOC}} \sim 1.53 \mathrm{~km} / \mathrm{s}\right)$ into the same parking orbit as the ERV in October 2033. In the process, Searcher uses a substantial percentage of its available propellant. To return to Earth, Searcher rendezvouses with the ERV and the forward crewed PL element is switched over to the ERV (shown in Fig. 12). No propellant transfer is required just a R\&D maneuver. Before the ERV performs the TEI maneuver $\left(\Delta \mathrm{V}_{\mathrm{TEI}} \sim 3.12 \mathrm{~km} / \mathrm{s}\right)$, the exterior consumables container and connecting tunnel $(\sim 6.2 \mathrm{t})$ are jettisoned from the PL element to reduce propellant consumption. The ERV utilizes an inbound Venus swing-by during the 326-day transfer back to Earth. At mission end, the crew reenters using the Orion MPCV capsule, while Searcher flies by Earth and is disposed of into heliocentric space.

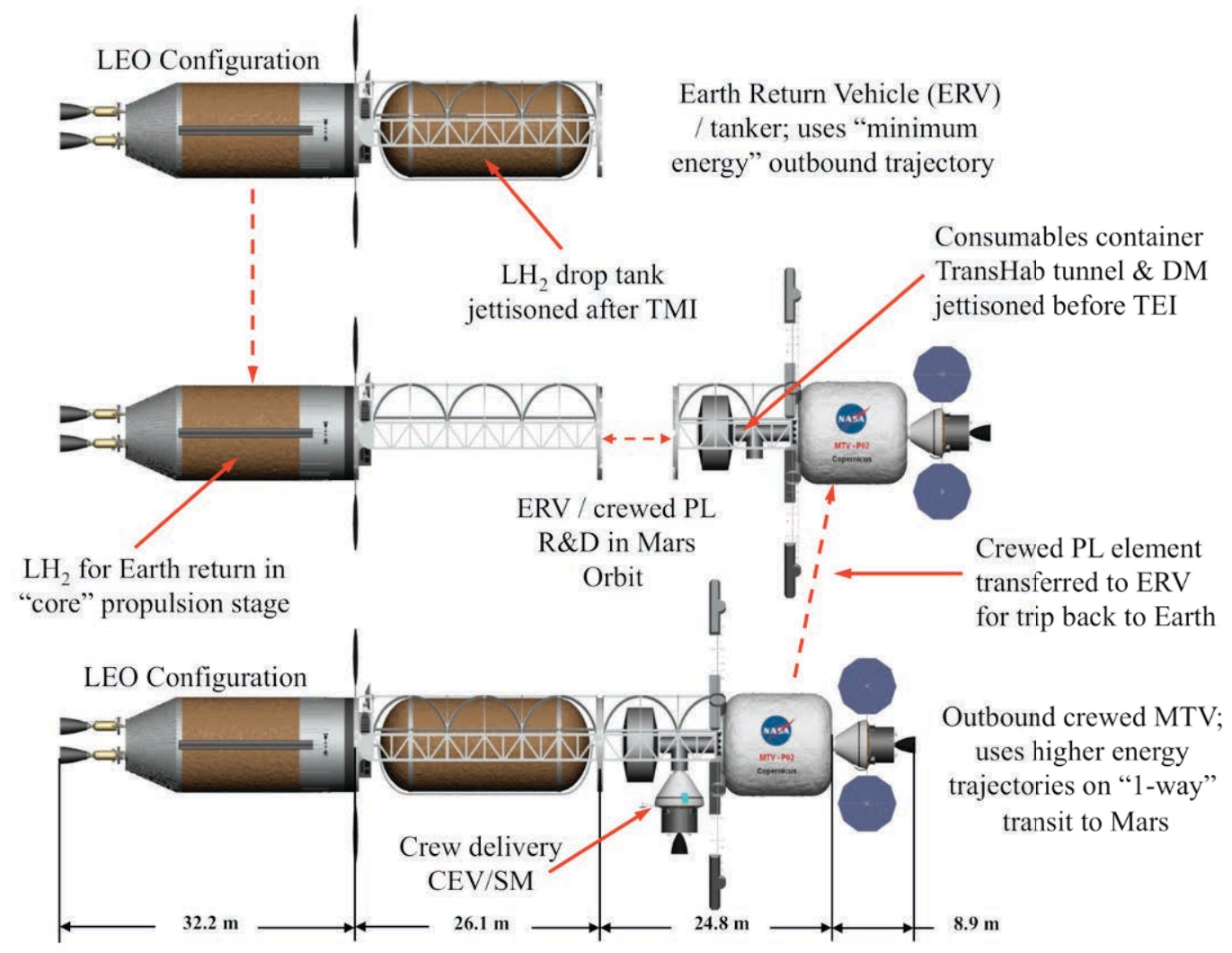

Figure 11. Copernicus MTV \& Components Configured for Short Round Trip "Split" Mars Orbital Mission

For its outbound Mars transit, Searcher has an IMLEO of $\sim 251.1 \mathrm{t}$ consisting of the NTPS $(\sim 107 \mathrm{t})$, the integrated saddle truss $/ \mathrm{LH}_{2}$ drop tank assembly $(\sim 84.3 \mathrm{t})$, and the crewed PL element $(\sim 59.8 \mathrm{t})$. The NTPS and $\sim 21.1 \mathrm{~m}$ long $\mathrm{LH}_{2}$ drop tank are substantially off-loaded in propellant $\left(66.8 \%\right.$ and $59.6 \%$, respectively), with $\sim 114.5 \mathrm{t}$ of $\mathrm{LH}_{2}$ propellant carried on the outbound mission leg ( $\sim 63 \%$ of the maximum available capacity of $\sim 181.7 \mathrm{t})$. In addition to 3 restarts, the total burn time on Searcher's three $25 \mathrm{klb}_{\mathrm{f}}$ engines is $\sim 47.7$ minutes, substantially lower than that needed for DRA 5.0, and well below the capabilities demonstrated on the NRX-XE. 


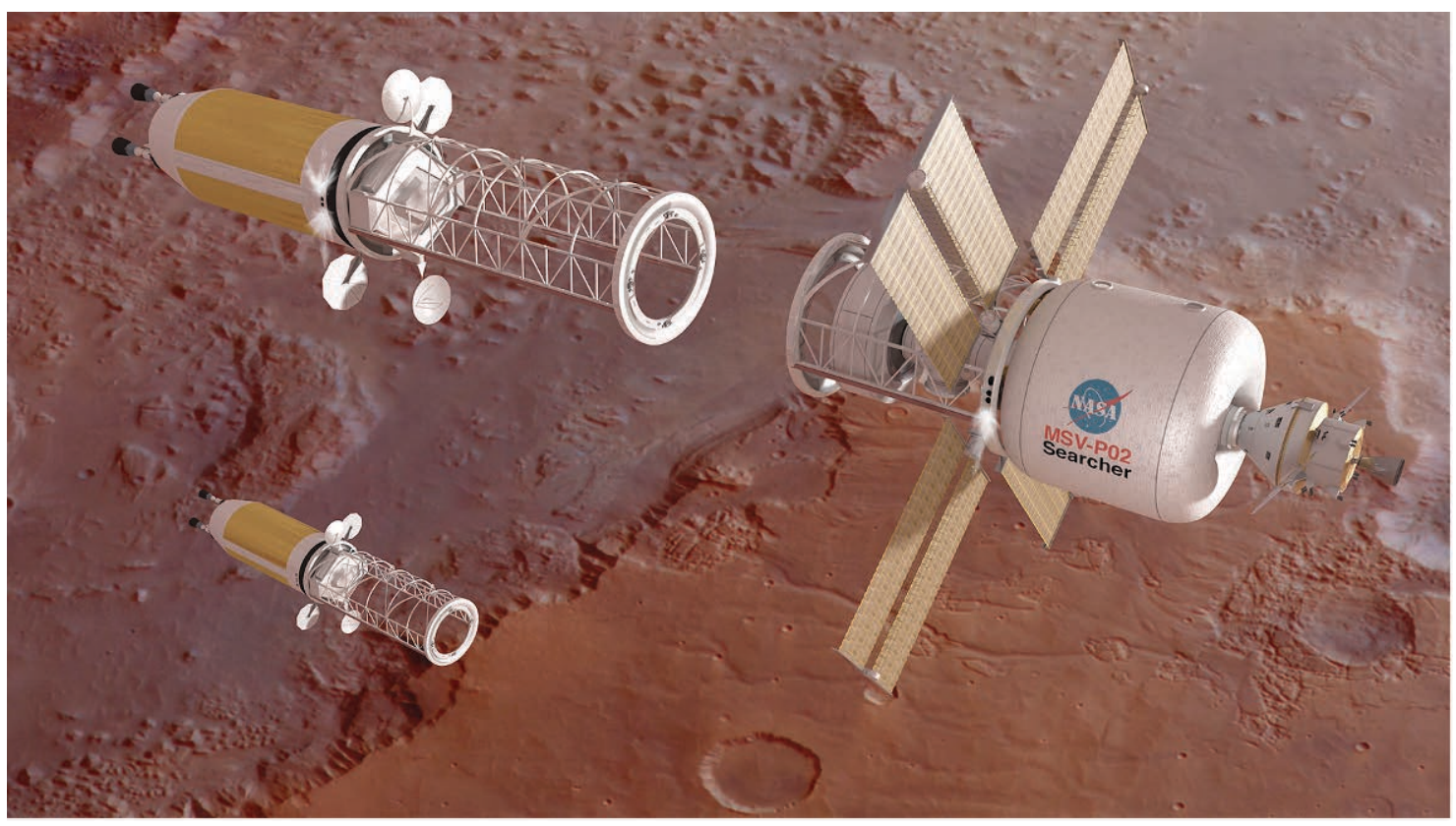

Figure 12. "Switch-over" - Crewed PL Element Transfer to ERV in Mars Orbit for Trip Back to Earth.

The "round trip" ERV / tanker has an IMLEO of $\sim 237.4 \mathrm{t}$ consisting of NTR propulsion stage $(\sim 127.6 \mathrm{t})$ and the integrated saddle truss $/ \mathrm{LH}_{2}$ drop tank assembly $(\sim 109.8 \mathrm{t})$. The ERV carries a larger $\mathrm{LH}_{2}$ propellant loading in its propulsion stage and forward drop tank totaling $\sim 153.6 \mathrm{t}(\sim 84.5 \%$ of the maximum available capacity of $\sim 181.7 \mathrm{t})$ which is needed to return Searcher's crewed PL back to Earth. In addition to 3 restarts, the total burn time on the ERV's three $25 \mathrm{klb}_{\mathrm{f}}$ engines is $\sim 64.2$ minutes ( $\sim 35.2$ minutes for the "2-perigee" burn TMI maneuver, 7.9 minutes for MOC, and 21.1 minutes for TEI), again well below the capabilities demonstrated on the NRX-XE. The ERV's longer TEI burn duration is attributed to the addition of the Searcher's $\sim 51.2 \mathrm{t}$ crewed PL plus the higher TEI $\Delta \mathrm{V}$ requirement $(\sim 3.12 \mathrm{~km} / \mathrm{s}$ versus $\sim 1.56 \mathrm{~km} / \mathrm{s}$ for DRA 5.0$)$. Lastly, the total mission IMLEO for the Searcher MSV and its ERV is $\sim 488.5 \mathrm{t}$.

\section{Short Round Trip / Short Orbital Stay “All Up” Expendable Mars Mission Option:}

The same 18 month round trip / 60-day stay Mars orbital mission discussed above can be performed using a single vehicle by positioning an "in-line" $\mathrm{LH}_{2}$ tank between the propulsion stage and integrated saddle truss / drop tank assembly to provide additional propellant capacity (Fig. 10 - Configuration 2 and Fig. 13). This "all up" configuration has an IMLEO of $\sim 429.4 \mathrm{t}$ consisting of the "wet" NTPS $(\sim 134.4 \mathrm{t})$, in-line tank $(\sim 117.7 \mathrm{t})$, saddle truss / drop tank assembly $(\sim 117.7 \mathrm{t})$ and the crew PL section $(\sim 59.6 \mathrm{t})$. The overall vehicle length is $\sim 117 \mathrm{~m}$ including the Orion MPCV at $\sim 8.9 \mathrm{~m}$. The $\mathrm{LH}_{2}$ loading in the propulsion stage, in-line and drop tanks are $\sim 87.1 \mathrm{t}$, $\sim 88.9 \mathrm{t}$, and $\sim 89.1 \mathrm{t}$, respectively. The $\mathrm{LH}_{2}$ tank length in the NTPS is $\sim 19.7 \mathrm{~m}$. The in-line and drop tank lengths are the same at $\sim 20 \mathrm{~m}$. With these equal tank lengths, the masses of in-line tank element and the saddle truss / drop tank assembly are balanced at $\sim 117.7 \mathrm{t}$. For this expendable "all up" Mars orbital mission, there are 4 primary burns (with 3 restarts) and the $\mathrm{LH}_{2}$ propellant used for the mission is $\sim 250 \mathrm{t}$. With $75 \mathrm{klb}_{\mathrm{f}}$ of total thrust and a $\mathrm{I}_{\mathrm{sp}}$ of $906 \mathrm{~s}$, the total engine burn time for this mission is $\sim 111$ minutes. The first TMI perigee burn is the longest single burn at $\sim 41.3$ minutes. After this burn, the drop tank is drained and then jettisoned to reduce vehicle mass and propellant consumption during the second perigee burn ( 27.6 minutes). The in-line tank and NTPS supply the propellant for the remaining MOC ( $\sim 16.8$ minutes) and TEI burns ( $\sim 25.3$ minutes). Compared to the split mission approach, the all up option requires one less HLV launch but it also requires development of the in-line tank element with its own ZBO cryocooler system. The total burn time requirement on the engines is also larger as is the maximum single burn duration which increases by $\sim 64 \%$ (from $\sim 25.2$ minutes for Searcher's first perigee burn to $\sim 41.3$ minutes for this same maneuver). Adding a fourth engine would help reduce total mission burn time and gravity losses $(\sim 380 \mathrm{~m} / \mathrm{s})$ during the TMI maneuver but also increases NTPS inert mass at the expense of $\mathrm{LH}_{2}$ propellant loading. 


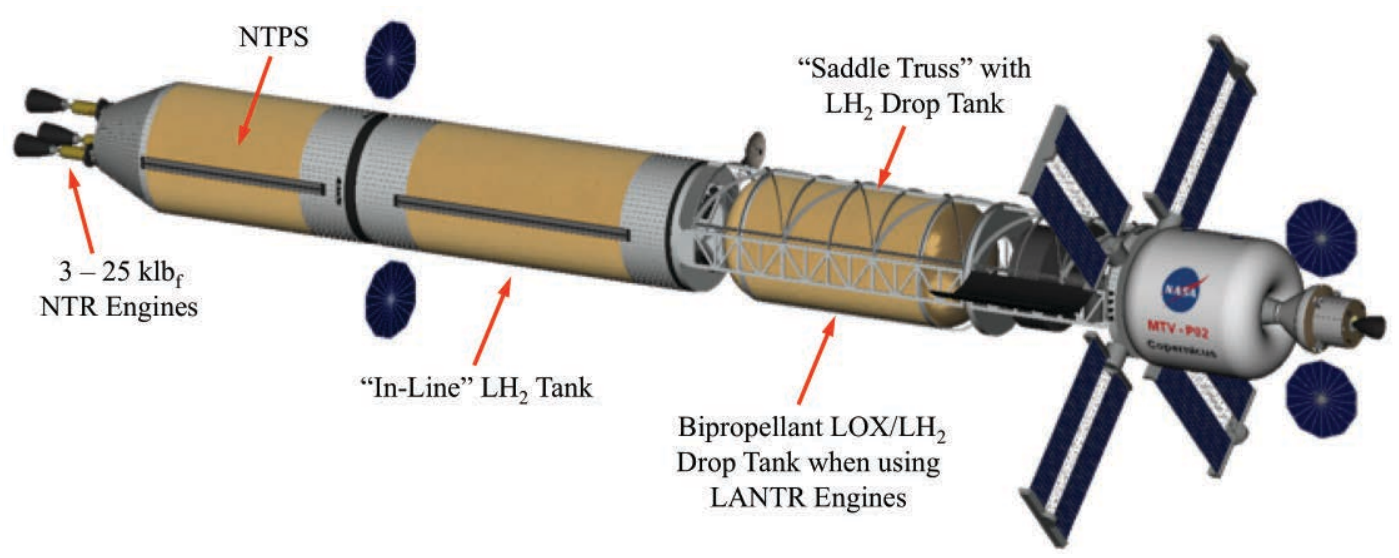

Figure 13. Configuration 2: Supports Expendable Short Stay or Reusable DRA 5.0 Missions using LANTR

\section{Reusable DRA 5.0 Copernicus Option 1 (3 - LANTR Engines, 24-hr EEO capture $\left.\Delta V_{\text {EOC }} \sim 1.855 \mathrm{~km} / \mathrm{s}\right)$ :}

There are two possible options for converting the Copernicus MTV from an expendable to a reusable spacecraft. In Option 1 (Fig. 13), the $\mathrm{LH}_{2}$ drop tank is replaced by a bipropellant $\left(\mathrm{LOX} / \mathrm{LH}_{2}\right)$ tank and oxygen "afterburner" nozzles are added to Copernicus' three NTR engines to help increase the vehicle's total thrust output and shorten the engine burn time during Earth departure. In the "LOX-Augmented" NTR (LANTR) option [28,29], oxygen is injected into the divergent section of the nozzle downstream of the sonic throat. Here it mixes with reactor-heated $\mathrm{H}_{2}$ and undergoes supersonic combustion adding both mass and chemical energy to the engine's exhaust. By operating the LANTR engines with an oxygen-to-hydrogen mixture ratio $(\mathrm{MR})=1$ during the first TMI perigee burn, the engine's thrust level is increased by over $62 \%$ - from $25 \mathrm{klb}_{\mathrm{f}}$ to $\sim 40.6 \mathrm{klb}_{\mathrm{f}}$. The addition of oxygen at this MR, however, lowers the $\mathrm{I}_{\mathrm{sp}}$ to $\sim 726 \mathrm{~s}$. To limit the number of HLV launches to 4, crew size is reduced from 6 to 4 thereby lowering the requirements on TransHab mass and mission consumables. The drained bipropellant drop tank is also jettisoned after the first perigee burn and all subsequent maneuvers use straight NTP and $\mathrm{LH}_{2}$ propellant. The engines' composite fuel is also run at higher temperature to achieve a $\mathrm{I}_{\mathrm{sp}}$ of $\sim 935 \mathrm{~s}$.

The IMLEO for Option 1 is $\sim 466.6 \mathrm{t}$ consisting of the "wet" NTPS ( $\sim 136 \mathrm{t})$, in-line tank ( $138 \mathrm{t})$, saddle truss / drop tank assembly $(\sim 138.6 \mathrm{t})$ and the crew PL section $(\sim 54 \mathrm{t})$. The overall vehicle length is $\sim 116.3 \mathrm{~m}$ including the $8.9 \mathrm{~m}$ long Orion MPCV. The propellant loading in the propulsion stage, in-line and drop tanks are $\sim 87.2 \mathrm{t}, \sim 105.5 \mathrm{t}$, and $\sim 111.6 \mathrm{t}$, respectively. The bipropellant drop tank includes $\sim 58.1 \mathrm{t}$ of LOX and $\sim 53.5 \mathrm{t}$ of $\mathrm{LH}_{2}$. For this "all up" reusable Mars orbital mission, there are 5 primary burns ( 4 restarts). During the first perigee burn with LANTR "afterburners", the total vehicle thrust is increased to $\sim 121.8 \mathrm{klb}_{\mathrm{f}}$. With $\sim 112.4 \mathrm{t}$ of $\mathrm{LOX} / \mathrm{LH}_{2}$ propellant consumed and a $\mathrm{I}_{\mathrm{sp}}$ of $\sim 726 \mathrm{~s}$, the burn duration is $\sim 24.6$ minutes. The duration of the remaining burns using straight NTP (total thrust $\sim 75 \mathrm{klb}_{\mathrm{f}}, \mathrm{I}_{\mathrm{sp}} \sim 935 \mathrm{~s}$ ) is as follows: second perigee burn ( $\sim 31.9$ minutes), MOC ( $\sim 20.5$ minutes), TEI ( $\sim 14.4$ minutes) and $\operatorname{EOC}(\sim 13.8$ minutes). The total engine burn time for the entire mission is $\sim 105.2$ minutes.

\section{Reusable DRA 5.0 Copernicus Option 2 (4 - 25 klb NTR Engines, 24-hr EEO capture $\left.\Delta V_{\text {EOC }} \sim 1.855 \mathrm{~km} / \mathrm{s}\right)$ :}

In Option 2 (Fig. 10 - Configuration 3 and Fig. 14), Copernicus uses four conventional $25 \mathrm{klb}_{\mathrm{f}}$ NTR engines cooled with $\mathrm{LH}_{2}$ propellant, and carries the same 6-person crew and payload baselined in DRA 5.0. The IMLEO for Option 2 is $\sim 542.6 \mathrm{t}$ including the NTPS $(\sim 137.6 \mathrm{t})$, the in-line tank $(\sim 105.1 \mathrm{t})$, a 4-sided "star truss" with 4 modular $\mathrm{LH}_{2}$ drop tanks $(\sim 233.6 \mathrm{t})$ and the crew PL section ( $\left.\sim 66.3 \mathrm{t}\right)$. Two drop tanks $(\sim 112.9 \mathrm{t})$ carrying $\sim 88.5 \mathrm{t}$ of $\mathrm{LH}_{2}$ ( $\sim 44.2 \mathrm{t}$ per tank) are delivered to LEO on a single HLV launch, then attached to the $\sim 16 \mathrm{~m}$ long star truss $(\sim 7.8 \mathrm{t})$ during the LEO assembly phase. Each drop tank is $\sim 11 \mathrm{~m}$ long. The overall vehicle length is $\sim 102.1 \mathrm{~m}$ including the $8.9 \mathrm{~m}$ long Orion MPCV. The $\mathrm{LH}_{2}$ loading in the propulsion stage, in-line and 4 drop tanks is $\sim 85.3 \mathrm{t}, \sim 76.9 \mathrm{t}$, and $\sim 176.9 \mathrm{t}$, respectively, and the lengths of NTPS and in-line $\mathrm{LH}_{2}$ tanks are $\sim 19.7 \mathrm{~m}$ and $\sim 17.6 \mathrm{~m}$. For Option 2 , there are 5 primary burns ( 4 restarts) and $\sim 319.1 \mathrm{t}$ of $\mathrm{LH}_{2}$ propellant is used during the mission. With $100 \mathrm{klb}_{\mathrm{f}}$ of total thrust and $\mathrm{I}_{\mathrm{sp}} \sim 906 \mathrm{~s}$, the total engine burn time for this mission is $\sim 106.2$ minutes. The first TMI perigee burn is the longest single burn at $\sim 38.2$ minutes. The subsequent burn durations are as follows: second perigee burn $(\sim 28.8$ minutes), MOC ( $\sim 16.7$ minutes), TEI ( $\sim 11.5$ minutes) and EOC ( $\sim 11$ minutes). Four HLV launches are needed to deliver the major transportation systems elements (the NTPS, in-line tank and "twin" drop tank sets) to LEO. The SLS (70 $t$ to LEO version) delivers the crewed payload element and the large but lightweight star truss. 


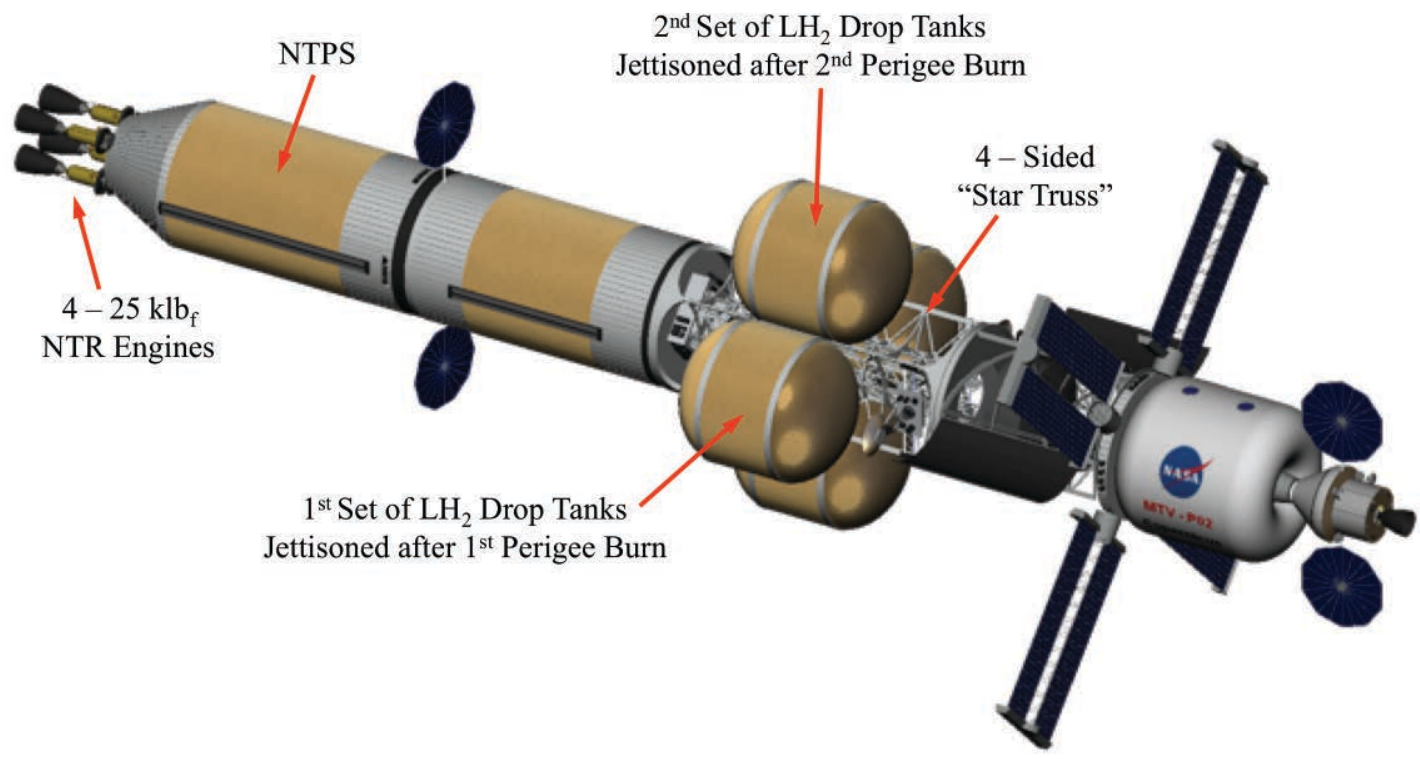

Figure 14. Configuration 3: Supports Reusable DRA 5.0 and 2033 Short Orbital Stay Mars Missions

\author{
Reusable 2033 Short Orbital Mars Mission (4 - 25 klb Engines, 24-hr EEO capture $\left.\Delta V_{\text {EOC }} \sim 1.557 \mathrm{~km} / \mathrm{s}\right)$ :
}

Configuration 3 can also support a reusable 18 month round trip Mars orbital mission in 2033 with a crew of 4 by increasing the lengths of the in-line and drop tanks (to $\sim 21.1 \mathrm{~m}$ and $\sim 12.4 \mathrm{~m}$, respectively) to carry $\mathrm{more}^{\mathrm{L}} \mathrm{LH}_{2}$. The vehicle has an IMLEO of $\sim 581.3 \mathrm{t}$, which includes the NTPS $(\sim 140 \mathrm{t})$, the in-line tank $(\sim 121.4 \mathrm{t})$, the "star truss" with 4 modular $\mathrm{LH}_{2}$ drop tanks $(\sim 270.8 \mathrm{t})$ and the crew PL section $(\sim 49.1 \mathrm{t})$. The overall vehicle length is $\sim 112 \mathrm{~m}$. The $\mathrm{LH}_{2}$ loading in the propulsion stage, in-line and 4 drop tanks is $\sim 84.3 \mathrm{t}, \sim 94.5 \mathrm{t}$, and $\sim 200.3 \mathrm{t}$, respectively, and the total usable propellant is $\sim 356.2 \mathrm{t}$. As illustrated in Fig. 14, the first set of $\mathrm{LH}_{2}$ drop tanks are jettisoned after the first perigee burn to reduce vehicle mass and propellant consumption during the second perigee burn. With $100 \mathrm{klb}_{\mathrm{f}}$ of thrust and $\mathrm{I}_{\mathrm{sp}} \sim 906 \mathrm{~s}$, the total engine burn time is $\sim 118.6$ minutes, close to the $\sim 2$ hours demonstrated on the NRX-XE engine. The duration of the individual burns are as follows: first perigee burn ( 41.6 minutes), second perigee burn ( $\sim 28.1$ minutes), MOC ( 15.7 minutes), TEI ( 24.1 minutes) and EOC ( 9.1 minutes). Again, four HLV and two SLV launches would be required to deliver the vehicle elements to LEO. Although reusable short orbital stay missions are possible using the modular approach, significant propellant and hardware mass (jettisoned drop tanks) is expended in conducting a mission that has a limited orbital stay time at Mars (60 days) compared to the total mission duration (545 days). It is therefore logical to ask the following question, "Should long surface stay expendable missions with faster transit times be considered instead and what is the impact on vehicle design?"

\title{
Options for Faster "1-Way" Transit Times in DRA 5.0:
}

The key to achieving shorter "1-way" transit times in fast-conjunction Mars missions like that used in DRA 5.0 is more propellant. For the 2033 opportunity, the total mission $\Delta \mathrm{V}$ budget (TMI, MOC and TEI minus gravity losses) is $\sim 6.05 \mathrm{~km} / \mathrm{s}$ for 180 -day transit times to and from Mars. It increases to $\sim 8.83 \mathrm{~km} / \mathrm{s}$ for 120 -day transit times and even more dramatically to $\sim 15.2 \mathrm{~km} / \mathrm{s}$ for 90 -day transit times to and from Mars. By reconfiguring Copernicus with an in-line and twin drop tanks to increase its propellant capacity, along with a fourth NTR engine (shown in Fig. 15) to increase vehicle thrust and reduce gravity losses, transit times to and from Mars can be cut by $\sim 33 \%$ to 120 days each way. The vehicle IMLEO is $\sim 551.3 \mathrm{t}$ including the NTPS $(\sim 139.9 \mathrm{t})$, the in-line tank $(\sim 133.8 \mathrm{t})$, the "star truss" with drop tanks $(\sim 210.2 \mathrm{t})$ and the crew PL section $(\sim 67.3 \mathrm{t})$. The overall vehicle length is $\sim 116 \mathrm{~m}$. The $\mathrm{LH}_{2}$ loading in the propulsion stage, in-line and 2 drop tanks is $\sim 83.1 \mathrm{t}, \sim 98.6 \mathrm{t}$, and $\sim 159.3 \mathrm{t}$, respectively, and the total usable propellant is $\sim 321 \mathrm{t}$. With $100 \mathrm{klb}_{\mathrm{f}}$ of thrust and $\mathrm{I}_{\mathrm{sp}} \sim 906 \mathrm{~s}$, the total engine burn time is $\sim 106.9$ minutes. After a long first perigee burn ( $\sim 52.3$ minutes $)$ is completed, both drop tanks are jettisoned. The remaining burn durations are as follows: second perigee burn ( 20.8 minutes), MOC ( 22.3 minutes) and TEI ( 11.5 minutes). Four HLV and two SLV launches are again required to deliver the vehicle elements to LEO. 


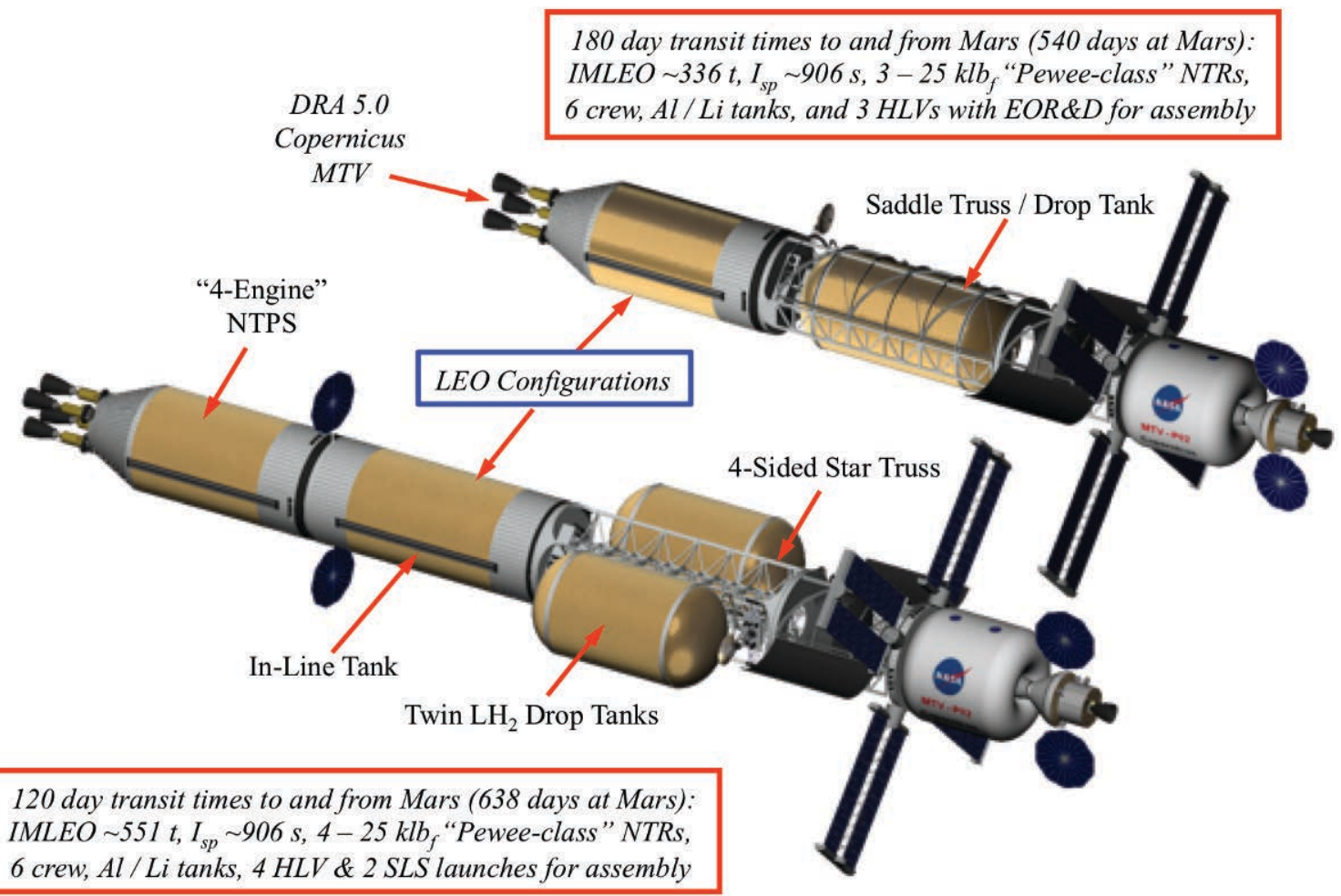

Figure 15. Adding In-Line \& Twin Drop Tanks to Copernicus Enables 120-Day Transit Times for DRA 5.0

\section{Human NEA Mission Possibilities Using NTP}

The benefits of using NTP for human missions to both small, low energy and large, high energy NEA targets are examined in this section. The small NEA selected is 2000 SG344. It has a 2028 launch date and a round trip time of $\sim 327$ days that includes a 7-day NEA stay time. Specific mission $\Delta \mathrm{V}$ budget details include trans-NEA injection (TNI) $\Delta \mathrm{V}_{\mathrm{TNI}} \sim 3.254 \mathrm{~km} / \mathrm{s}, \Delta \mathrm{V}_{\text {Arrival }} \sim 0.144 \mathrm{~km} / \mathrm{s}, \Delta \mathrm{V}_{\mathrm{TEI}} \sim 0.392 \mathrm{~km} / \mathrm{s}$ and $6-\mathrm{hr}$ EEO capture $\Delta \mathrm{V}_{\text {EOC }} \sim 1.203 \mathrm{~km} / \mathrm{s}$ (based on an arrival V-infinity at Earth of $\sim 0.855 \mathrm{~km} / \mathrm{s}$ ). The 2028 mission date is consistent with both the ISECG's GER that shows a first crewed NEA mission beginning in 2028, as well as, "preliminary" development plans that envision an Initial Operational Capability (IOC) for a crewed NTP transportation system in this same timeframe.

Small asteroids, like 2000 SG344 $(\sim 35-60 \mathrm{~m})$, are likely to be fast rotating and have a monolithic composition with less surface regolith. Large asteroids $-100 \mathrm{~m}$ or larger, tend to rotate more slowly and have a high probability of being rubble piles of rock offering a greater diversity of surface terrain and material composition desired by the scientific community [27]. The large, high energy NEA target analyzed in this paper is Apophis $(\sim 270-350 \mathrm{~m})$. Like $2000 \mathrm{SG} 344$, it too has a 2028 launch date but the round trip time is longer ( $\sim 344$ days) for the same 7-day stay time. The $\Delta \mathrm{V}$ budget for the Apophis mission is also larger than that for $2000 \mathrm{SG} 344$ with $\Delta \mathrm{V}_{\mathrm{TNI}} \sim 3.783 \mathrm{~km} / \mathrm{s}$, $\Delta \mathrm{V}_{\text {Arrival }} \sim 1.542 \mathrm{~km} / \mathrm{s}, \Delta \mathrm{V}_{\text {TEI }} \sim 0.342 \mathrm{~km} / \mathrm{s}$, and $\Delta \mathrm{V}_{\text {EOC }} \sim 1.950 \mathrm{~km} / \mathrm{s}$ (assuming capture into a 24-hr EEO with an arrival V-infinity of $\sim 5.882 \mathrm{~km} / \mathrm{s}$ ). Apophis is of particular interest to NASA because on Friday, April 13, 2029, it will pass Earth's surface at an altitude of $\sim 18,300$ miles - within the orbits of geosynchronous communications satellites [30]. It will return for another close Earth approach in 2036.

Two human mission architectures have been examined [31] - one is "fully reusable" and the other "expendable". The reusable mission scenario is shown in Fig. 16. Three SLS / HLV launches (with lift capabilities ranging from $\sim 70 \mathrm{t}-140 \mathrm{t}$ ) deliver the components for the Asteroid Survey Vehicle (ASV) to LEO over a 60 day period (30 day launch centers are assumed). The crewed ASV, shown in Fig. 17, is a "Copernicus-class" vehicle called "Searcher". Like Copernicus, Searcher is a 0 - $_{\mathrm{E}}$, in-line vehicle design that uses automated R\&D for assembly and has three key elements: (1) the "core" NTPS; (2) the integrated "saddle truss" and $\mathrm{LH}_{2}$ drop tank assembly; and (3) the crewed NEA payload element. The crew would be launched on either a commercial crew delivery system or atop the SLS in the Orion MPCV that would then dock with the orbiting ASV at the front end of the TransHab crew module. 
AIAA-2012-5144

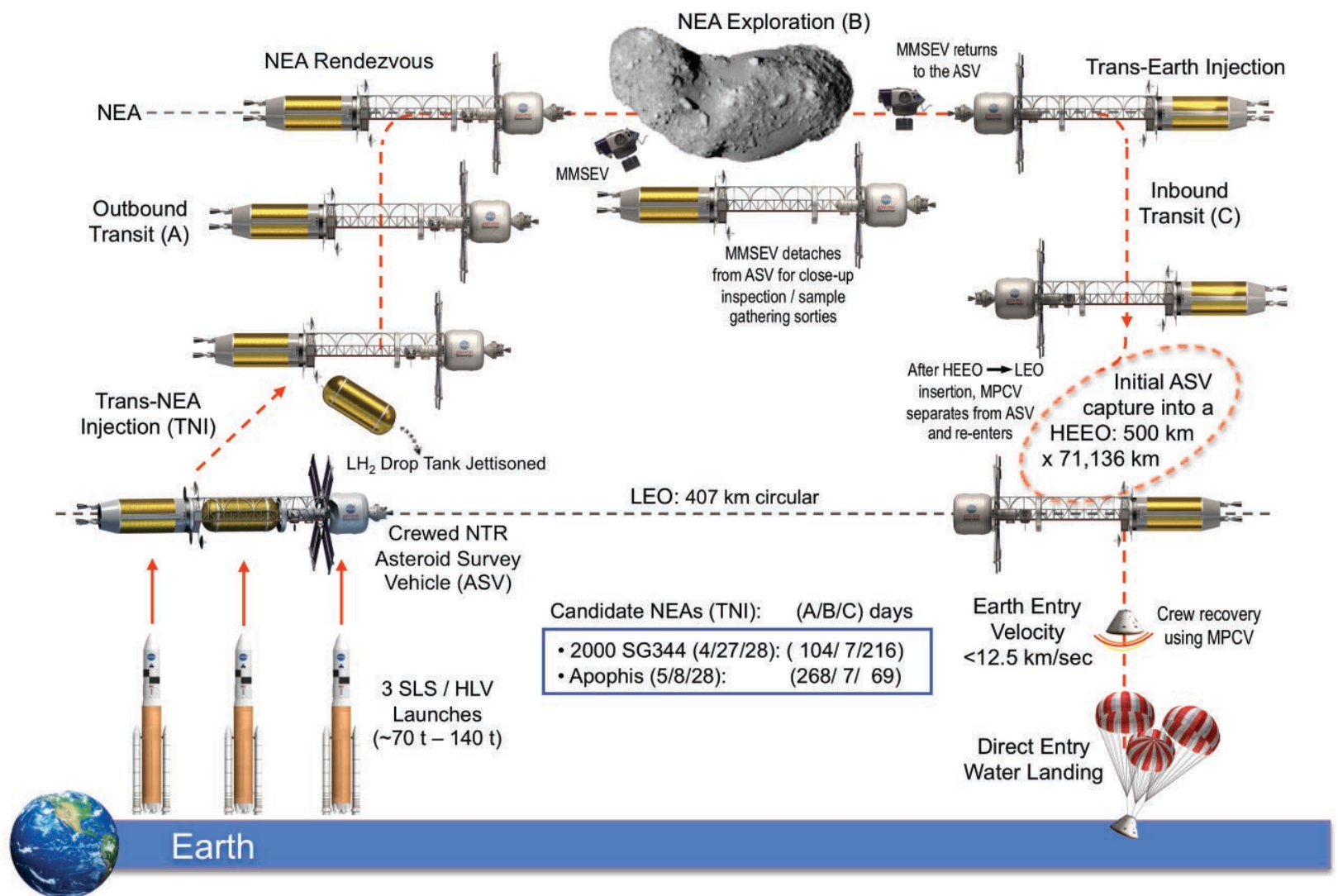

Figure 16. "Fully Reusable" Mission Scenario - ASV and MMSEV Returned to Earth Orbit

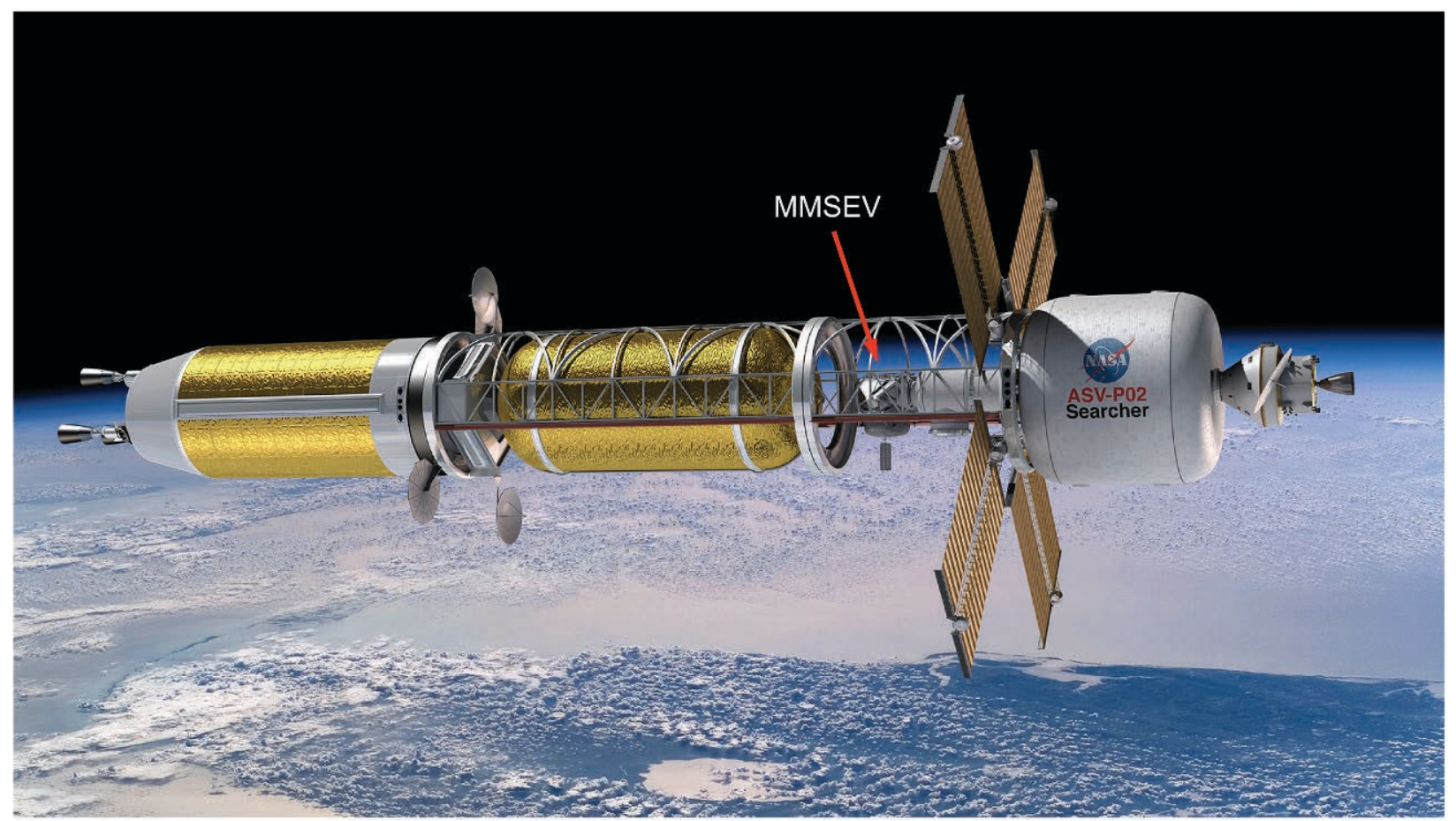

Figure 17. DRA 5.0 Copernicus Crewed MTV Outfitted as Asteroid Survey Vehicle - "Searcher" 
Following a "2-perigee burn" TNI maneuver, the drained $\mathrm{LH}_{2}$ drop tank is jettisoned from the saddle truss and the ASV coasts to the target NEA under $0-\mathrm{g}_{\mathrm{E}}$ conditions with its PVAs tracking the Sun. Attitude control, midcourse correction and vehicle orientation maneuvers are again provided by Searcher's split RCS with bipropellant AMBR thrusters located on the NTPS and on the short saddle truss forward adaptor ring just behind the TransHab module. After propulsively braking near the target NEA, Searcher uses the post burn "cool-down thrust" provided by its three NTR engines, together with its RCS, to rendezvous with the NEA. Two crewmembers then transfer over to the MMSEV, undock from the transfer tunnel, and travel over to the NEA to begin the surface exploration and sample-gathering phase of the mission (Fig. 18). With Searcher at an appropriate standoff distance from the target NEA, multiple MMSEV sorties with rotating crews are flown to different NEA locations to gather a diverse sampling of materials.

As the 7-day stay at the target NEA draws to a close, the crew begins a period of vehicle checkout and systems verification before performing the TEI burn to begin the journey back to Earth. In the fully reusable architecture, the MMSEV is returned to Earth along with ASV. On final Earth approach, Searcher performs a braking burn and captures into a 24-hour EEO ( $\sim 500 \mathrm{~km} \times 71,136 \mathrm{~km})$ like the reusable Mars MTV options discussed above. Its post burn engine cool-down thrust is then used to assist in orbit lowering. An auxiliary tanker vehicle, operating from a LEO servicing node/propellant depot, supplies the additional $\mathrm{LH}_{2}$ needed by Searcher for final orbit lowering and rendezvous with the LEO transportation node where it is refurbished and resupplied before its next mission. The crew then enters the Orion MPCV, separates from Searcher and does a direct entry and landing on Earth. The departure dates, outbound, stay and return times for 2000 SG344 and Apophis are also shown in Fig. 16.

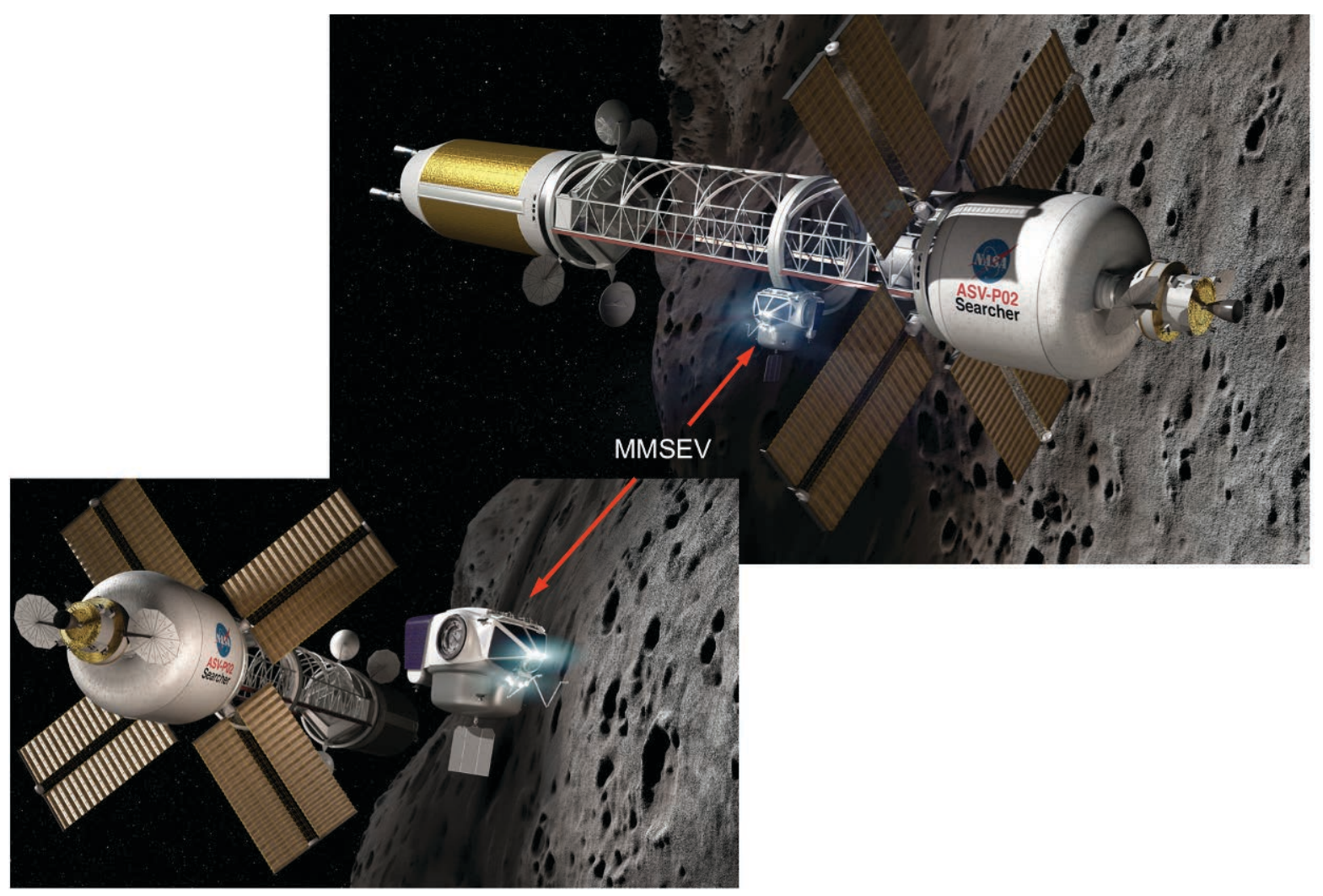

Figure 18. MMSEV Separates from ASV for Up Close NEA Examination and Sample Gathering

In the expendable architecture, all of the mission elements are disposed of in order to keep the total mission IMLEO and the size of the transportation system components as low as possible. The MMSEV is not returned to Earth but is left at the target NEA for continued teleoperated exploration after the crew has departed. To reduce vehicle mass and propellant requirements further, the transfer tunnel is also jettisoned before the TEI maneuver. On the final approach to Earth, the crew enters the Orion MPCV, separates from the ASV and does a direct entry and landing while the ASV flies by Earth at a "sufficiently high altitude" and is disposed of into heliocentric space. 


\section{Asteroid Survey Vehicle (ASV) Configuration Options for Candidate NEA Missions}

The "Copernicus / Searcher" spacecraft design illustrated in Figs. 8 and 17 is used as the baseline configuration for assessing the benefits of using NTP for human NEA missions. Two target NEAs - both with departure dates in 2028 - have been selected for analysis in this paper. They are 2000 SG344 (a small asteroid with a low energy / $\Delta \mathrm{V}$ requirement) and Apophis (a large asteroid with a high energy / $\Delta \mathrm{V}$ requirement). The impact of key mission variables (like crew size, the assumed mission architecture, and launch vehicle performance - specifically lift capability and PL volume) on vehicle size and mass has been assessed and is discussed below. Key features and component lengths for three different size ASV options examined for our target NEA missions are shown in Fig. 19.

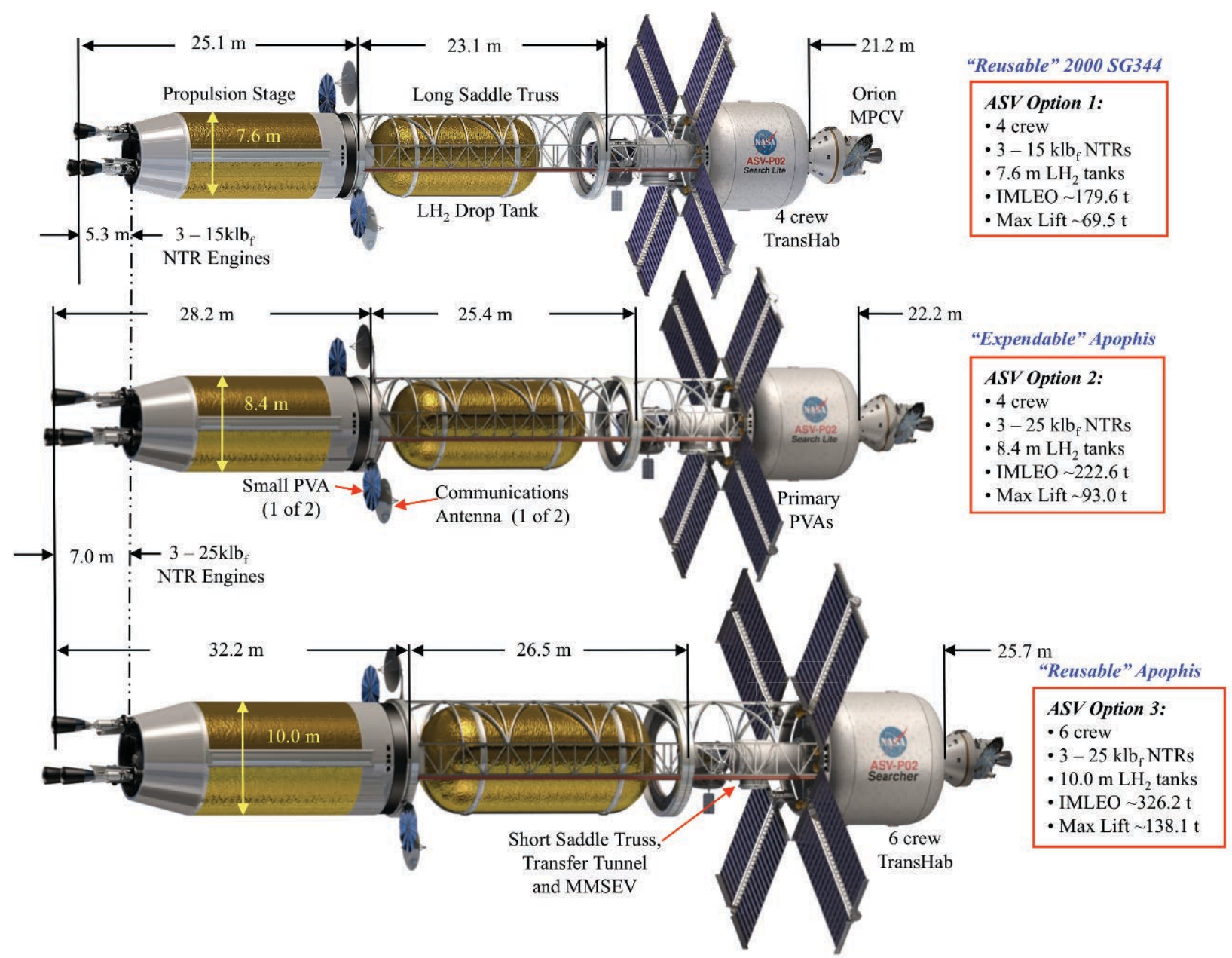

Figure 19. ASV Configuration Options for Reusable and Expendable Human NEA Missions

\section{ASV Option 1 (Reusable Mission to 2000 SG344):}

Because of its low energy requirements, a human mission to 2000 SG344 can readily be accomplished with a "scaled-down" version of the larger $10 \mathrm{~m}$ diameter Searcher ASV, called "Search Lite". Search Lite Option 1 uses three smaller $15 \mathrm{klb}_{\mathrm{f}}$ NTR engines on its propulsion stage rather than the baseline $25 \mathrm{klb}_{\mathrm{f}}$ Pewee-class engines. It also uses $7.6 \mathrm{~m} \mathrm{D} \mathrm{LH}_{2}$ tanks and carries a smaller TransHab module to accommodate a crew of 4 . Housed within the forward cylindrical adaptor section of all the propulsion stage options shown in Fig. 19 is the RCS, avionics, batteries, deployable twin Orion-type circular PVAs, and docking system, along with a reverse turbo-Brayton cryocooler system for $\mathrm{ZBO} \mathrm{LH} \mathrm{LH}_{2}$ storage. The Brayton cryocooler system mass and power requirements increase with tank diameter and are sized to remove the heat load penetrating the 60 layer MLI system while the stage is in LEO where the highest tank heat flux occurs (see Table 2). The small circular PVAs on the propulsion stage provide the electrical power for the ZBO system in LEO. 
With Option 1, a human mission to 2000 SG344 can be performed using three 70 t-class SLS launches. The vehicle IMLEO is $\sim 179.6 \mathrm{t}$ which includes the NTPS $(\sim 69.5 \mathrm{t})$, the saddle truss and drop tank assembly $(\sim 54.8 \mathrm{t})$ and the crew PL section ( $\sim 55.3 \mathrm{t}$ ). The overall vehicle length is $\sim 78.3 \mathrm{~m}$ including the $8.9 \mathrm{~m}$ long Orion MPCV. The $\mathrm{LH}_{2}$ tank lengths for the NTPS and the drop tank are identical at $\sim 15.7 \mathrm{~m}$ with each tank carrying $\sim 38.9 \mathrm{t}$ of $\mathrm{LH}_{2}$ propellant ( $\sim 98 \%$ of tank's maximum capacity of $\sim 39.7 \mathrm{t}$ ). The NTPS used for Option 1 is the same as that used for a reusable, crewed lunar landing mission discussed later in the paper. It is this lunar mission application that actually determines the NTPS's physical dimensions and characteristics. Maximizing the use of common hardware elements (e.g., same size NTPS, propellant tanks) for different mission applications is an important consideration that can help reduce vehicle development and recurring costs and is utilized throughout this paper.

The long "saddle truss" connecting the propulsion stage and PL sections is a composite structure whose mass scales with tank diameter and length and varies from $\sim 4.2 \mathrm{t}-8.9 \mathrm{t}$ for $7.6 \mathrm{~m}-10.0 \mathrm{~m}$ diameter tanks. (The short saddle truss included in the PL section uses the same composite structure.) The crewed PL section also includes deployable rectangular PVAs used for primary power. The four PVAs shown in Fig. 19 are appropriate for use at Mars because of the decreased solar radiation $\left(\sim 486 \mathrm{~W} / \mathrm{m}^{2}\right)$. For NEA missions that are flown near 1 A.U. (solar radiation $\sim 1368 \mathrm{~W} / \mathrm{m}^{2}$ ), two smaller panels producing $\sim 15-25 \mathrm{~kW}$ should be adequate.

The reusable crewed mission to 2000 SG344 requires 5 primary burns (4 restarts) that use $\sim 73.7 \mathrm{t}$ of $\mathrm{LH}_{2}$ propellant. With $45 \mathrm{klb}_{\mathrm{f}}$ of total thrust and a $\mathrm{I}_{\mathrm{sp}}$ of $\sim 906 \mathrm{~s}$, the total engine burn time is $\sim 54.5$ minutes. The first of the two TNI perigee burns is the longest single burn at $~ 29.6$ minutes after which the vehicle's drop tank is drained and jettisoned. The NTPS provides the $\mathrm{LH}_{2}$ propellant needed for the remaining propulsive maneuvers: the second perigee burn ( $\sim 10.5$ minutes), braking at 2000 SG344 ( 1.3 minutes), TEI ( $\sim 3.4$ minutes), and EOC (9.7 minutes). With the vehicle's available propellant capacity, it is also capable of capturing into a lower apogee, higher energy 6-hr EEO at the end of the mission.

\section{ASV Option 2 (Expendable Mission to Apophis):}

Search Lite Option 2 shown in Fig. 19 is sized for a 344-day expendable mission to Apophis with a crew of 4. With an estimated diameter of $\sim 270-350 \mathrm{~m}$, Apophis is $\sim 5-10$ times larger than 2000 SG344. A size comparison between a notional "Apophis-like" NEA and Search Lite Option 2 is shown in Fig. 20. Option 2 uses three clustered $25 \mathrm{klb}_{\mathrm{f}}$ engines and $8.4 \mathrm{~m}$ diameter $\mathrm{Al} / \mathrm{Li} \mathrm{LH} \mathrm{LH}_{2}$ propellant tanks on both the propulsion stage and drop tank. (The $\mathrm{Al} / \mathrm{Li} \mathrm{LH}_{2}$ tank on the SLS "core stage" currently has this same diameter.) Even with its higher $\Delta \mathrm{V}$ requirement, a crewed mission to Apophis is still possible, in an expendable mode, using three $100 \mathrm{t}$-class SLS launches and ASV Option 2 (illustrated in Fig. 21). As with Option 1, the drop tank is drained and jettisoned after the first perigee burn and the NTPS supplies the propellant for the second perigee burn, NEA braking and TEI maneuvers that follows.

The vehicle IMLEO is $\sim 222.6 \mathrm{t}$ including the NTPS ( $\sim 93 \mathrm{t})$, the saddle truss / drop tank assembly $(\sim 73.3 \mathrm{t})$ and the crew PL section $(\sim 56.3 \mathrm{t})$. The overall vehicle length is $\sim 84.7 \mathrm{~m}$ with the Orion MPCV. The $\mathrm{LH}_{2}$ tank lengths are the same for both the propulsion stage and the drop tank at $\sim 16.9 \mathrm{~m}$ and each contains $\sim 52.5 \mathrm{t}$ of $\mathrm{LH}_{2}$ propellant.

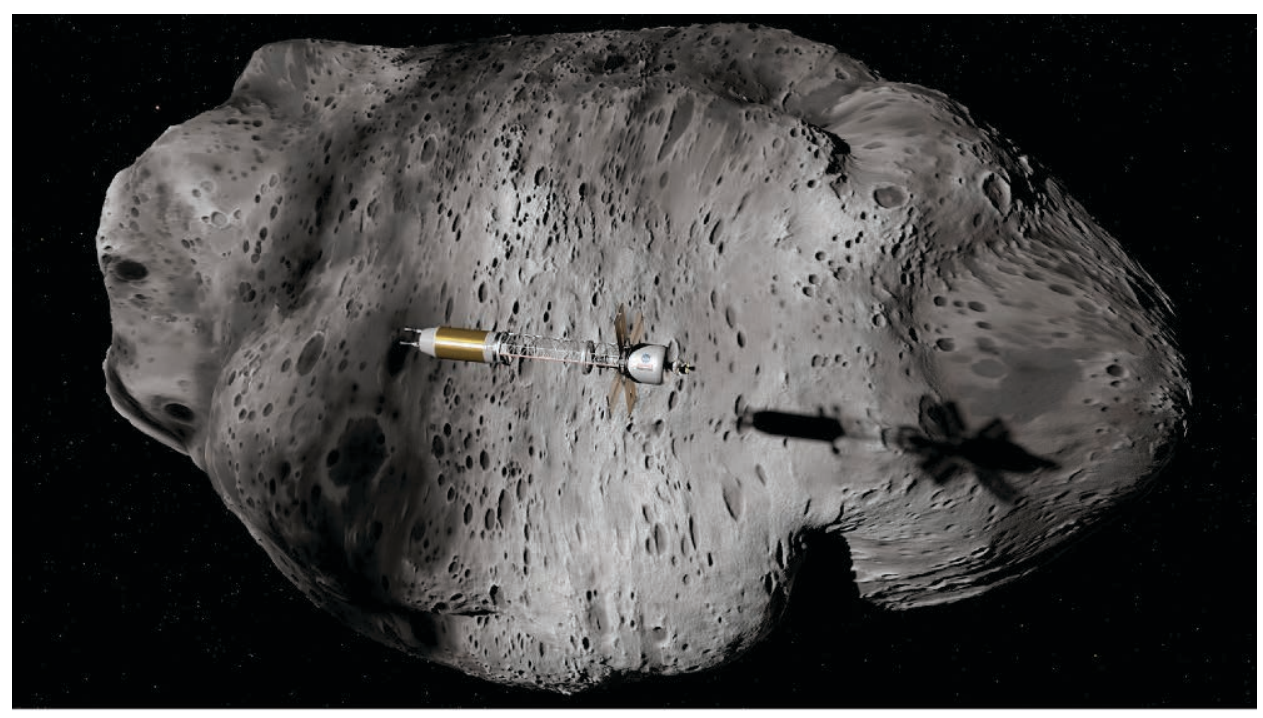

Figure 20. Size Comparison of ASV Option 2 and a Notional 300 m Long NEA 
For this expendable mission to Apophis, there are 4 primary burns and 3 engine restarts. The total $\mathrm{LH}_{2}$ propellant used in the mission is $\sim 98.7 \mathrm{t}$ and the total engine burn time is $\sim 43.8$ minutes. The first perigee burn is the longest at $\sim 25$ minutes and provides $\sim 2 / 3^{\text {rd }}$ of total $\Delta \mathrm{V}$ required for the TNI maneuver. The durations of the remaining burns are as follows: the second perigee burn ( $\sim 8.4$ minutes), braking at Apophis ( $\sim 8.8$ minutes), and TEI ( 1.6 minutes).

With its smaller diameter tanks, Search Lite Option 2 does not have sufficient propellant capacity to be reusable. This deficiency can be corrected through the addition of an "in-line" $\mathrm{LH}_{2}$ tank as discussed previously. The resulting "4-element" version of Option 2 described elsewhere [31] has an IMLEO of $\sim 347.9 t$ including the NTPS ( 98.6 t), the in-line tank (98.2 $\mathrm{t}$ ), the saddle truss and $\mathrm{LH}_{2}$ drop tank ( $\sim 91.3 \mathrm{t}$ ), and the crewed PL element $(\sim 59.8 \mathrm{t})$. The total engine burn time is $\sim 84$ minutes, and the longest single burn is again the first perigee burn at $\sim 40.9$ minutes. Increasing the SLS/HLV lift capability and usable PL volume allows a reusable "3-element" ASV discussed below.

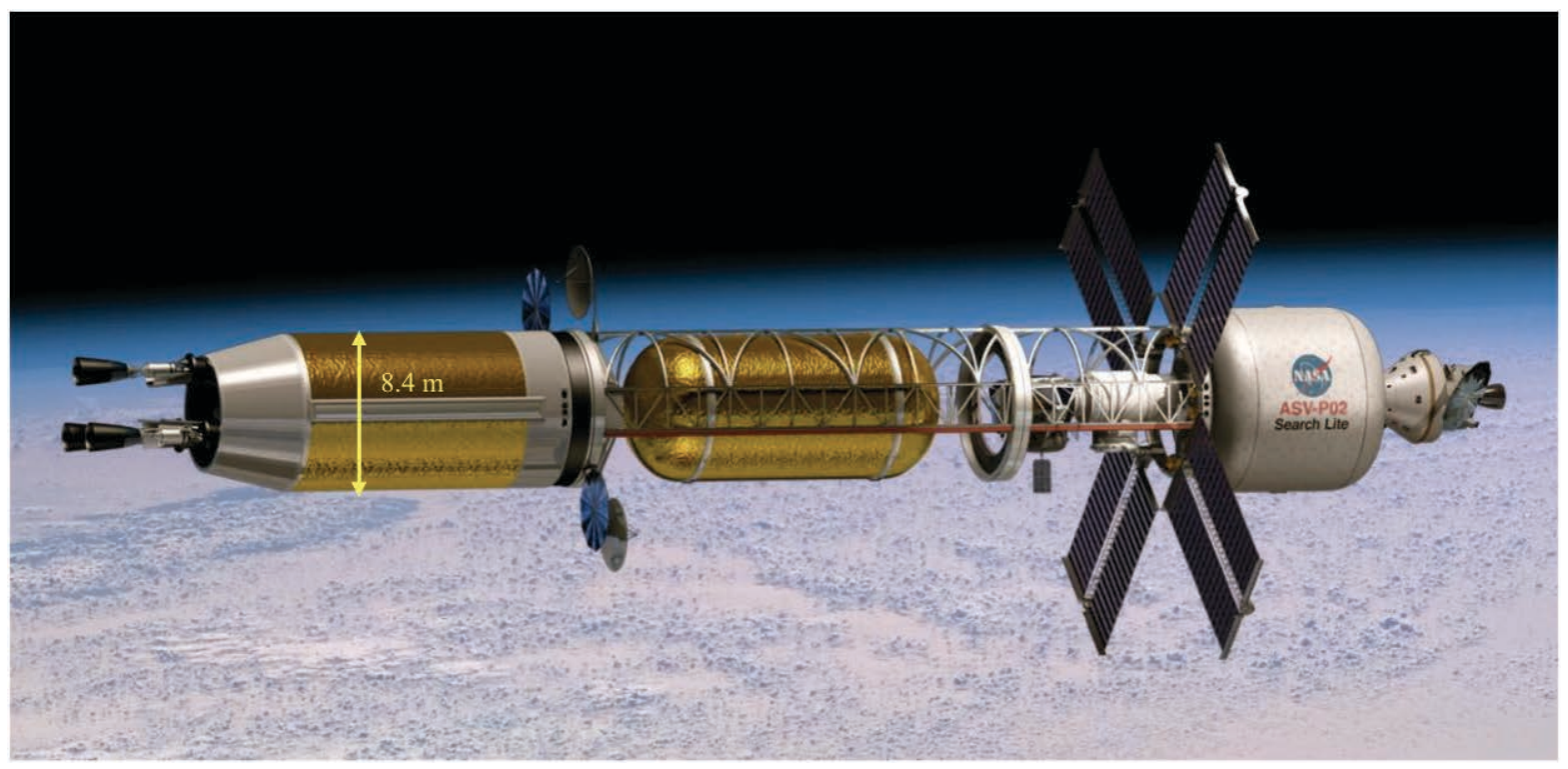

Figure 21. "Search Lite" ASV used in Expendable Human Mission to Apophis in 2028

\section{ASV Option 3 (“Searcher” Reusable Mission to Apophis):}

Option 3 is the Copernicus spacecraft outfitted with an MMSEV for a reusable mission to Apophis in 2028 (shown in Figs. 17, 18, and 19). Searcher uses three $25 \mathrm{klb}_{\mathrm{f}}$ NTR engines, has $10 \mathrm{~m}$ diameter $\mathrm{LH}_{2}$ tanks and carries a crew of 6 . The Apophis mission has a total $\Delta \mathrm{V}$ requirement of $\sim 7.617 \mathrm{~km} / \mathrm{s}$ (including the $24-\mathrm{hr}$ EEO capture maneuver) which is $\sim 4 \%$ larger than that needed for the expendable Mars DRA 5.0 mission. For a reusable mission scenario to this difficult target, Searcher's engines are operated at a higher temperature and $\mathrm{I}_{\mathrm{sp}}(\sim 940 \mathrm{~s})$ during the two TNI perigee burns to reduce propellant consumption and its drop tank length is increased by $\sim 0.4 \mathrm{~m}$ to $\sim 21.5 \mathrm{~m}$ to accommodate the required propellant. Searcher has an IMLEO of $\sim 326.2 \mathrm{t}$ which includes its propulsion stage ( $\sim 138.1 \mathrm{t})$, saddle truss and $\mathrm{LH}_{2}$ drop tank $(\sim 125.9 \mathrm{t})$, and crewed PL element $(\sim 62.3 \mathrm{t})$. Searcher's overall length is $\sim 93.3 \mathrm{~m}$ including the $8.9 \mathrm{~m}$ Orion MPCV. During launch, the engines have a portion of their nozzle $(\sim 2.2 \mathrm{~m})$ retracted so the propulsion stage length does not exceed $30 \mathrm{~m}$. Once in orbit, the nozzles are extended and the propulsion stage length increases to $\sim 32.2 \mathrm{~m}$. The tank length for Searcher's propulsion stage is the same as that on Copernicus at $\sim 19.7 \mathrm{~m}$ but its drop tank is slightly longer at $\sim 21.5 \mathrm{~m}$. The corresponding propellant loads are $\sim 87.2 \mathrm{t}$ and $\sim 96.4 \mathrm{t}$ for a maximum $\mathrm{LH}_{2}$ capacity of $\sim 183.6 \mathrm{t}$. For Apophis, the total $\mathrm{LH}_{2}$ propellant used is $\sim 174.2 \mathrm{t}$ and the total engine burn time is $\sim 77.3$ minutes. The first perigee burn again provides $\sim 2 / 3^{\text {rd }}$ of total $\Delta \mathrm{V}$ required for TNI and is the longest single burn at $\sim 37.2$ minutes. The durations of the remaining burns are as follows: the second perigee burn ( $\sim 12$ minutes), braking at Apophis ( $\sim 13$ minutes), TEI ( $\sim 2.5$ minutes) and EOC ( $\sim 12.6$ minutes).

Other options for the Apophis mission include returning just the Searcher ASV to EEO and leaving the MMSEV at Apophis for continued autonomous exploration, or reducing the TransHab mass and associated consumables to accommodate 4 crewmembers (NASA's baseline for NEA missions). This later option reduces IMLEO to $\sim 313.7 \mathrm{t}$ and requires no increases in engine $\mathrm{I}_{\mathrm{sp}}$ or drop tank length. 


\section{VIII. "Search Lite" Vehicle Utilization for Lunar Cargo and Crewed Landing Missions}

The Search Lite vehicle configurations described above can also play an important role in returning humans to the Moon "to stay" by providing an affordable in-space transportation system with reuse capability that could allow initial lunar outposts to evolve into eventual settlements capable of supporting commercial activities. Utilization of efficient NTP for lunar cargo delivery and crewed lunar landing missions is also consistent with the "Asteroid Next" pathway that includes human missions to the Moon to test out key surface systems (e.g., habitats, power systems, and long-range pressurized rovers) needed for an eventual human landing on Mars.

Using the SLS lift capability of $\sim 70 \mathrm{t}-100 \mathrm{t}$ to LEO, two classes of Search Lite vehicles are examined. The Class-I vehicle uses a NTPS with $3-15 \mathrm{klb}_{\mathrm{f}}$ engines, $7.6 \mathrm{~m}$ D propellant tanks and has a mass limit of $\sim 70 \mathrm{t}$. The Class-II vehicle uses $3-25 \mathrm{klb}_{\mathrm{f}}$ engines, $8.4 \mathrm{~m}$ D propellant tanks and has a mass limit of $\sim 100 \mathrm{t}$.

For reusable cargo delivery missions, three SLS launches are used to deliver the vehicle and payload elements to LEO. The NTP cargo transport then departs from LEO $\left(\Delta \mathrm{V}_{\mathrm{TLI}} \sim 3.3 \mathrm{~km} / \mathrm{s}\right.$ including g-losses of $\left.\sim 200 \mathrm{~m} / \mathrm{s}\right)$ and captures into a circular LLO $\left(\sim 300 \mathrm{~km}, \Delta \mathrm{V}_{\mathrm{LOC}} \sim 915 \mathrm{~m} / \mathrm{s}\right)$ approximately 72 hours later. Key phases of the cargo delivery mission are illustrated in Fig. 22. Once in orbit, the habitat lander(s) separate from the lunar NTR (LNTR) transport and descends to the surface, landing autonomously at a predetermined location on the Moon. It is assumed that the habitat landers use $\mathrm{LOX} / \mathrm{LH}_{2}$ chemical engines and are also equipped with either deployable wheels or articulated landing gear allowing movement in both the vertical and horizontal directions so that the landers can either "drive or walk" short distances from the landing site. Connecting several "functionally different" lander modules together (for habitation, science, etc) would form a large contiguous pressurized volume for the crew and also provide a "building block" approach to establishing an initial lunar base.

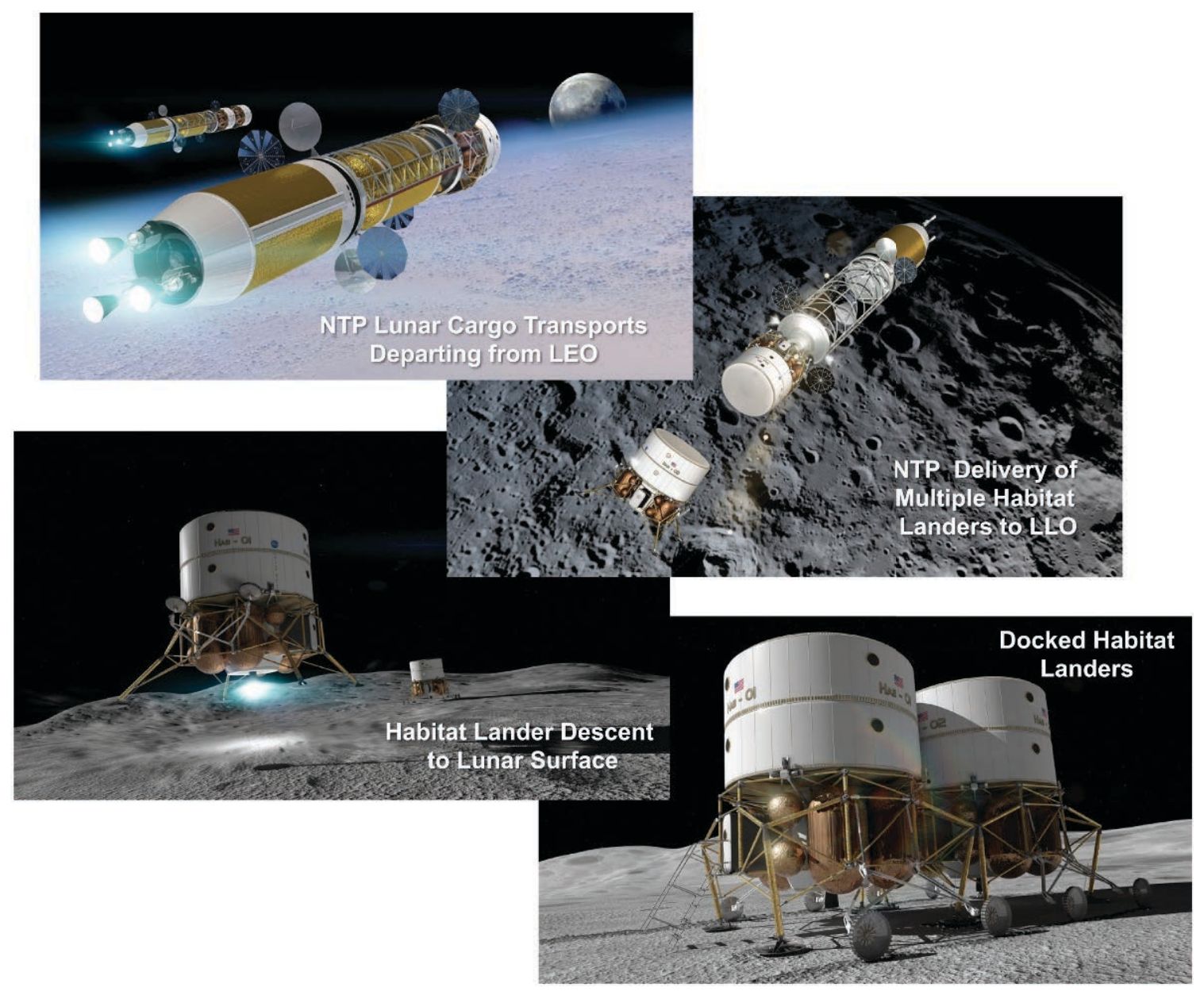

Figure 22. Reusable NTP Lunar Cargo Delivery Mission Phases 
After payload separation, the LNTR transport departs LLO $\left(\Delta \mathrm{V}_{\mathrm{TEI}} \sim 915 \mathrm{~m} / \mathrm{s}\right)$ and returns to Earth capturing into a 24-hr EEO $\left(\Delta \mathrm{V}_{\mathrm{EOC}} \sim 0.355 \mathrm{~km} / \mathrm{s}\right)$. Post burn engine cool-down thrust and an auxiliary tanker vehicle are again used to return the LNTR vehicle to the LEO transportation node for refurbishment and resupply before its next mission.

The key phases of the crewed NTR landing mission are illustrated in Fig. 23. Again, three SLS launches - two for the LNTR vehicle and one for the crewed payload element - are used for this reusable lunar mission that returns the LNTR transport vehicle, MPCV and LLV to EEO. After capture and rendezvous with the LEO propellant tanker, the crew separates the MPCV from the LNTR and re-enters using the Orion capsule.

After R\&D of the LNTR elements, the crewed payload element is launched then attached to the LNTR vehicle. The crewed element includes the Orion MPCV plus a "single stage" $\mathrm{LOX} / \mathrm{LH}_{2} \mathrm{LLV}$ that carries a crew of 4 and $5 \mathrm{t}$ of surface payload stored in two "swing-down" containers mounted on each side of the crew cab. After the "2perigee burn" TLI maneuver ( $\Delta \mathrm{V}_{\mathrm{TLI}} \sim 3.3 \mathrm{~km} / \mathrm{s}$ including g-losses), the drop tank is jettisoned from the saddle truss at which time the Orion MPCV separates from the front of the LNTR vehicle. It then repositions itself inside the saddle truss where it docks with the LLV using a common "docking port" mounted to the forward saddle truss ring (shown in Fig. 23). After a 3-day coast to the Moon, the LNTR vehicle performs the LOC burn $\left(\Delta \mathrm{V}_{\mathrm{LOC}} \sim 915 \mathrm{~m} / \mathrm{s}\right.$ ) inserting itself and its payload into LLO. The crew then enters the LLV, separates from the LNTR transport and prepares to land.

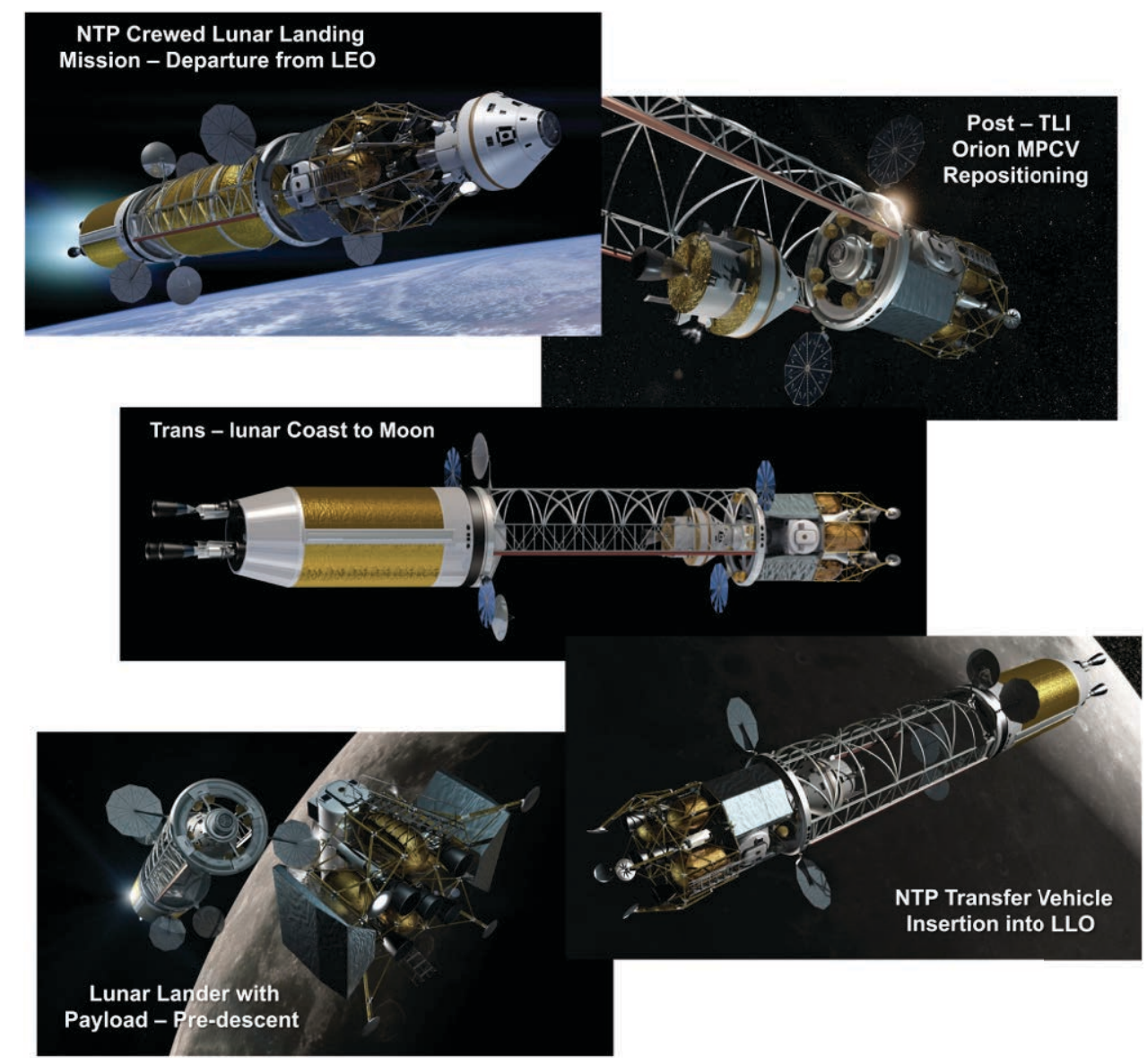

Figure 23. Reusable NTP Crewed Lunar Landing Mission - Outbound Mission Leg

The LLV has total "wet" mass of $\sim 35.3 \mathrm{t}$ (Table 1) that includes the crew cab $(\sim 2.5 \mathrm{t})$, the descent / ascent stage ( $\sim 6.1 \mathrm{t})$ and its $\mathrm{LOX} / \mathrm{LH}_{2}$ propellant $(\sim 20.9 \mathrm{t})$, surface payload $(\sim 5 \mathrm{t})$, plus the 4 crew and their suits $(\sim 0.8 \mathrm{t})$. After separating from LNTR, the LLV's two payload containers are rotated 180 degrees and lowered into their landing position in preparation for descent to the lunar surface. The $\Delta \mathrm{V}$ budget for the LLV includes the following [12]: $\Delta \mathrm{V}_{\text {des }} \sim 2.115 \mathrm{~km} / \mathrm{s}$ and $\Delta \mathrm{V}_{\text {asc }} \sim 1.985 \mathrm{~km} / \mathrm{s}$. The LLV uses five RL 10A-4 engines that operate with a $\mathrm{I}_{\text {sp }} \sim 450 \mathrm{~s}$ consistent with the Martin Marietta design [12]. It expends $\sim 13.4 \mathrm{t}$ of $\mathrm{LOX} / \mathrm{LH}_{2}$ propellant during the descent to the 


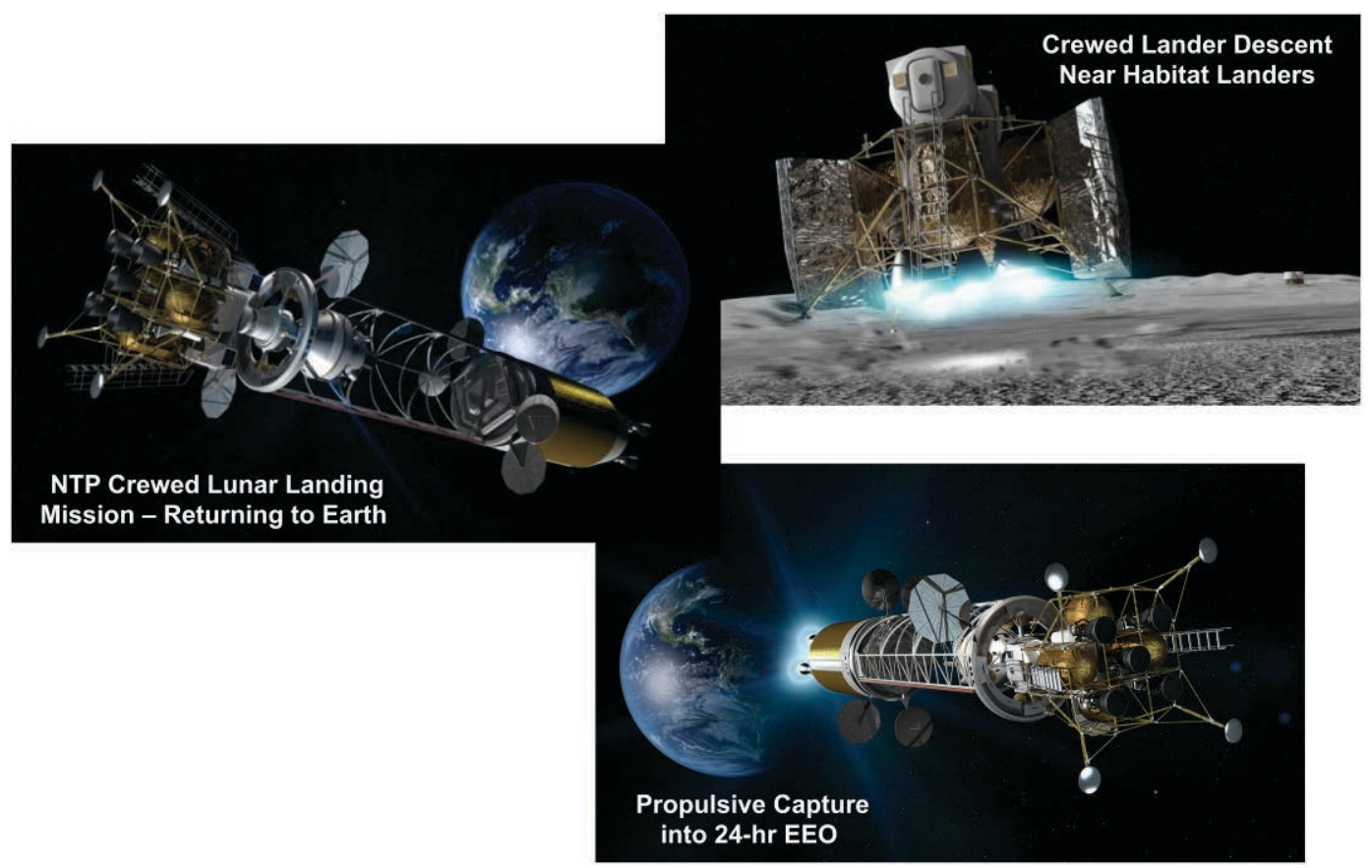

Figure 24. Reusable NTP Crewed Lunar Landing Mission - Landing and Return Mission Leg

surface (shown in Fig. 24). After lunar touchdown, the crew can operate out of the LLV for $\sim 14$ days using its surface landed payload or longer ( $\sim 180$ days) using the pre-deployed habitat landers.

As the "surface systems test and exploration" phase of the mission nears its completion, the crew prepares the LLV for departure. At liftoff, the LLV mass is $\sim 15.1 \mathrm{t}$ and $\sim 5.5 \mathrm{t}$ of propellant is used during the ascent to LLO. The LLV, with $100 \mathrm{~kg}$ of lunar samples, then rendezvous with the LNTR vehicle and preparations for the TEI maneuver begin. After completing the TEI burn $\left(\Delta \mathrm{V}_{\mathrm{TEI}} \sim 915 \mathrm{~m} / \mathrm{s}\right)$, the crew spends the next 3 days readying the LNTR for the final phase of the mission - capture into a 24-hr EEO with its MPCV and LLV payload (depicted in Fig. 24) followed by MPCV separation and capsule re-entry of the crew.

\section{Lunar Mission Capabilities using "Search Lite" Class-I and -II Vehicle Configurations}

The key features, component lengths, and launch mass requirements for lunar cargo and crewed landing missions using the smaller Class-I ASV elements are shown in Fig. 25. The Class-I Search Lite ASV used for the reusable, crewed mission to $2000 \mathrm{SG} 344$ is also included for comparison. As mentioned previously, Class-I vehicles use a NTPS with $3-15 \mathrm{klb}_{\mathrm{f}}$ engines, have $7.6 \mathrm{~m} \mathrm{D}$ propellant tanks and have a mass limit on vehicle elements of $\sim 70 \mathrm{t}$. The LNTR cargo transport shown in Fig. 25 has an IMLEO of $\sim 203.3 \mathrm{t}$ consisting of the NTPS ( 69.2 $t$ ), the saddle truss and drop tank assembly $(\sim 64.5 \mathrm{t})$ and the habitat lander $(\sim 67 \mathrm{t})$ with its connecting structure $(\sim 2.6 \mathrm{t})$. The overall vehicle length is $\sim 59.7 \mathrm{~m}$. The $\mathrm{LH}_{2}$ propellant loads in the NTPS and drop tank are $\sim 39.7 \mathrm{t}$ and $\sim 44.8 \mathrm{t}$. The corresponding tank lengths are $\sim 15.7 \mathrm{~m}$ and $\sim 18.4 \mathrm{~m}-$ lengths sized by the crewed lunar landing mission.

For the reusable cargo delivery mission, the 5 primary engine burns use $\sim 79.4 \mathrm{t}$ of $\mathrm{LH}_{2}$ propellant. The drop tank is jettisoned after the second perigee burn. With $45 \mathrm{klb}_{\mathrm{f}}$ of total thrust and $\mathrm{I}_{\mathrm{sp}} \sim 906 \mathrm{~s}$, the total engine burn time is $\sim 58.7$ minutes. The first of the two TLI perigee burns is the longest at $\sim 25.4$ minutes. The duration of the remaining burns are as follows: second perigee burn ( 20.1 minutes), LOC ( $\sim 8.9$ minutes $)$, TEI ( $\sim 3.2$ minutes $)$ and EEO capture ( $\sim 1.1$ minutes). Given projected full power operational lifetimes of $\sim 6-10$ hours for NERVA-derived engines using composite fuel [23], cargo transport vehicles with multi-mission capability appear viable.

The crewed lunar landing mission has an IMLEO of $\sim 189.7 \mathrm{t}$ including the NTPS $(\sim 69.3 \mathrm{t})$, the saddle truss and drop tank assembly $(\sim 67.6 \mathrm{t})$, the wet LLV $(\sim 29.5 \mathrm{t})$ with its surface payload $(\sim 5 \mathrm{t})$, the Orion MPCV $(\sim 13.5 \mathrm{t})$, connecting structure $(\sim 3.5 \mathrm{t})$, consumables $(\sim 0.5 \mathrm{t})$, and 4 crewmembers $(\sim 0.8 \mathrm{t}$ includes lunar EVA suits). The overall vehicle length is $\sim 64.5 \mathrm{~m}$. For the crewed mission, the $\mathrm{LH}_{2}$ propellant loads in the NTPS and drop tank are at their maximum capacity of $\sim 39.7 \mathrm{t}$ and $\sim 53.4 \mathrm{t}$ for the specified tank lengths of $\sim 15.7 \mathrm{~m}$ and $\sim 18.4 \mathrm{~m}$. 
AIAA-2012-5144

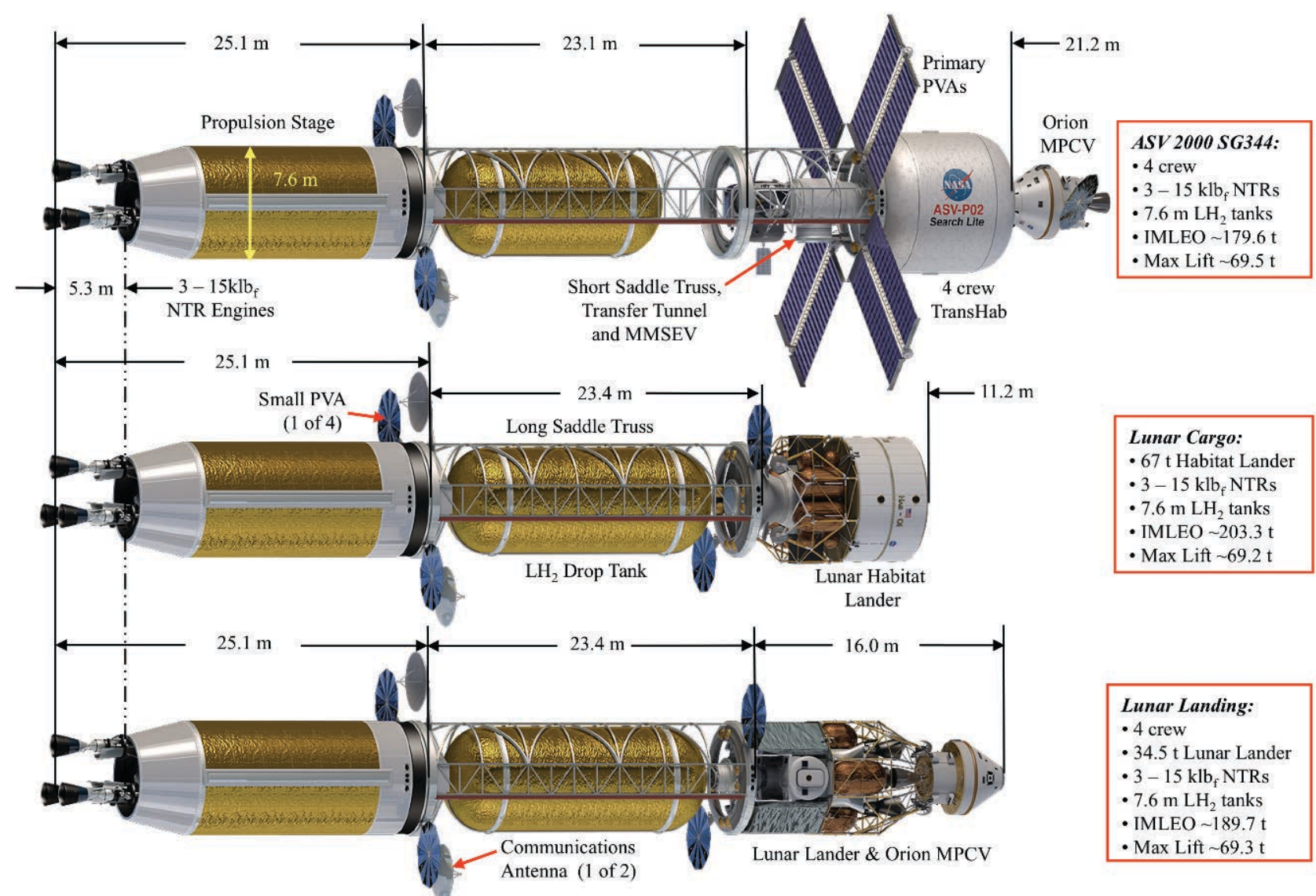

Figure 25. Class-I Vehicle Configurations for Reusable NEA, Lunar Cargo \& Crewed Landing Missions

The common NTPS used for all three Class-I vehicles shown in Fig. 25 has an $\sim 15.7 \mathrm{~m}$ long $\mathrm{LH}_{2}$ propellant tank. The ASV uses a drop tank of this same length as well. It is positioned near the aft end of the saddle truss to minimize the length and mass of the propellant lines as well as transfer losses. All three vehicles also carry a saddle truss of the same approximate length - a little over $23 \mathrm{~m}$ to further maximize component commonality.

The crewed landing mission also requires 5 primary burns and jettisons its drop tank after the second perigee burn. With $45 \mathrm{klb}_{\mathrm{f}}$ of total thrust, $\mathrm{I}_{\mathrm{sp}} \sim 906 \mathrm{~s}$, and $\sim 82.1 \mathrm{t}$ of $\mathrm{LH}_{2}$ propellant used during the mission, the total engine burn time is $\sim 60.9$ minutes, again well under the capabilities demonstrated on the NRX-XE. The first perigee burn is the longest at $\sim 24.3$ minutes and the remaining maneuvers having the following burn durations: second perigee burn ( $\sim 18.1$ minutes $)$, LOC ( $\sim 8.3$ minutes $)$, TEI ( $\sim 7.5$ minutes $)$ and EOC ( $\sim 2.7$ minutes $)$.

The component lengths and launch mass requirements for the larger Class-II lunar vehicles are shown in Fig. 26. The Class-II Search Lite ASV (Figs. 19 and 21) used in the expendable, crewed Apophis mission is also shown for comparison. Class-II vehicles use $3-25 \mathrm{klb}_{\mathrm{f}}$ engines, $8.4 \mathrm{~m}$ D propellant tanks, and require a $100 \mathrm{t}$-class SLS for component delivery. The Apophis mission discussed previously determines the dimensions and mass of the NTPS, saddle truss and drop tank, and these same components are used for the lunar cargo and crewed lunar landing missions. With larger diameter tanks and mass allowance for the vehicle components, two lighter "mini-hab" landers can also be delivered to LLO by the LNTR cargo transport as shown in Fig. 26.

The Class-II lunar cargo vehicle has an IMLEO of $\sim 250.8 \mathrm{t}$ including the NTPS ( 91.6 $\mathrm{t})$, the saddle truss and drop tank assembly $(\sim 75.2 \mathrm{t})$ and the twin habitat landers $(\sim 81 \mathrm{t})$ with their connecting structure $(\sim 3.0 \mathrm{t})$. The $\mathrm{LH}_{2}$ tank lengths are the same for both the propulsion stage and the drop tank at $\sim 16.9 \mathrm{~m}$ and each contains $\sim 52.5 \mathrm{t}$ of $\mathrm{LH}_{2}$ propellant. At launch, the Class-II NTPS length is $\sim 26 \mathrm{~m}$ with the nozzle skirt extensions on the larger $25 \mathrm{klb}_{\mathrm{f}}$ engines retracted $\sim 2.2 \mathrm{~m}$. At TLI, with the skirts fully extended, the overall length of the cargo transport is $\sim 76 \mathrm{~m}$.

The cargo mission jettisons its drop tank after the second perigee burn, has 5 primary burns and uses $\sim 98.8 \mathrm{t}$ of $\mathrm{LH}_{2}$ propellant. With a higher total thrust $\left(75 \mathrm{klb}_{\mathrm{f}}\right)$ on the Class-II vehicles and $\mathrm{I}_{\mathrm{sp}}$ of $\sim 906 \mathrm{~s}$, the total engine burn time is shortened to $\sim 43.9$ minutes. The first perigee burn is again the longest single mission burn at $\sim 19.5$ minutes. 
AIAA-2012-5144

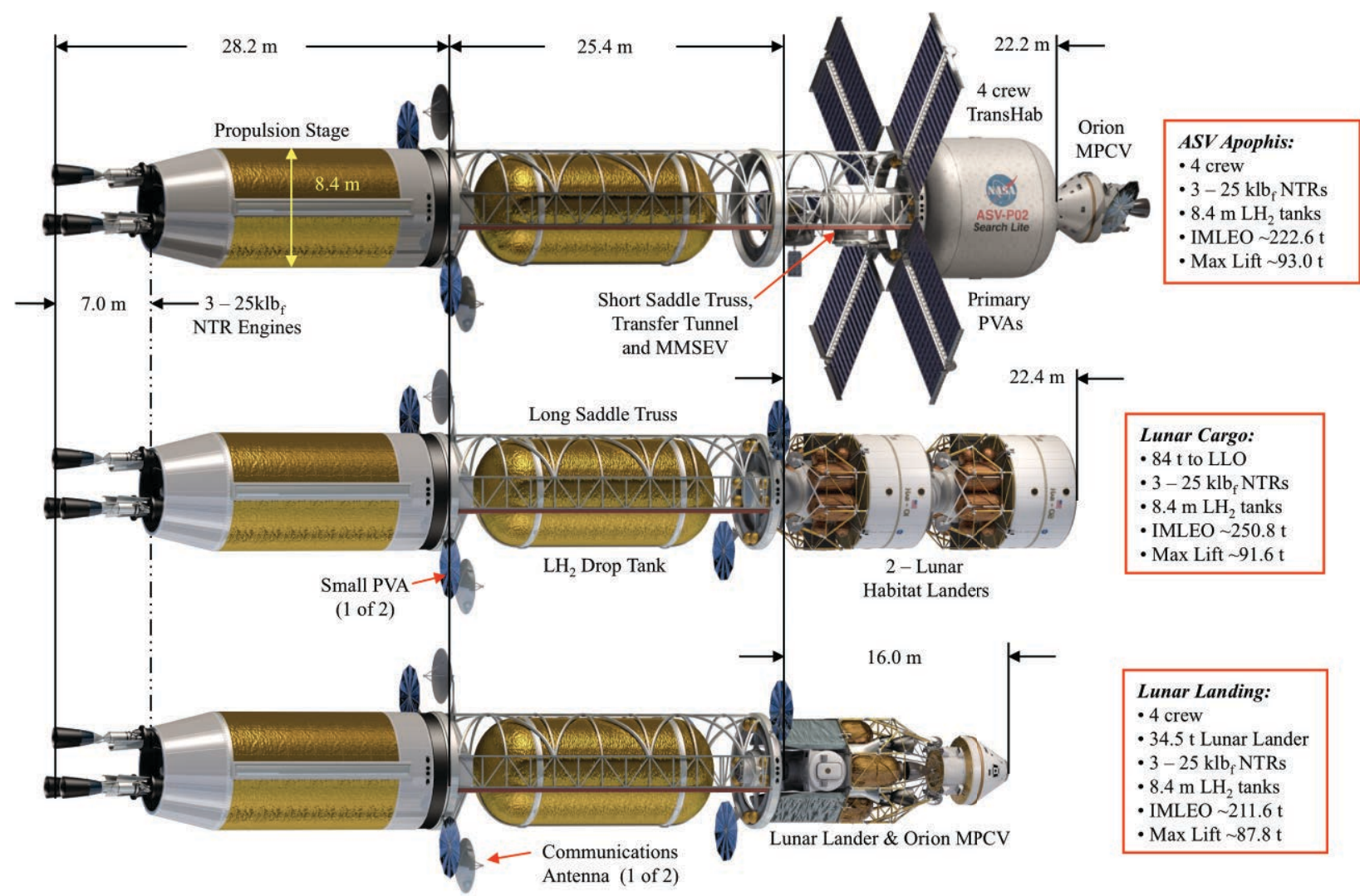

Figure 26. Class-II Vehicles for Expendable Apophis / Reusable Lunar Cargo \& Crewed Landing Missions

The remaining propulsive maneuvers have the following burn durations: second perigee burn ( 14.3 minutes), LOC ( $\sim 6.7$ minutes), TEI ( $\sim 2.5$ minutes) and EOC ( $\sim 0.9$ minutes).

Like the cargo transport, the LNTR vehicle for the crewed landing mission (shown in Fig. 26) uses the same NTPS, saddle truss and drop tank to maximize hardware commonality. It has an IMLEO of $\sim 211.6 \mathrm{t}$ that includes the NTPS $(\sim 87.8 \mathrm{t})$, the saddle truss and drop tank assembly $(\sim 71.7 \mathrm{t})$, the LLV $(\sim 29.5 \mathrm{t})$ and surface payload $(\sim 5 \mathrm{t})$, the Orion MPCV $(\sim 13.5 \mathrm{t})$, connecting structure $(\sim 2.8 \mathrm{t})$, consumables $(\sim 0.5 \mathrm{t})$, plus the 4 crew and their EVA suits ( $\sim 0.8 \mathrm{t})$. The overall vehicle length is $\sim 69.6 \mathrm{~m}$. The NTPS and drop tank are also slightly off-loaded with each tank carrying $\sim 48.7 \mathrm{t}$ of $\mathrm{LH}_{2}$ propellant ( $\sim 93 \%$ of maximum capacity).

The reusable crewed landing mission uses $\sim 91.7 \mathrm{t}$ of $\mathrm{LH}_{2}$ propellant. With the NTPS's higher thrust level, the total engine burn time is $\sim 40.7$ minutes. The duration of the 2-perigee departure burn is $\sim 28.4$ minutes with the first burn again the longest at $\sim 16.4$ minutes. After the second perigee burn, the drop tank is again jettisoned. The remaining burn durations include LOC ( $\sim 5.5$ minutes $)$, TEI ( $\sim 5.0$ minutes $)$ and EOC ( $\sim 1.8$ minutes).

\section{Notional Plans for NTP Technology Development and Demonstration}

In FY'11, NASA started a technology development effort in NTP under the Advanced In-Space Propulsion (AISP) component of its Exploration Technology Development and Demonstration (ETDD) program. The NTP effort included two key tracks: "Foundational Technology Development" followed by "Technology Demonstration" projects (details shown in Fig. 27). Near-term activities initiated under Foundational Technology Development (now part of NASA's Advanced Exploration Systems' Nuclear Cryogenic Propulsion Stage (NCPS) project [32]), included five key tasks and objectives:

Task 1. Mission Analysis, Engine/Stage System Characterization and Requirements Definition to help establish performance goals for fuel development and guide concept designs for small, scalable demonstration engines and the full size engines needed for future human Moon, NEA and Mars missions;

Task 2. NTP Fuels and Coatings Assessment and Technology Development aimed at recapturing fabrication techniques, maturing and testing fuel, then selecting between the two primary fuel forms previously identified by the 
DOE and NASA - NERVA "composite" and $\mathrm{UO}_{2}$ in tungsten "cermet" fuel [33]. Partial, then full-length fuel elements will be tested in the NTR Element Environmental Simulator (NTREES) [34] at the MSFC using up to $\sim 1.2$ MW of RF heating to simulate the NTP thermal environment that includes exposure to hot $\mathrm{H}_{2}$. Candidate fuels and fuel element designs will be screened in NTREES prior to irradiation testing and final selections;

Task 3. Engine Conceptual Design, Analysis, and Modeling aimed at developing conceptual designs of small demonstration engines and the full size $25 \mathrm{klb}_{\mathrm{f}}$-class engines utilizing the candidate fuels discussed above. State-ofthe-art numerical models are being used to determine reactor core criticality, detailed energy deposition and control rod worth within the reactor subsystem [35], provide thermal, fluid and stress analysis of fuel element geometries [36], and predict engine operating characteristics and overall mass [37];

Task 4. Demonstration of Affordable Ground Testing focused on "proof-of-concept" validation of the SAFE (Subsurface Active Filtration of Exhaust) [38] or "bore-hole" test option at the Nevada Test Site (NTS). Nonnuclear, subscale hot gas injection tests, some with a radioactive tracer gas, will be conducted in a vertical bore-hole to obtain valuable test data on the effectiveness of the porous rock (alluvium) to capture, holdup and filter the engine exhaust. The data will also help calibrate design codes needed by DOE to design the SAFE test facility and support infrastructure needed for the small engine ground technology demonstration tests and the larger $25 \mathrm{klb}_{\mathrm{f}}$-class engine tests to follow; and

Task 5. Formulation of an Affordable and Sustainable NTP Development Strategy aimed at outlining the content of an affordable development plan that utilizes separate effects tests (e.g., NTREES and irradiation tests), existing assets and innovative SAFE testing at the NTS, and small scalable engines for ground and flight technology demonstrations.

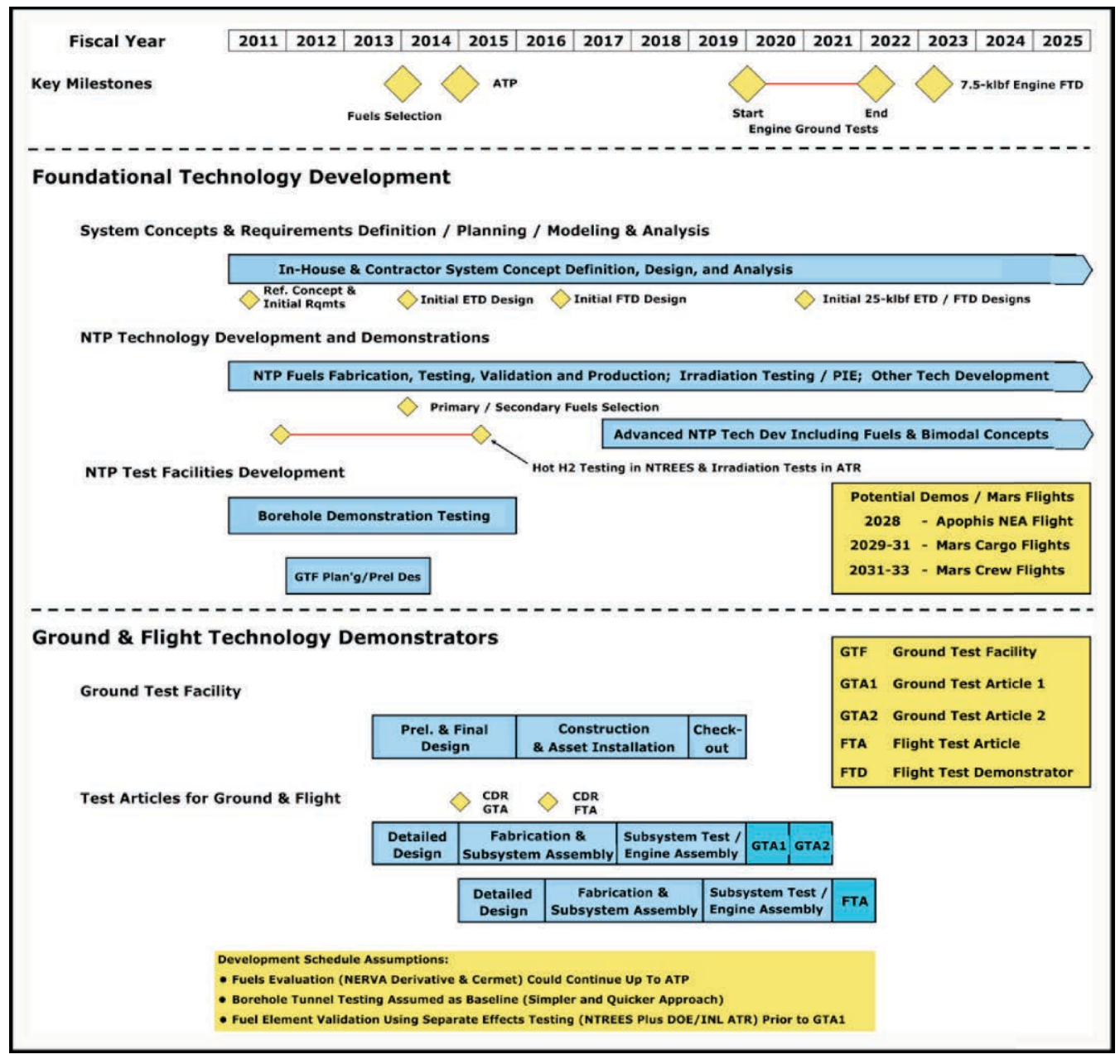

Figure 27. Notional NTP Development Plan includes Foundational, Ground and Flight Technology Demonstrations. 
The above tasks, successfully carried out over the next 3 years under the NCPS project, could provide the basis for "authority to proceed" (ATP) in 2015 with ground technology demonstration (GTD) tests at the NTS in late 2019 , followed by a flight technology demonstration (FTD) mission in 2023. To reduce development costs, the GTD and FTD tests would use a small, low thrust $\left(\sim 6.5-7.5 \mathrm{klb}_{\mathrm{f}}\right)$ engine with a "common" fuel element design that is scalable to higher thrust levels by increasing the number of elements in a larger diameter core producing a greater thermal power output. The GTD effort would test two ground test articles (GTA1, GTA2) and one flight test article (FTA) that provide system-level technology demonstration and design validation for a follow-on FTD mission.

The small engine ground and flight demonstration tests would also maximize the use of existing and proven liquid rocket components to further ensure affordability. A small NTP FTD could fit within the 5-meter fairing of the Delta 4 M $(5,4)$ launch system (shown in Fig. 28) and leverage a lot of DCSS components like the hydrogen tank, systems for pressurization, attitude control, avionics and power, plus inter-stage and thrust structure [39, 40]. The hydrogen tank's cylindrical barrel section would be increased to accommodate the propellant needed for a particular mission. A candidate FTD mission for a small NTP stage is a robotic flight to $2000 \mathrm{SG} 344$. With a $7 \mathrm{klb}_{\mathrm{f}}$ engine, $\mathrm{I}_{\mathrm{sp}}$ of $\sim 905 \mathrm{~s}$ and $\sim 6.2 \mathrm{t}$ of $\mathrm{LH}_{2}$ propellant, the total engine burn time is $\sim 29.5$ minutes.

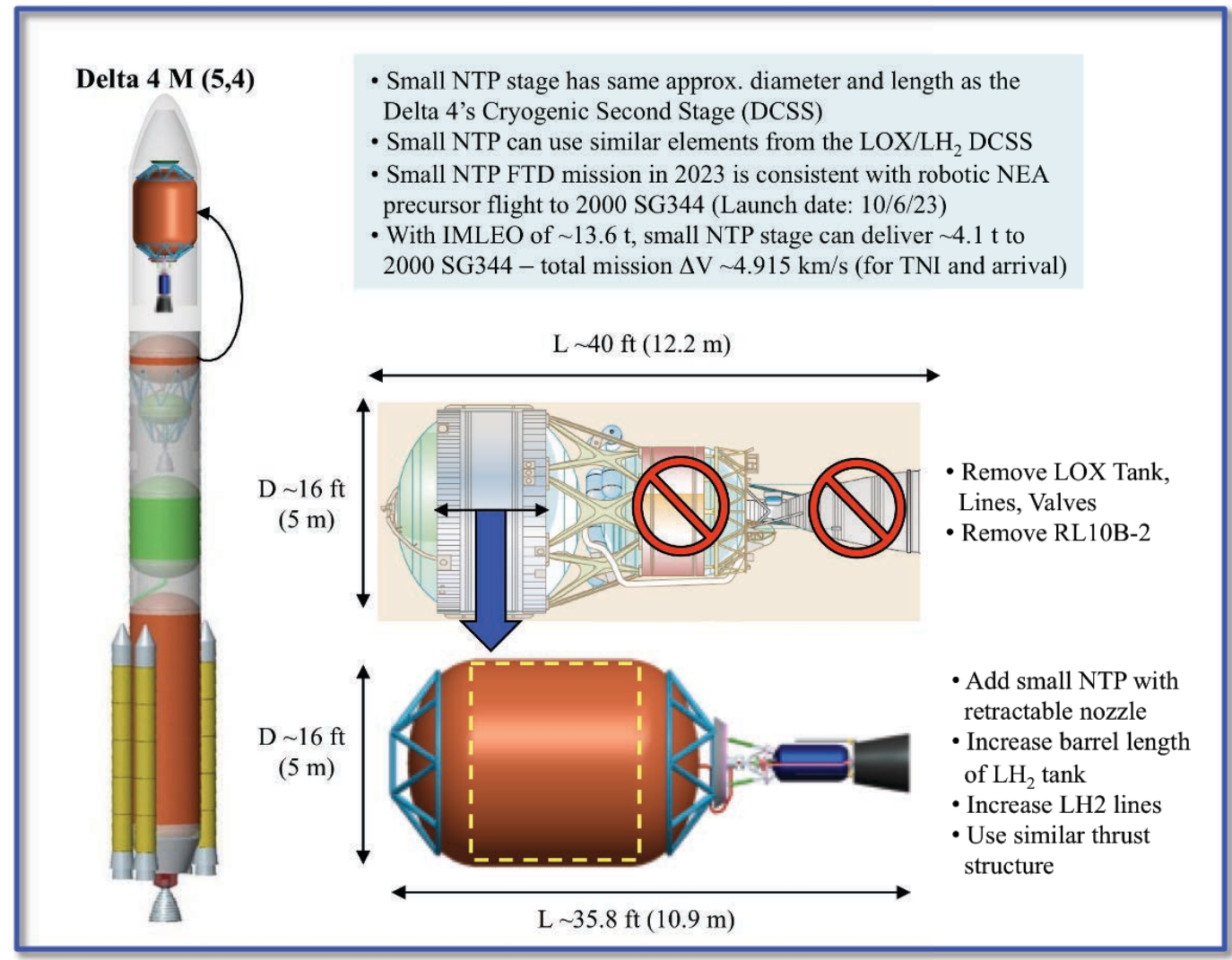

Figure 28. Small NTP Stage Launched on Delta 4 M $(5,4)$ Could Validate NTR / Stage Hardware and Support a Robotic Precursor Flight to 2000 SG344 in Late 2023 Timeframe.

A single small engine stage can be used for a variety of robotic science missions, or a $2-3$ engine cluster can be arranged on a larger capacity propellant tank for higher payload cargo delivery and modest-size crewed missions in cislunar space (e.g., Lagrange points). The FTD will also provide the technical foundation for an "accelerated approach" to design, fabrication, ground and flight testing of the fill-size $25 \mathrm{klb}_{\mathrm{f}}$-class engine by $\sim 2026$. The Rover program used a common fuel element/tie tube design and similar approach to test the $50 \mathrm{klb}_{\mathrm{f}} \mathrm{Kiwi}^{\mathrm{B}} 4 \mathrm{E}$, the $75 \mathrm{klb}_{\mathrm{f}}$ Phoebus-1B, the $250 \mathrm{klb}_{\mathrm{f}}$ Phoebus-2A, and $25 \mathrm{klb}_{\mathrm{f}}$ Pewee engines, in that order, between 1964 and 1968. Flight testing a stage with clustered $15 \mathrm{klb}_{\mathrm{f}}-25 \mathrm{klb}_{\mathrm{f}}$ engines would follow next in time to support human NEA then lunar missions in the late 2020's followed by short round trip / short orbital stay Mars missions in the early 2030's. 


\section{Summary and Conclusions}

The Global Exploration Roadmap developed by the ISECG, on behalf of NASA and the other participating space agencies, has identified two possible options for future human exploration known as the "Asteroid Next" and the "Moon Next" pathways. The "Asteroid Next" path has as its focus a first human NEA mission in 2028 necessitating the development and demonstration of key in-space exploration technologies and capabilities needed for traveling through and living in deep space. Advanced propulsion is one of these key technologies. The "Moon Next" path is focused on using the Moon to test and demonstrate key surface systems (e.g., habitats, power systems, and longrange pressurized rovers) required to support an eventual human landing on Mars. This paper shows the benefits of using NTP for human exploration missions to the Moon, NEAs and Mars that is consistent with either exploration pathway. It also outlines a growth path using "modular" components that can increase a vehicle's capability to support more demanding missions assuming a range of SLS / HLV lift capability varying from $\sim 70 \mathrm{t}-140 \mathrm{t}$.

This "modular growth strategy" is first applied to the Copernicus crewed MTV design developed for DRA 5.0. To support short round trip/short orbital stay high energy opposition-class missions in the $2033-2035$ timeframe, a "split mission" approach using the basic Copernicus MTV and its two key components configured as an ERV can be considered. For an "all-up" vehicle, the addition of an "in-line" $\mathrm{LH}_{2}$ tank, positioned between the propulsion stage and integrated saddle truss / drop tank assembly, can provide the extra propellant capacity needed for this option.

Although Copernicus was operated in an "expendable mission mode" in DRA 5.0 to reduce total IMLEO, the addition of an in-line $\mathrm{LH}_{2}$ tank and "star truss" assembly with 4 modular drop tanks, in place of the integrated saddle truss/drop tank assembly, can provide the additional propellant needed to operate Copernicus in a "reuse mode". Increasing the length and propellant capacity of in-line and drop tanks even further allows reusability for the 2033 Mars orbital mission as well. Reusability, however, is only possible if the necessary LEO infrastructure is in place (e.g., a transportation node / propellant depot with auxiliary tanker refueling capability) to support it.

Modular components can also be used to achieve even shorter "1-way" transit times to and from Mars using fastconjunction trajectories like that used in a DRA 5.0. Again, the key requirement is more propellant. By increasing the length of the in-line tank and adding two large drop tanks to Copernicus to increase its propellant capacity along with a fourth NTR engine to increase vehicle thrust and reduce gravity losses, transit times to and from Mars can be cut by $\sim 33 \%$ - from 180 days down to 120 days each way but at the cost of larger launch mass to LEO.

Since Copernicus was sized to perform fast-conjunction Mars missions over the entire 15-year synodic cycle, it has significant capability that can be used to conduct human missions to difficult, high energy NEAs, like Apophis. This asteroid is of particular interest because of its large size and its close approach to Earth in 2029. Outfitted with a MMSEV instead of an external consumables container, Copernicus can be transformed into an ASV, called Searcher, capable of carrying a crew of 6 on a 344-day round trip mission to Apophis, then returning to a 24-hour EEO for tanker servicing and return to LEO.

Scaled-down versions of the larger Copernicus/Searcher-class ASV, called Search Lite, have also been examined. Using three $70 \mathrm{t}$-class SLS launches, $3-15 \mathrm{klb}_{\mathrm{f}}$ engines, and $7.6 \mathrm{~m}$ diameter $\mathrm{LH}_{2}$ propellant tanks, a Class-I Search Lite ASV can readily support a reusable, 327-day round trip low-energy mission to the small NEA, 2000 SG344, carrying a crew of 4 . With three 100 t-class SLS launches, $3-25 \mathrm{klb}_{\mathrm{f}}$ engines, and $8.4 \mathrm{~m}$ diameter propellant tanks, a Class-II ASV can perform the more difficult mission to Apophis with $4 \mathrm{crew}$ in an expendable mode. A reusable mission to Apophis is also possible by adding an in-line tank.

Using the same two size classes of "Search Lite" vehicles, reusable cargo delivery and crewed lunar landing missions are also possible using a $70 \mathrm{t}-100 \mathrm{t}$ SLS. Search Lite vehicles can play an important role in returning humans to the Moon "this time to stay" by providing an affordable in-space transportation system that is reusable and can allow initial lunar outposts to evolve into eventual settlements capable of supporting commercial activities.

Lastly, NASA has initiated Foundational Technology Development work on NTP in a number of key areas under the NCPS project. If successful, this effort could be followed by major system-level Technology Demonstrations that include ground testing a small, scalable NTR by 2020, followed by a flight test of a small NTPS in 2023. A single small engine stage can support a variety of robotic science missions, or a cluster of $2-3$ small engines can be arranged on a larger capacity propellant tank to support higher payload cargo delivery and modest-size crewed missions in cislunar space (e.g., Lagrange points).

\section{Acknowledgments}

The authors express their thanks to Chris Moore and John Warren (NASA/HQ), along with John Taylor and Tim Wickenheiser (GRC) for their continued encouragement and strong support of this work. The author (SKB) also expresses his thanks to Bob Sauls (XP4D, LLC) for artwork depicted in this paper. 


\section{References}

[1] Schmidt, H. R., "Can We Afford to Wait for Nuclear Rockets?", Astronautics \& Aeronautics, American Institute of Aeronautics and Astronautics, pgs. 16 - 25, March 1965.

[2] Jordan Jr., W. Y., Harris, R. J., and Saxton, D. R., "Toward Modular Nuclear-Rocket Systems", Astronautics \& Aeronautics, American Institute of Aeronautics and Astronautics, pgs. 48 - 52, June 1965.

[3] Dollard, J. F., "Common Nuclear Module for Planetary Exploration”, J. Spacecraft, Vol. 6, No. 2, pgs. 136 142, February 1969.

[4] Gronich, S., Holl, R. J., Johnson, K. P., "Nonintegral Burn of Nuclear Rockets - An Approach to Low-Cost Space Exploration", J. Spacecraft, Vol. 6, No. 6, pgs. 723 - 729, June 1969.

[5] Koeing, D. R., "Experience Gained from the Space Nuclear Rocket Programs (Rover / NERVA)," Los Alamos National Laboratory, Report LA-10062-H, Los Alamos, NM, May 1986.

[6] von Braun, W., "Future NASA Space Programs", Statement to Senate Aeronautics and Space Science Committee Hearing, $91^{\text {st }}$ Congress, First Session, pgs. 14 - 30, August 5, 1969.

[7] von Braun, W., "Manned Mars Landing \& Integrated Space Program Plan", presentation to the Space Task Group (STG) at NASA Headquarters, August 4, 1969.

[8] Altseimer, J. H., Mader, G. F., and Stewart, J. J., "Operating Characteristics and Requirements for the NERVA Flight Engine", J. Spacecraft, Vol. 8, No. 7, pgs. 766-773, 1971.

[9] The White House, Office of the Press Secretary, "Remarks by the President at the $20^{\text {th }}$ Anniversary of the Apollo Moon Landing", presented at the Air and Space Museum, Washington D.C., July 20, 1989.

[10] "Report of the 90-Day Study on Human Exploration of the Moon and Mars", National Aeronautics and Space Administration, November 1989.

[11] "America at the Threshold - America's Space Exploration Initiative", Report of the Synthesis Group, Available from Superintendent of Documents, U.S. Government Printing office, Washington, DC, June 1991.

[12] Hodge, J., et al., "Space Transfer Vehicle - Lunar Transportation Ground Based LEO Rendezvous and Docking Study", NAS8-37856, Martin Marietta, August 1991.

[13] Borowski, S. K., "The Rationale/Benefits of Nuclear Thermal Rocket Propulsion for NASA's Lunar Space Transportation System", AIAA-91-2052, June 1991.

[14] Borowski, S. K., Corban, R. R., McGuire, M. L., and Beke, E. G., "Nuclear Thermal Rocket/Vehicle Design Options for Future NASA Missions to the Moon and Mars", AIAA-93-4170, September 1993.

[15] Borowski, S. K., "Fast Track NTR Systems Assessment for NASA’s First Lunar Outpost Scenario", AIAA-923812, July 1992.

[16] Borowski, S. K., Dudzinski, L. A., and McGuire, M. L., "Artificial Gravity Vehicle Design Option for NASA's Human Mars Mission Using "Bimodal” NTR Propulsion,” AIAA-99-2545, June 1999.

[17] Borowski, S. K., Dudzinski, L. A., and McGuire, M. L., "Bimodal Nuclear Thermal Rocket (NTR) Propulsion for Power-Rich, Artificial Gravity Human Exploration Missions to Mars," IAA-01-IAA.13.3.05, 52 ${ }^{\text {nd }}$ International Astronautical Congress, Toulouse, France (2001).

[18] Human Exploration of Mars Design Reference Architecture 5.0, Drake, Bret G., ed., National Aeronautics and Space Administration, NASA-SP-2009-566, Washington, DC, July 2009.

[19] Borowski, S. K., McCurdy, D. R., and Packard, T. W., "7-Launch NTR Space Transportation System for NASA's Mars Design Reference Architecture (DRA) 5.0”, AIAA-2009-5308, August 2009.

[20] Borowski, S. K., McCurdy, D. R., and Packard, T. W., "Nuclear Thermal Rocket (NTR) Propulsion: A Proven Game-Changing Technology for Future Human Exploration Missions", GLEX-2012.09.4.6x12341, Global Space Exploration Conference, Washington, DC, May 2012.

[21] The Global Exploration Roadmap, National Aeronautics and Space Administration, NP-2011-09-766-HQ, Washington, DC, September 2011.

[22] National Space Policy of the United States, June 28, 2010, pg.11.

[23] Taub, J. M., "A Review of Fuel Element Development for Nuclear Rocket Engines", Los Alamos National Laboratory, Report LA-5931, Los Alamos, NM, June 1975.

[24] Kruger, G. B., "710 High Temperature Gas Reactor Program Summary Report", GEMP-600, General Electric, Cincinnati, OH, September 1973.

[25] Marchaterre, J. F., et al., "Nuclear Rocket Program Terminal Report", ANL-7236, Argonne National Laboratory, Argonne, IL, February 1968.

[26] Schnitzler, B. G., Borowski, S. K., and Fittje, J. E., "25,000-lbf Thrust Engine Options Based on the Small Nuclear Rocket Engine Design”, AIAA-2009-5239, August 2009. 
[27] Drake, B. G., "Strategic Considerations of Human Exploration of Near Earth Asteroids", IEEEAC paper \#1069, IEEE Aerospace Conference, Big Sky, MT, March 2012.

[28] Borowski, S. K., Dudzinski, L. A., and McGuire, M. L., "Vehicle and Mission Design Options for Exploration of Mars / Phobos using Bimodal NTR and LANTR Propulsion”, AIAA-98-3883, July 1998.

[29] Bulman, M. J., Messitt, D. G., Neill, T. M., and Borowski, S. K., "Continued LOX-Augmented Nuclear Thermal Rocket (LANTR) Testing", AIAA-2002-3650, July 2002.

[30] "NASA Refines Asteroid Apophis' Path Toward Earth", National Aeronautics and Space Administration, October 7, 2009, http://www.nasa.gov/home/hqnews/2009/oct/HQ_09-232_Apophis_Update.html

[31] Borowski, S. K., McCurdy, D. R., and Packard, T. W., "Near Earth Asteroid Human Missions Possibilities Using Nuclear Thermal Rocket (NTR) Propulsion”, AIAA-2012-4209, July 2012.

[32] Houts, M. G., et al., "Nuclear Cryogenic Propulsion Stage", Nuclear and Emerging Technologies for Space (NETS) - 2012 Conference, paper \#3093, The Woodlands, TX, March 2012.

[33] Burkes, D. Wachs, D., Werner, J., (DOE/INL), Bell, G., Miller, J., Papano, P., (DOE/ORNL), and Borowski, S. K., (NASA/GRC), "The Rationale and Justification for Selection of Carbide "Composite" and Ceramic Metallic "Cermet" NTP Fuel Options", a Joint DOE / NASA White Paper for NASA HQ, May 2007.

[34] Emrich, William J., and Kirk, Daniel R., "Design Considerations for the Nuclear Thermal Rocket Element Environmental Simulator (NTREES)", AIAA- 2006-5270, July 2006.

[35] Schnitzler, Bruce G., and Borowski, Stanley K., "Neutronics Models and Analysis of Small Nuclear Rocket Engine (SNRE)", AIAA-2007-5618, July 2007.

[36] Stewart, Mark E., and Schnitzler, Bruce G., "Thermal Hydraulic Simulations of NTP Reactor Core", AIAA2007-5619, July 2007.

[37] Fittje, James E., "Upgrades to the NESS (Nuclear Engine System Simulation) Code", AIAA-2007-5620, July 2007.

[38] Howe, Steven D., Travis, B., and Zerkle, D.K., "SAFE Testing of Nuclear Rockets", Journal of Propulsion and Power, Vol. 17, No. 3, pg. 534-539 (2001).

[39] Joyner, C. R., Levack, D., and Borowski, S. K., "Affordable Development of a Nuclear Thermal Propulsion Flight Demonstrator Based on a Small Propulsion Engine that is Scalable to Human Missions", GLEX2012.4.4x12224, Global Space Exploration Conference, Washington, DC, May 2012.

[40] Joyner, C. R., Levack, D., and Borowski, S. K., "Development of a Small Nuclear Thermal Propulsion Flight Demonstrator Concept that is Scalable to Human Missions", $48^{\text {th }}$ AIAA/ASME/SAE/ASEE Joint Propulsion Conference, Atlanta, GA, July 29 - August 1, 2012. 